Aus der Klinik für Kardiologie und Pneumologie

(Prof. Dr. med. G. Hasenfuß)

der Medizinischen Fakultät der Universität Göttingen

\title{
Über den Einfluss einer verringerten BRAP-Expression auf die Entwicklung \\ der Atherosklerose im ApoE-defizienten Mausmodell
}

\author{
INAUGURAL-DISSERTATION \\ zur Erlangung des Doktorgrades \\ der Medizinischen Fakultät der \\ Georg-August-Universität zu Göttingen
}

vorgelegt von

Moritz Martin Sabrow

aus

Berlin

Göttingen 2018 
Dekan:

Referent/in

Ko-Referent/in:
Prof. Dr. rer. nat. H.K. Kroemer

PD Dr. med. T. Seidler

Prof. Dr. med. I. Bogeski

Datum der mündlichen Prüfung: 27. Februar 2019 
Hiermit erkläre ich, die Dissertation mit dem Titel " Über den Einfluss einer verringerten BRAP-Expression auf die Entwicklung der Atherosklerose im ApoE-defizienten Mausmodell" eigenständig angefertigt und keine anderen als die von mir angegebenen Quellen und Hilfsmittel verwendet zu haben.

Göttingen, den 11.07.2018 


\section{Inhaltsverzeichnis}

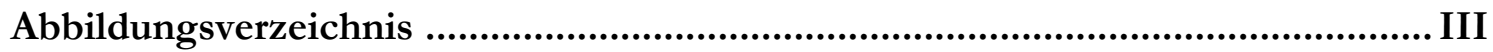

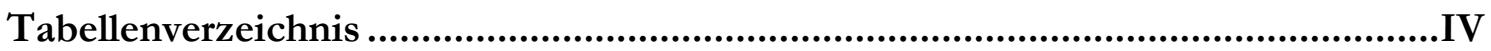

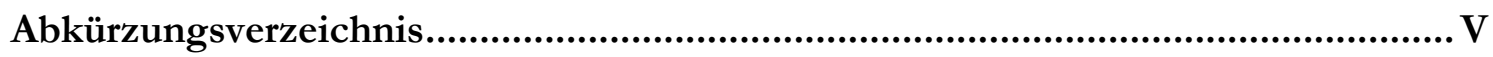

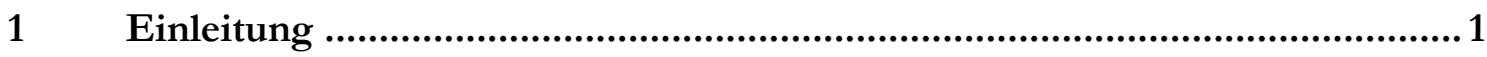

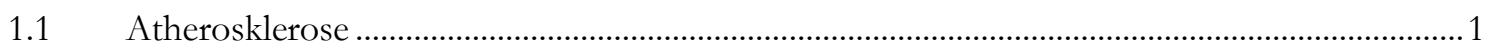

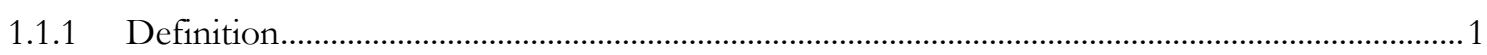

1.1.2 Molekularbiologische Grundlagen der Atherosklerose ........................................................

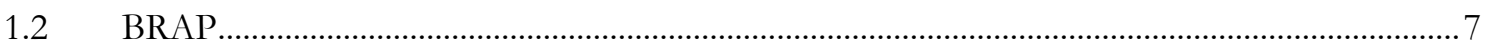

1.2.1 Atherosklerose und BRAP ............................................................................................

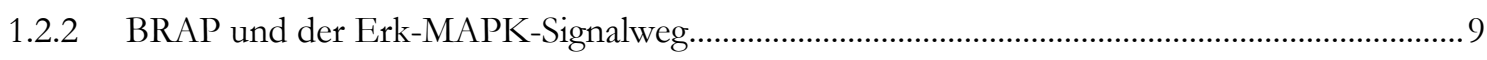

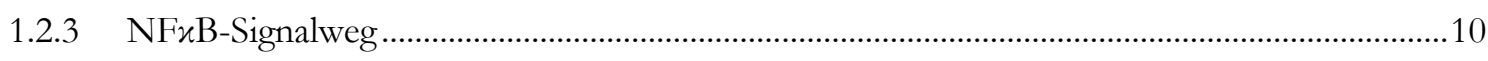

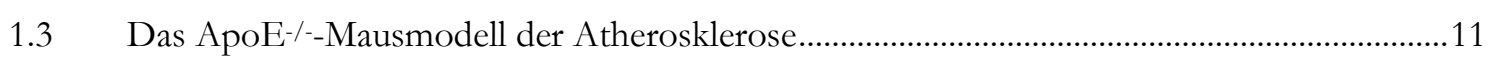

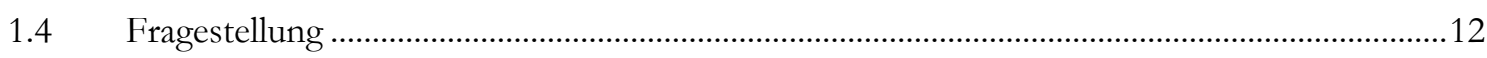

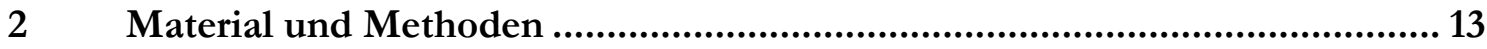

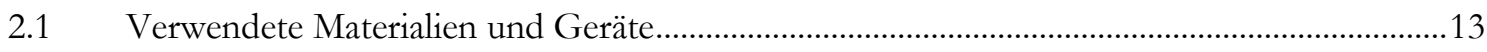

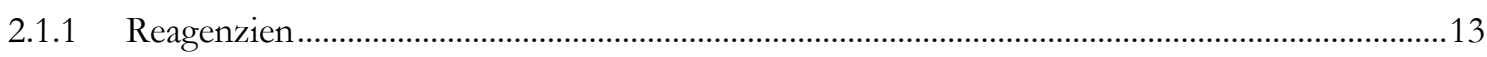

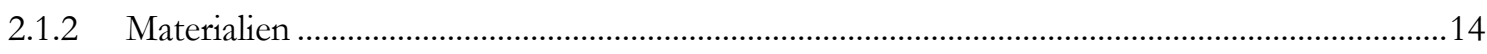

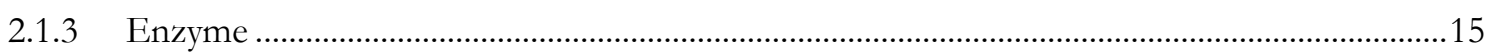

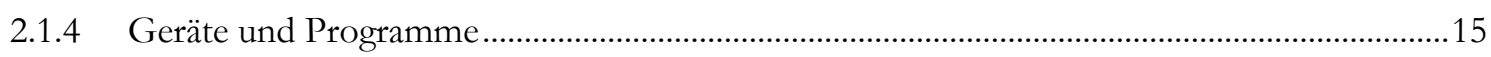

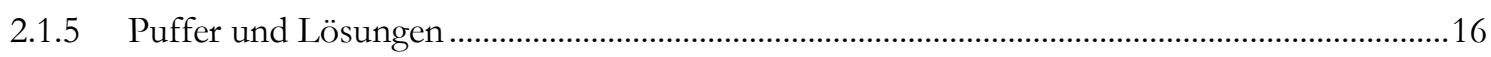

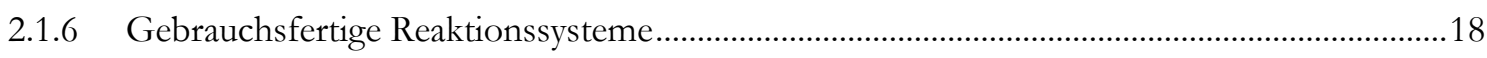

2.1.7 Verwendete Mauslinien .................................................................................................18

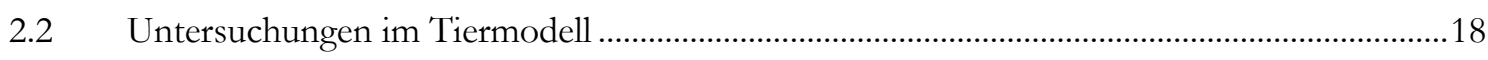

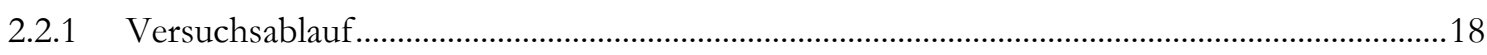

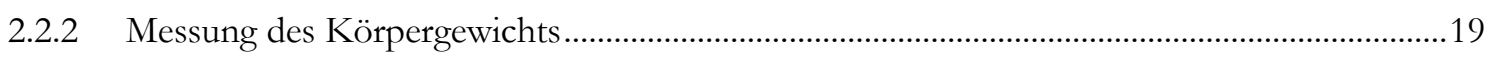

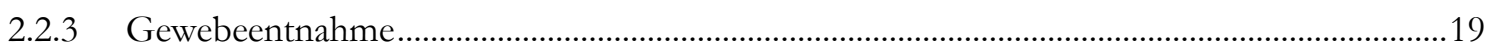

2.2.4 Genotypisierung der transgenen Mäuse...........................................................................21

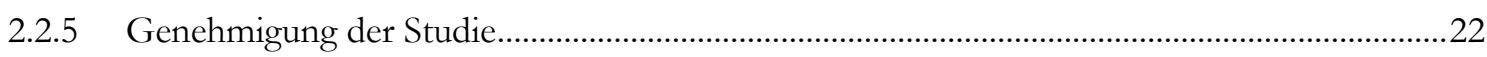

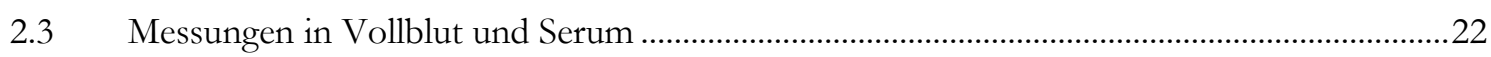

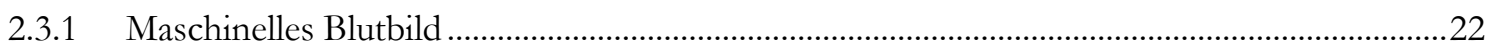

2.3.2 Bestimmung von Cholesterin, low density lipoprotein (LDL), high density lipoprotein (HDL) und Triglyzeriden in Serum .........................................................................................22

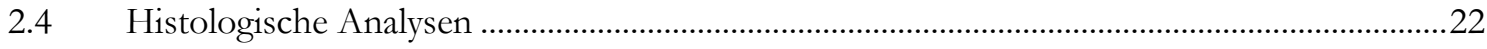

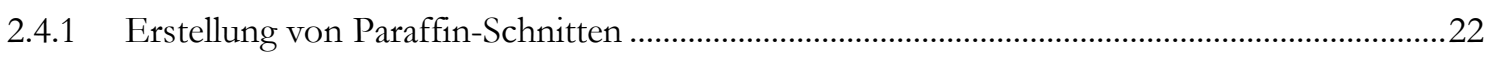

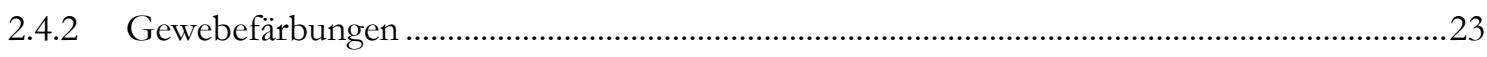

2.4.3 Evaluation der Vulnerabilität von atherosklerotischen Läsionen............................................25

2.4.4 Immunhistochemische Färbungen ....................................................................................26 


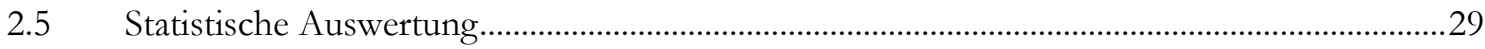

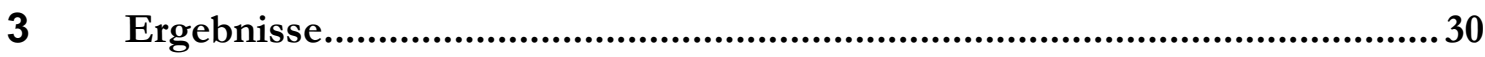

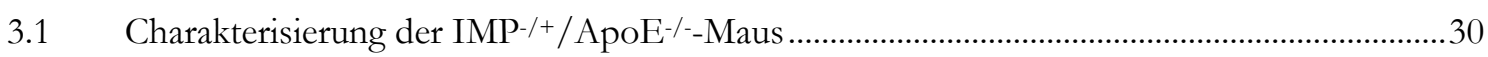

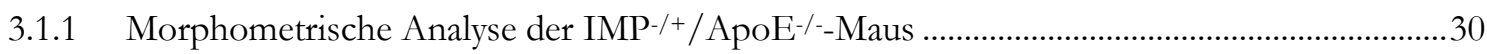

3.1.2 Automatisierte Quantifizierung der korpuskulären Blutbestandteile......................................36

3.1.3 Bestimmung von Lipoproteinen im Serum..........................................................................37

3.2 Morphometrie der atherosklerotischen Läsionen ....................................................................43

3.2.1 Ausprägung atherosklerotischer Läsionen im Bereich der Aortenwurzel unter Hochfett- und Normaldiät.................................................................................................4

3.2.2 Ausprägung der Läsionen im Bereich der Arteria brachiocephalica unter Hochfettdiät.......45

3.3 Zusammensetzung und Stabilität der atherosklerotischen Läsionen .....................................48

3.3.1 Zelluläre Zusammensetzung der Läsionen im Bereich der Aortenwurzel unter Hochfettdiät

3.3.2 Zusammensetzung der Läsionen im Bereich der A. brachiocephalica unter Hochfettdiät

3.3.3 Vulnerabilität der atherosklerotischen Läsionen in der A. brachiocephalica unter

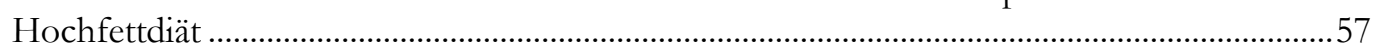

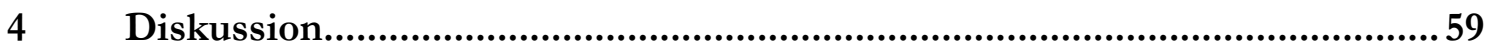

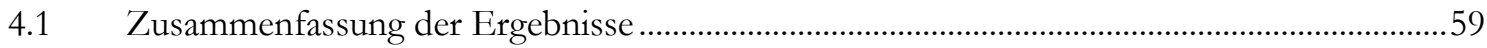

4.2 Einfluss einer reduzierten BRAP-Expression auf den Phänotyp der ApoE-/--Maus unter Hochfettdiät....

4.3 Einfluss einer reduzierten BRAP-Expression auf die korpuskulären Blutbestandteile .........65

4.4 Einfluss der BRAP-Expression auf die atherosklerotische Belastung..................................66

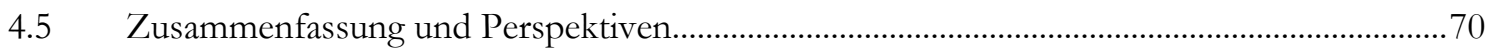

$5 \quad$ Literaturverzeichnis ..................................................................... 72 


\section{Abbildungsverzeichnis}

Abbildung 1: Effekt der Akkumulation von LDL in der arteriellen Intima........................................3

Abbildung 2: Evolution der atherosklerotischen Läsion ................................................................6

Abbildung 3: Körpergewicht in der Kontroll- und IMP-KO-Gruppe..............................................31

Abbildung 4: Lebergewicht in der Kontroll- und IMP-KO-Gruppe..................................................32

Abbildung 5: Quotient aus Leber- und Körpergewicht ....................................................................33

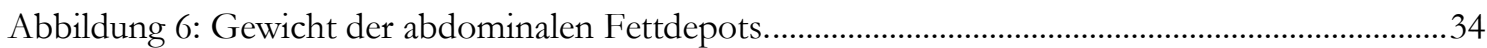

Abbildung 7: Quotient aus dem Gewicht der abdominalen Fettdepots und Körpergewicht.............35

Abbildung 8: Bestimmung des Gesamtcholesterins im Serum...........................................................38

Abbildung 9: Bestimmung des HDL-Cholesterins im Serum..............................................................39

Abbildung 10: Bestimmung des LDL-Cholsterins im Serum. .............................................................40

Abbildung 11: Bestimmung der Triglyzeride im Serum....................................................................41

Abbildung 12: Berechnung des Quotienten aus LDL- und HDL-Cholesterin.................................42

Abbildung 13: Berechnung des Quotienten aus Gesamtcholesterin und HDL-Cholesterin..............43

Abbildung 14: Prozentuale Reduktion des durchflossenen Gefäßdurchschnitts im Bereich der Aortenwurzel.

Abbildung 15: Beispiel von atherosklerotischen Plaques in der Aortenwurzel nach sechs Monaten Hochfettdiät.

Abbildung 16: Prozentuale Reduktion des durchflossenen Gefäßdurchschnitts im Bereich der A. brachiocephalica nach sechs Monaten Hochfettdiät.

Abbildung 17: Ausprägung der atherosklerotischen Plaques in der A. brachiocephalica nach sechs Monaten Hochfettdiät

Abbildung 18: Die Media-Fläche der A. brachiocephalica auf Höhe der Lumenstenose nach sechs Monaten Hochfettdiät

Abbildung 19: Verhältnis von Intima- zu Media-Fläche der A. brachiocephalica auf Höhe der Lumenstenose nach sechs Monaten Hochfettdiät.

Abbildung 20: Die Fläche des Gesamtquerschnitts der A. brachiocephalica nach sechs Monaten Hochfettdiät in der Kontroll- und IMP-KO-Gruppe.

Abbildung 21: Anteil der Mac3-positiven Fläche an der Gesamtplaquefläche ...................................49

Abbildung 22: Immunhistochemische Färbung von Makrophagen. ....................................................49

Abbildung 23: Anteil der CD3-positiven Fläche an der Gesamtplaquefläche.....................................50

Abbildung 24: Immunhistochemische Färbung von T-Lymphozyten. ................................................50

Abbildung 25: Anteil der SMA-positiven Fläche an der Gesamtplaquefläche...................................51

Abbildung 26: Immunhistochemische Färbung von SMA-positiven Zellen.......................................51

Abbildung 27: Anteil der PCNA-positiven Fläche an der Gesamtplaquefläche..................................52

Abbildung 28: Immunhistochemische Färbung von PCNA-positiven Zellen.....................................52

Abbildung 29: Anteil der Mac2-positiven Fläche an der Gesamtplaquefläche. ...................................53

Abbildung 30: Immunhistochemische Färbung von Makrophagen. ....................................................53

Abbildung 31: Anteil der CD3-positiven Fläche an der Gesamtplaquefläche....................................54

Abbildung 32: Immunhistochemische Färbung von CD3-positiven Lymphozyten..........................54

Abbildung 33: Anteil der SMA-positiven Fläche an der Gesamtplaqueflächet...................................55

Abbildung 34: Immunhistochemische Färbung von SMA-positiven Zellen.......................................55

Abbildung 35: Kollagenanteil an der Gesamtplaquefläche..............................................................56

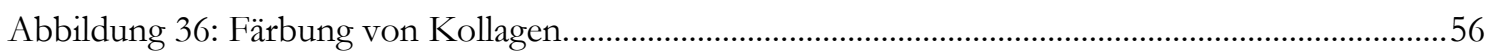


Abbildung 37: Anzahl der buried fibrous caps unter Hochfettdiät in atherosklerotischen Plaques der A. brachiocephalica als Hinweis auf abgelaufene Plaquerupturen .........................................57

Abbildung 38: Verhältnis von Plaquekappe zu Gesamtplaque (cap-to-intima-Ratio). ...............................58

Abbildung 39: Expression von BRAP mRNA bzw. NFxB-Aktivität in HCAEC-Kulturen nach Behandlung mit unspezifischer oder BRAP-spezifischer siRNA.

\section{Tabellenverzeichnis}

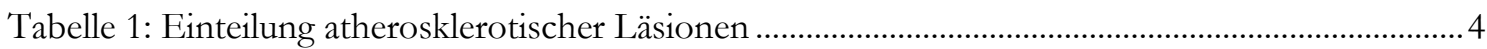

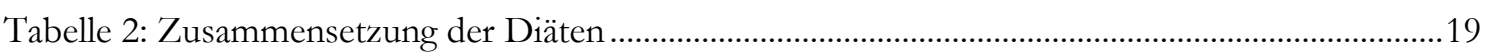

Tabelle 3: Geschlechterverteilung unter Normaldiät............................................................................

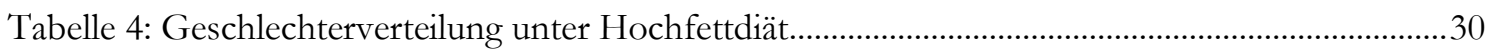

Tabelle 5: Die korpuskulären Blutbestandteile nach sechs Monaten Normaldiät ...................................36

Tabelle 6: Die korpuskulären Blutbestandteile nach sechs Monaten Hochfettdiät..................................37 


\section{Abkürzungsverzeichnis}

\begin{tabular}{|c|c|}
\hline ACS & acute coronary syndrome \\
\hline $\mathrm{AEC}$ & 3-Amino-9-Ethylcarbazol \\
\hline ApoE & Apolipoprotein E \\
\hline BRAP & BRCA1-associated protein \\
\hline BRCA1 & breast cancer-1 \\
\hline BSA & bovine serum albumin \\
\hline $\mathrm{CD}$ & cluster of differentiation \\
\hline $\mathrm{DAB}$ & 3,3'-Diaminobenzidin \\
\hline DNA & desoxyribonucleic acid \\
\hline EDTA & Ethylendiamintetraacetat \\
\hline Erk & extracellular signal-regulated kinase \\
\hline HDL & bigh density lipoprotein \\
\hline HRP & horse-radish peroxidase \\
\hline IFN- $\gamma$ & Interferon- $\gamma$ \\
\hline IL & Interleukin \\
\hline IMP & impedes mitogenic signal propagation \\
\hline $\mathrm{JNK}$ & c-Jun N-terminal kinases \\
\hline $\mathrm{Kb}$ & Kilobase \\
\hline KHK & koronare Herzerkrankung \\
\hline KSR & kinase suppressor of ras \\
\hline LDL & low density lipoprotein \\
\hline MAPK & mitogen-activated protein kinase \\
\hline M-CSF & macrophage colony stimulating factor \\
\hline MEK & mitogen-activated protein/extracellular signal-regulated kinase \\
\hline MTC & Masson-Trichrom-Färbung \\
\hline NFAT & nuclear factor of activated $t$-cells \\
\hline $\mathrm{NF} x \mathrm{~B}$ & nuclear factor 'kappa-light-chain-enhancer' of activated b-cells \\
\hline ox-LDL & oxidativ verändertes LDL \\
\hline PBS & phosphate-buffered saline \\
\hline PCNA & proliferating-cell-nuclear-antigen \\
\hline PDGF & platelet-derived growth factor \\
\hline PPAR $-\gamma$ & peroxisome proliferator-activated receptor- $\gamma$ \\
\hline Ras & rat sarcoma \\
\hline RNA & ribonucleic acid \\
\hline SMA & smooth muscle a-actin \\
\hline SNP & single-nucleotid polymorphism \\
\hline
\end{tabular}


TNF- $\alpha \quad$ Tumornekrosefaktor- $\alpha$

VES Verhoeff's Elastica Stain

WHO world health organization

ZTE zentrale tierexperimentelle Einrichtung 


\section{Einleitung}

\subsection{Atherosklerose}

\subsubsection{Definition}

Atherosklerose ist ein chronisch-entzündlicher Prozess, der durch ein multifokales Auftreten von Intimaverdickungen (so genannte Plaques) in mittleren und großen arteriellen Gefäßen geprägt ist. Diese Plaques können durch Größenzunahme zu einer verminderten Durchblutung von Herz, zentralem Nervensystem oder Extremitäten führen sowie bei Ruptur bzw. Erosion mit nachfolgender Thrombose einen ischämisch bedingten Untergang von Funktionsgewebe verursachen (Ross 1999).

Die möglichen Folgeerscheinungen und Komplikationen der Atherosklerose sind vielfältig und abhängig von der Lokalisation. Sie umfassen unter anderem die Entitäten Angina Pectoris, akutes Koronarsyndrom (ACS) und ischämische Kardiomyopathie bei Auftreten im Bereich der Koronararterien sowie apoplektischen Insult und vaskuläre Demenz bei Befall der cerebrovaskulären Stromgebiete (Falk et al. 2013; Lloyd-Jones et al. 2010). Diese Erkrankungen werden inzwischen für drei von zehn Todesfällen weltweit verantwortlich gemacht (WHO 2013). Eine Manifestation in den Extremitäten wird als periphere arterielle Verschlusskrankheit bezeichnet und ist mit dem Auftreten der oben genannten kardio- und cerebrovaskulären Ereignisse assoziiert (Criqui et al. 1992).

\subsubsection{Molekularbiologische Grundlagen der Atherosklerose}

\subsubsection{Prädisponierende Faktoren}

Atherosklerotische Läsionen entwickeln sich häufiger an Gefäßabgängen, Bifurkationen oder starken Krümmungen im Gefäßverlauf. Dies wird auf die dort entstehenden Störungen des laminaren Flusses und die sich daraus ergebende Verlangsamung der Flussgeschwindigkeit zurückgeführt - und somit auf eine Reduktion der auf das Endothel wirkenden Scherkräfte (Caro et al. 1971; Zarins et al. 1983). Die verringerte Scherkrafteinwirkung wird von den Endothelzellen via Mechanotransduktion wahrgenommen und mit einem veränderten Genexpressionsmuster beantwortet - unter anderem kommt es in der ansonsten unauffälligen Intima zu einer Hochregulation von proinflammatorischen Genen. In ihrer Gesamtheit führen diese Prozesse zu einer Verdickung der Intima, die als zunächst physiologische Antwort auf die veränderte 
Belastung des Endothels gedeutet wird und schon in fetalen Arterien zu finden ist (Stary et al. 1992). Allerdings entwickeln sich atherosklerotische Läsionen häufig an eben diesen Lokalisationen, unter anderem auch auf Grundlage intimaler Verdickungen, und weisen Parallelen in ihren Genexpressionsmustern auf (Nakashima et al. 2002; Guyton und Klemp 1993; Jongstra-Bilen et al. 2006).

Die eigentliche Entstehung einer atherosklerotischen Läsion kann in drei Phasen unterteilt werden: Initiationsphase, Progressionsphase und Komplikationsphase (Libby 2000).

\subsubsection{Initiationsphase}

Der erste Schritt zur Entwicklung und Progression einer atherosklerotischen Läsion ist die Akkumulation von low density lipoprotein-Partikeln (LDL) in der extrazellulären Matrix der Intima. Dort erfahren die LDL-Partikel oxidative Veränderungen in unterschiedlichem Ausmaß durch radikale Sauerstoffspezies und diverse Oxidasen wie beispielsweise NADPH-Oxidase, Lipoxygenase oder Myeloperoxidase (Stocker und Keany 2004). Gefördert wird dies durch die bekannten kardiovaskulären Risikofaktoren wie Rauchen, Diabetes mellitus, Dyslipidämie und arterieller Hypertonus. Sie haben alle gemein, dass sie zu oxidativem Stress in der Gefäßwand führen (Mitra et al. 2011). In Hinblick auf die hier vorgelegte Arbeit ist es bemerkenswert, dass das Vorliegen einer Hypercholesterinämie auch ohne die Anwesenheit weiterer Risikofaktoren ausreicht, um diesen Prozess anzustoßen (Glass und Witztum 2001).

Oxidativ verändertes LDL (ox-LDL) wirkt direkt chemotaktisch auf Monozyten und TLymphozyten und führt so zu einer vermehrten Einwanderung von Immunzellen und einer lokal begrenzten Inflammationsreaktion (Quinn et al. 1987; McMurray et al. 1993). Läsionen in diesem frühen Stadium werden auch als type I lesions bezeichnet und sind nur mikroskopisch sichtbar (Stary et al. 1994). 


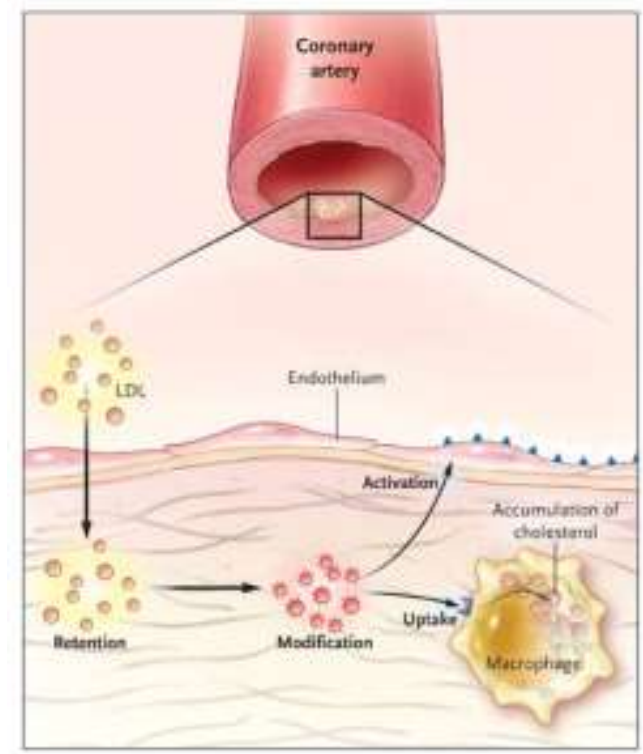

Abbildung 1: Effekt der Akkumulation von LDL in der arteriellen Intima. Aus Hansson 2005, S. 1687. Der Abdruck erfolgte mit freundlicher Genehmigung der Massachusetts Medical Society.

Die Anwesenheit von ox-LDL im subendothelialen Raum führt im nächsten Schritt zur Expression von so genannten Scavenger-Rezeptoren auf der Zelloberfläche der eingewanderten Makrophagen. Auch glatte Muskelzellen bilden im Verlauf der Plaqueprogression Scavenger-Rezeptoren aus (Mietus-Snyder et al. 1997). Über diese Rezeptoren wird ox-LDL unlimitiert - d. h. ohne negativen Feedback-Mechanismus aufgenommen und in Form von Cholesterolestern im Zytoplasma abgelagert; es entstehen Lipidtropfen, die das charakteristische Aussehen der Schaumzellen prägen (Glass und Witztum 2001; Linton und Fazio 2001). Gefördert wird sowohl die Differenzierung von Monozyten zu Makrophagen als auch die Ausbildung von Scavenger-Rezeptoren auf Makrophagen durch den macrophage colony stimulating factor (M-CSF). Ohne M-CSF kommt es zu deutlich geringer ausgeprägten atherosklerotischen Läsionen (Smith et al. 1995).

Die beschriebenen Vorgänge führen in ihrer Gesamtheit zur Entstehung von so genannten fatty streaks, welche oft auch makroskopisch sichtbar sind. In fatty streaks, auch als type II lesions bezeichnet, dominieren vorwiegend Schaumzellen (vorwiegend lipidreiche Makrophagen, aber auch glatte Muskelzellen), neben T-Lymphozyten in einem generell inflammatorischen Milieu (Stary et al. 1994). Es wird diskutiert, ob der atherosklerotische Prozess bis zu diesem Punkt noch reversibel ist (Napoli et al. 1997). 
Tabelle 1: Einteilung atherosklerotischer Läsionen (vgl. Stary 1994)

\begin{tabular}{|l|l|}
\hline Typ & Beschreibung \\
\hline I & $\begin{array}{l}\text { Mikroskopisch sowie chemisch detektierbare Lipidansammlungen und } \\
\text { damit verbundene zelluläre Reaktionen. }\end{array}$ \\
\hline II & $\begin{array}{l}\text { Auch als fatty streaks bezeichnete, bereits makroskopisch sichtbare } \\
\text { Ansammlungen von Schaumzellen in der Intima betroffener Gefäße. }\end{array}$ \\
\hline III & $\begin{array}{l}\text { Läsion im Übergang von Typ II zum Vollbild einer atherosklerotischen } \\
\text { Läsion. Charakteristisch sind das parallele Vorkommen von intra- und } \\
\text { extrazellulären Lipidansammlungen sowie ein beginnender Umbau der } \\
\text { Intima. }\end{array}$ \\
\hline IV & $\begin{array}{l}\text { Fortgeschrittene atherosklerotische Läsion, die alle histologischen } \\
\text { Kriterien erfüllt (lipidhaltiger Kern, deutliche Veränderung der Intima } \\
\text { und der arteriellen Gefäßstruktur im Allgemeinen). }\end{array}$ \\
\hline
\end{tabular}

\subsubsection{Progressionsphase}

Die Weiterentwicklung eines fatty streaks ist durch eine weitere Größenzunahme der Läsionen, eine Veränderung ihrer zellulären und extrazellulären Zusammensetzung sowie einer breiten Expression überwiegend pro-inflammatorischer Zytokine geprägt (Libby 2000). Insbesondere die Ausbildung und die Veränderung des so genannten nekrotischen Kerns (necrotic core) und der darüber gelegenen fibrotisierten Zone, die fibrotische Kappe (fibrous cap), sind in dieser Phase relevant und entscheiden über die Stabilität der atherosklerotischen Läsion bzw. die Wahrscheinlichkeit einer Plaqueruptur (Glass und Witztum 2001).

Zur Größenzunahme der Plaques tragen mehrere Faktoren bei. Zunächst werden durch die bestehende Inflammation weitere Lipoproteine in die extrazelluläre Matrix aufgenommen (Ross 1999). Makrophagen vergrößern durch die Synthese von Sauerstoffradikalen das in der Läsion verfügbare Angebot an ox-LDL-Partikeln, die wiederum - nachdem sie phagozytiert wurden - die Entstehungsrate von Schaumzellen steigern (Hazen und Heinecke 1997; Leeuwenburgh et al. 1997). Die Bildung von Schaumzellen wird durch eine Reihe von Zytokinen gefördert, dies geschieht unter anderem über die weitere Induktion von Scavenger-Rezeptoren durch peroxisome proliferator-activated receptor- $\gamma$ (PPAR- $\gamma$ ), zu dessen Liganden ox-LDL, Interferon- $\gamma$ (IFN- $\gamma$ ) und Tumornekrosefaktor- $\alpha$ (TNF- $\alpha$ ) gehören (Tontonoz et al. 1998).

Es konnte auch gezeigt werden, dass die Fähigkeit von Makrophagen, die atherosklerotische Läsion wieder zu verlassen, gestört ist und so die Inflammation weiter unterhalten wird (Llodrá et al. 2004). Im weiteren Verlauf kann es daher - möglicherweise durch Überladung mit Lipiden - zum Untergang dieser Zellen kommen (Ball et al. 1995). Auf Grund ineffektiver Abräumung verbleiben die Zellreste aber anschließend im extrazellullären Raum und setzen die in ihnen enthaltenen Lipoproteine und Cholesterinkristalle frei (Schrijvers et al. 2005). Zusätzlich kommt es zu DNA-Schäden durch oxidativen Stress, ausgelöst von Makrophagen und Endothelzellen. Dies führt zu erhöhter Aktivität des proliferating-cell-nuclear-antigen (PCNA) als Zeichen vermehrt aktiver 
DNA-Reparaturmechanismen (Martinet et al. 2002). Das Zusammenspiel dieser Faktoren fördert die Inflammation im Allgemeinen und die Entstehung des nekrotischen Kerns im Speziellen. Sein Auftreten ist charakteristisch für fortgeschrittene Läsionen (Tabas 2010).

Ebenso charakteristisch für fortgeschrittene Läsionen sind Akkumulationen von glatten Muskelzellen und der von ihnen produzierten Bestandteile der extrazellulären Matrix, insbesondere die gemeinsam aus Kollagen und glatten Muskelzellen gebildete fibrotische Kappe (Lusis 2000). Dieser Prozess wird von T-Lymphozyten, Makrophagen und endothelialen Zellen maßgeblich beeinflusst (McLaren et al. 2011).

Erste Ansammlungen von glatten Muskelzellen finden sich bereits in präatherosklerotischen intimalen Verdickungen (Nakashima et al. 2008). In diesem Punkt unterscheiden sich die Gegebenheiten in humanen Arterien vom Mausmodell, bei dem glatte Muskelzellen in der physiologischen Intima kaum vorhanden sind und erst im Verlauf der Plaqueentstehung einwandern (Nakashima et al. 2008; Newby und Zaltsman 1999). Die Akkumulation wird - zum Teil autokrin - durch platelet-derived growth factor (PDGF) und heparin-binding EGF-like growth factor-1 (HB-EGF) gefördert, die sowohl einen mitogenen als auch einen chemotaktischen Effekt auf glatte Muskelzellen in der Intima ausüben und selbst durch oxidierte LDL-Partikel induziert werden. Eine chemotaktische Wirkung auf Zellen in der Media wird diskutiert (Stiko-Rahm et al. 1992; Dreux et al. 2006).

Ohne Bindung zur Basalmembran verändern glatte Muskelzellen ihren ursprünglich kontraktilen Phänotyp bei Kontakt mit Fibronectin zu einem aktiven sekretorischen Phänotyp (Hedin et al. 1989). Von ihnen werden Bestandteile der extrazellulären Matrix wie Fibronectin, Elastin und Kollagen in Abhängigkeit vom vorherrschenden Zytokinmuster synthetisiert. Auch die Degradation von Matrixmolekülen wird über diese Mechanismen gesteuert (Liu und Davidson 1988). Eine Reduzierung der extrazellulären Matrix führt letztendlich zu einer geringeren Stabilität und höheren Rupturneigung der Plaques (Libby 2000).

Auf- und Abbau der extrazellulären Matrix und die Entwicklung der glatten Muskelzellen werden engmaschig durch Makrophagen und T-Lymphozyten gesteuert (Lusis 2000). Ein relevanter Steuerungsmechanismus ist hierbei die Interaktion von CD40 mit dem CD40Liganden (CD40L, auch als CD154 bezeichnet). Beide werden unter anderem auf T-Zellen, B-Zellen, glatten Muskelzellen, Makrophagen und Endothelzellen ko-exprimiert, wobei die Funktion von CD40 auf T-Zellen noch nicht abschließend geklärt ist (Mach et al. 1997a; Mach et al. 1997b; Munroe und Bishop 2007). Im Einzelnen aktiviert CD40 via mitogenactivated protein kinase-Signalwege (MAPK) die nukleären Transkriptionsfaktoren NFuB, activator protein-1 (AP-1) und nuclear factor of activated T-cells (NFAT) (Schönbeck und Libby 2001). Der Netto-Effekt der CD40/CD40L-Interaktion führt erst zu einer Begünstigung der Entwicklung hin zu einer komplizierten Läsion und im späteren Verlauf dann zu einer zunehmenden Destabilisierung der Plaques (Mach et al. 1998). 
Insgesamt sind ca. 10-20\% der Zellen einer Läsion CD3-positive T-Zellen, die meisten von ihnen sind $\mathrm{T}_{\mathrm{H} 1}$-polarisierte Zellen. Die größte Anzahl an T-Zellen findet sich in den Schulterregionen der Plaques (Jonasson et al. 1986). $\mathrm{T}_{\mathrm{H} 2}$-Zellen sind in atherosklerotischen Läsionen ebenfalls präsent, ihre Funktion ist aber bislang unklar (Wolf et al. 2014). Ferner befinden sich auch regulatorische T-Zellen in den Läsionen. Sie haben einen atheroprotektiven, IFN- $\gamma$-antagonisierenden Effekt durch die Synthese von IL-10 und TGF- $\beta$ (Klingenberg et al. 2013). Die Datenlage bezüglich B-Lymphozyten ist widersprüchlich und ihre Funktion noch unzureichend geklärt, verschiedene Subtypen scheinen jeweils atherogene oder atheroprotektive Einflüsse zu besitzen (Wolf et al. 2014).
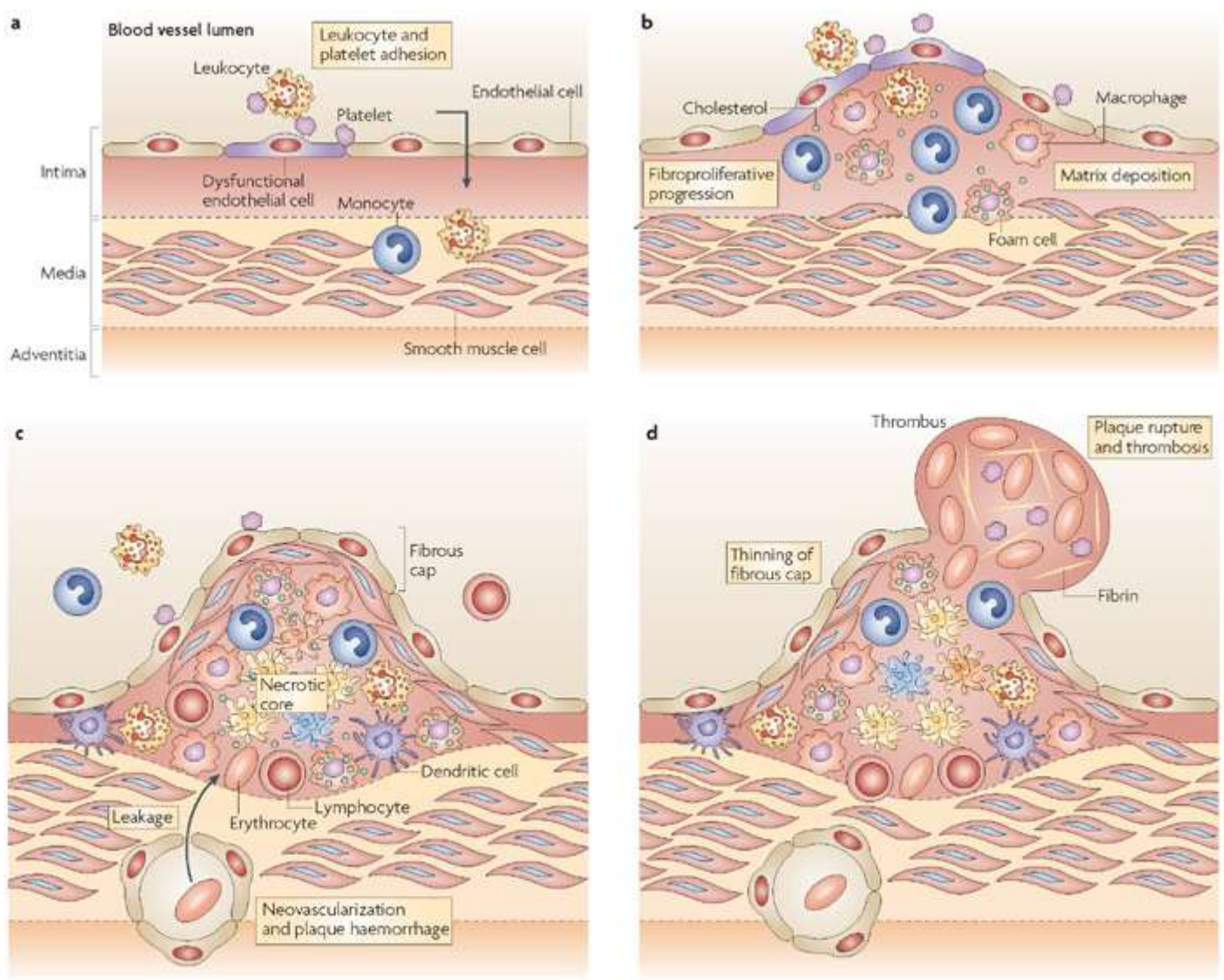

Nature Reviews | Immunology

Abbildung 2: Evolution der atherosklerotischen Läsion. a Endotheliale Dysfunktion infolge von LDLAkkumulation und Entstehung eines pro-inflammatorischen Milieus. b Entstehung eines fatty streaks durch Schaumzellbildung. c Progression der Plaque, u. a. mit Ausbildung des necrotic cores, der Plaquekappe und Neovaskularisation. d Plaqueruptur mit Thrombusbildung bedingt durch eine ausgedünnte Plaquekappe und einen ausgedehntem necrotic core. Weber et al. 2008 S. 803. Der Abdruck erfolgte mit freundlicher Genehmigung von Springer Nature. 


\subsubsection{Komplikationsphase}

Im Laufe der beschriebenen Entwicklung zu einer komplexen Läsion kommt es zu einer Größenzunahme der Plaques und unter Umständen auch zu einer konsekutiven Stenose des Gefäßlumens (Libby 2000). Häufig ist dabei eine kompensatorische Vergrößerung des Gefäßdurchmessers zu beobachten, gelegentlich tritt in den betroffenen Gefäßsegmente aber auch ein gegenteiliger Effekt auf (Ward et al. 2000). Instabilere Plaques und somit auch eine höhere Wahrscheinlichkeit für das Auftreten einer Ruptur finden sich in Gefäßabschnitten, die eine kompensatorische Vergrößerung aufweisen (Varnava et al. 2002).

In einem Konsensus-Beschluss von 2003 wurde eine Plaqueruptur als eine Exposition des thrombogenen Plaqueinneren gegenüber dem Blutstrom auf Grund eines Defekts der Plaquekappe definiert (Schaar et al. 2003). Kriterien für eine instabile Plaque und somit Risikofaktoren für eine Ruptur sind nach Falk et al. unter anderem ein ausgeprägter nekrotischer Kern, eine dünne fibrotische Kappe, eine fibrotische Kappe mit vielen Makrophagen oder wenigen glatten Muskelzellen sowie eine kompensatorische Vergrößerung des Gefäßlumens (Falk et al. 2013).

\subsection{BRAP}

\subsubsection{Atherosklerose und BRAP}

Eine Assoziation von BRCA1-associated protein (BRAP) und atherosklerotischen Prozessen wurde erstmals in einer Genom-weiten Assoziationsstudie in taiwanesischen und japanischen Populationen gefunden. Hier zeigte sich, dass zwei EinzelnukleotidPolymorphismen (single-nucleotid polymorphism, SNP) mit einem erhöhten Risiko für Myokardinfarkte in diesen Populationen verbunden sind und ein starkes Kopplungsungleichgewicht (linkage disequilibrium) aufweisen. Ein SNP im Intron 3 (rs11066001, 270A $>$ G) ging dabei mit einer erhöhten Expression von BRAP einher, die von einem bislang nicht identifizierten Molekül durch Bindung an die entsprechende Region gesteuert wird. Der zweite SNP im Exon 5 rs3782886 zeigte diesen Effekt nicht, allerdings wurde dieser SNP in BRAP von einer Genom-weiten Assoziationsstudie mit einem chinesischen Kollektiv als Kandidaten-Gen für Schizophrenie identifiziert (Zhang et al. 2014). Weiterhin konnte von Ozaki et al. gezeigt werden, dass BRAP die NFxBExpression positiv reguliert (Ozaki et al. 2009). Hinohara et al. konnten die Bedeutung des SNPs rs11066001 als unabhängigen Risikofaktor für das Auftreten einer koronaren Herzerkrankung (KHK) in japanischen und koreanischen Populationen bestätigen (Hinohara et al. 2009). Der Nachweis des SNPs korreliert dabei in einem taiwanesischen Patientenkollektiv auch mit einem höheren Schweregrad der KHK. Dieser Effekt erfährt eine synergistische Verstärkung, wenn zusätzlich ein Diabetes mellitus vorliegt. Hsu et al. benutzten hierfür den clinical vessel score (CVS; Einteilung nach Anzahl der betroffenen 
Gefäße von 1-Gefäß-KHK bis 3-Gefäß-KHK) sowie den diffuse score (DS; Einteilung des Koronargefäßsystems in 15 Abschnitte und eine unterschiedliche Gewichtung der Läsion je nach Lokalisation) (Hsu et al. 2011). Auch das Risiko für das Auftreten von atherosklerotischen Läsionen in der A. carotis ist bei Vorliegen des GG-Genotyps (SNP rs11066001, 270A > G) 1,58-fach erhöht. Liao et al. fanden in dem Zusammenhang, dass BRAP durch Lipopolysaccharid, nicht aber durch artifiziell oxidiertes LDL in aortalen, glatten Muskelzellen induziert wird. Weiterhin konnten sie zeigen, dass BRAP mit dem $\mathrm{I} \varkappa \mathrm{B} \alpha$-Kinase-Komplex (IKK) interagiert und so die Translokation von NF $\varkappa \mathrm{B}$ in den Nukleus ermöglicht. Anders als Ozaki et al. konnten Liao et al. keinen Hinweis auf eine vermehrte Expression von NFxB unter BRAP-Einwirkung feststellen (Liao et al. 2011). Die Ergebnisse von Takashima et al. unterstützen die These, dass BRAP via Interaktion mit dem IKK die Translokation von NFxB in den Nukleus beeinflusst. Allerdings kommen sie zu dem Schluss, dass BRAP durch Assoziation zu dem Ubiquitin-Ligase Komplex SCF ${ }^{\beta-}$ ${ }_{\mathrm{TrCP}}$, der die Polyubiquitinierung und Degradation von $\mathrm{I} \varkappa \mathrm{B} \alpha$ induziert, die Translokation von NFxB hemmt. Dieser Effekt könnte aber auch ein Artefakt sein, bedingt durch die Überexpression von BRAP (Takashima et al. 2013).

Obwohl Atherosklerose eine wichtige Rolle in der Genese cerebrovaskulärer Ereignisse spielt, konnte kein Einfluss des BRAP-Polymorphismus' auf das Risiko eines cerebrovaskulären Insults nachgewiesen werden (Liao et al. 2013). Tsai et al. fanden hingegen eine Assoziation des SNPs mit dem Vorliegen eines niedrigen Knöchel-ArmIndexes (auch ankle-brachial-Index, ABI) in einer taiwanesischen Population. Ein erniedrigter Index wird hier als Risikofaktor für das Auftreten einer peripheren arteriellen Verschlusskrankheit interpretiert (Tsai et al. 2011). Dies wurde in einer weiteren Untersuchung der gleichen Arbeitsgruppe bestätigt. Hier zeigte sich ein additiver Effekt für das Risiko einer periphere arterielle Verschlusskrankheit (pAVK), der durch einen SNP in der antisense nicht-kodierenden RNA (ANRIL) auf Chromosom 9p21 vermittelt wird. Als Mechanismus wird eine gemeinsame Beeinflussung des NF^B-Signalwegs postuliert (Tsai et al. 2012). BRAP wird ebenfalls eine Rolle im Rahmen des metabolischen Syndroms zugesprochen, die genaue Bedeutung ist aber noch unklar. So zeigten Avery et al. in einer Meta-Analyse aus fünf Populationsstudien eine Assoziation des SNPs (rs11065987) in BRAP mit dem Auftreten von Dyslipidämie, Bluthochdruck und stammbetonter Adipositas bei Amerikanern europäischer Abstammung (Avery et al. 2011). Dagegen fanden Wu et al. in einer chinesischen Population eine negative Korrelation des von Ozaki et al. beschriebenen SNPs (rs11066001) mit Parametern des metabolischen Syndroms (Wu et al. 2013). Kürzlich konnte auch ein Zusammenhang zwischen dem SNP im Exon 5 (rs3782886) und Adipositas sowie weiteren metabolischen Merkmalen (u. a. systolischer Blutdruck, Nüchternblutzucker, Lipidstatus) nachgewiesen werden (Imaizumi et al. 2016). 


\subsubsection{BRAP und der Erk-MAPK-Signalweg}

Der mitogen-activated protein kinase (MAPK)-Signalweg beschreibt drei durch verschiedene Faktoren initiierbare intrazelluläre Phosphorylierungskaskaden, die in jeweils drei Schritten zur Aktivierung entweder von Erk (extracellular signal-regulated kinase), JNK (c-Jun N-terminal kinases) oder $\mathrm{p} 38$-MAPK- $\alpha / \beta$ durch Phosphorylierung führen. Diese MAP-Kinasen interagieren wiederum mit einer Reihe von Effektorproteinen wie beispielsweise Transkriptionsfaktoren und beeinflussen so die Genexpression der jeweiligen Zelle. (Robinson und Cobb 1997).

Ein Aktivator des MAPK-Signalwegs ist Ras (rat sarcoma), ein kleines G-Protein. Bindungspartner von Ras sind unter anderem die Isoformen der Kinase Raf (rapidly growing fibrosarcoma), die wiederum MEK (mitogen-activated protein/extracellular signal-regulated kinase) mit unterschiedlicher Affinität aktivieren (Pritchard et al. 1995). Hierfür wird KSR (kinase suppressor of Ras) benötigt, das als „Gerüst“ (engl. scaffold) für die Interaktion von Raf, MEK und Erk dient, ohne selbst eine Reaktion zu katalysieren (Therrien et al. 1996; Morrison 2001). Insgesamt konnte ein modulierender Effekt von KSR auf Zellproliferation, -transformation, -differenzierung und Apoptose gezeigt werden (Kolch 2005). Nguyen et al. konnten weiterhin zeigen, dass ein Knockout von KSR1 die Fähigkeit zur T-Zell-Aktivierung abschwächt (Nguyen et al. 2002).

BRAP (BRCA1-associated protein) ist ein vorwiegend zytoplasmatisches Protein und wurde erstmals von $\mathrm{Li}$ et al. in einem Xenopus yeast two-bybrid-Screening entdeckt. Es erhielt die Bezeichnung BRAP auf Grund seiner Eigenschaft, sich an die Kernlokalisationssequenz von BRCA-1 (breast cancer-1) zu binden (Li et al. 1998). Ähnliche Interaktionen konnten auch für andere Proteine mit Relevanz für den Zellzyklus gezeigt werden. Die Bedeutung hiervon ist aber noch unklar (Davies et al. 2013). Eine mögliche Rolle von BRAP besteht in der negativen Regulation der Konzentration zelleigener, aber auch fremder (z. B. viraler) Proteine im Nukleus (Fulcher et al. 2010). In C. elegans zeigte sich für das zu BRCA-1 orthologe Protein brc-1 eine Rolle in der Induktion von DNA-Reparaturmechanismen als Antwort auf exzessive Konzentrationen von radikalen Sauerstoffspezies. Koon und Kubiseski konnten hier nachweisen, dass BRAP zu einer Erhöhung der Toleranz gegenüber Sauerstoffradikalen führt (Koon und Kubiseski 2010). Während der Differenzierung von Monozyten hat BRAP eine anti-apoptotische Wirkung, indem es durch Bindung von p21 dessen Retention im Zytoplasma bewirkt (Asada et al. 2004). Matheny et al. konnten zeigen, dass BRAP (hier auch als impedes mitogenic signal propagation, IMP, bezeichnet) KSR via Hyperphosphorylierung hemmt und so die Bildung des RafMEK-Erk-Komplexes limitiert (Matheny et al 2004). BRAP selbst wird durch Rasinduzierte Auto-Ubiquitinierung und konsekutive proteasomale Degradierung inaktiviert. Die Interaktion mit USP-15 (ubiquitin-stabilizing protein) verhindert dagegen die Degradierung von BRAP und hat einen stabilisierenden Effekt auf die BRAPKonzentration im Zytoplasma (Hayes et al. 2012). Die Abwesenheit von BRAP führte in 
Zellkulturen mit HeLa- und Vorhautzellen zu einer stärkeren Reizantwort auf Mitogene bei gleicher Dauer der Antwort (Matheny et al. 2004). Diese Ergebnisse lassen vermuten, dass die Rolle von BRAP darin besteht, die Aktivierung des Erk-MAPK-Signalwegs durch nicht-adäquate Reize in Abwesenheit von Ras zu reduzieren (Ory und Morrison 2004).

Der Erk-MAPK-Signalweg spielt eine wichtige Rolle in der T-Zellaktivierung via TZellrezeptor (Zha et al. 2006). Czyzyk et al. fanden in diesem Zusammenhang eine erhöhte Expression der pro-inflammatorischen Zytokine IFN- $\gamma$ und IL-2 in aktivierten T-Zellen, wenn sie vorher mit BRAP-spezifischer siRNA transfiziert wurden. Weiterhin konnte gezeigt werden, dass eine solche Verminderung von BRAP die Motilität von T-Zellen und somit die Ansammlung von T-Zellen in peripheren lymphatischen Geweben herabsetzt (Czyzyk et al. 2008). Eine erhöhte T-Zellmotilität wird mit einer geringeren Neigung zu autoimmunen Reaktionen in Verbindung gebracht, da hier die Kontaktzeit zwischen TZellen und Antigen-präsentierenden Zellen reduziert ist und somit Aktivierungen durch Antigene mit geringerer Affinität zu dem jeweiligen T-Zellrezeptor weniger wahrscheinlich werden (Schneider et al. 2006). Lanctot et al. (2013) fanden für BRAP eine weitere Rolle in der Regulation der Differenzierung einzelner Zellen in der neuronalen Entwicklung. Hier kommt es zu einem Konzentrationsgradienten mitogener Moleküle, die von spezialisierten Zentren in der Mittellinie des ZNS sezerniert werden (Chizhikov und Millen 2005). BRAP formt in diesem Zusammenhang mit Nde1 und Lis1 einen molekularen Komplex, der die Aktivierungsschwelle des MAPK-Signalwegs an die Mitogen-Konzentration anpasst. Ein $\mathrm{Nde}^{-/ /} / \mathrm{Lis}^{+/}$-Doppel-Knockout führte im Mausmodell $\mathrm{zu}$ einem Verlust dieser Modulation (Lanctot et al. 2013).

\subsubsection{NF $\varkappa B-S i g n a l w e g$}

Nuclear Factor $x \mathrm{~B}$ bezeichnet eine Gruppe von fünf Transkriptionsfaktoren (RelA/p65, cRel, RelB, NF $x \mathrm{~B} 1$ und $\mathrm{NF} x \mathrm{~B} 2)$. Im Ruhezustand ist $\mathrm{NF} x \mathrm{~B}$ an $\mathrm{I} x \mathrm{~B}$ gebunden und vorwiegend im Zytoplasma lokalisiert. Dies wird zum einen durch Maskierung der Kernlokalisationssequenz durch $\mathrm{I} x \mathrm{~B}$ und zum anderen durch eine Nukleusexportsequenz von $\mathrm{I} x \mathrm{~B}$ vermittelt (Ghosh und Karin 2002). Die klassische Aktivierung des NFxBSignalwegs findet unter anderem durch Zytokine wie TNF- $\alpha$ oder IL-1 oder Aktivierung von Toll-like-Rezeptoren durch pathogene Partikel statt. Dies hat die Induktion des I $x$ BKinase Komplexes (IKK) zur Folge, der wiederum I $x$ B phosphoryliert (De Winther et al. 2005). Dieser Schritt ist für die Poly-Ubiquitinierung durch den Ubiquitin-Ligase Komplex $\mathrm{SCF}^{\beta-\mathrm{TrCP}}$ notwendig, die in die Inaktivierung und Degradation von I $x \mathrm{~B}$ mündet (Spencer et al. 1999). Im Nukleus induziert $\mathrm{NF}$ B B eine Vielzahl von Genen, die für eine Immunantwort oder eine inflammatorische Reaktion, aber auch für Zellwachstum sowie Apoptosekontrolle relevant sind (Baldwin 2001). Der NFxB-Signalweg ist von zentraler Bedeutung für die atherosklerotischen Prozesse und hat sowohl atherogene als auch atheroprotektive Aspekte (De Winther et al. 2005). 


\subsection{Das ApoE E $^{-/}$-Mausmodell der Atherosklerose}

Genetisch nicht veränderte Mäuse haben keinerlei Neigung, atherosklerotische Läsionen zu entwickeln. Dies liegt unter anderem an dem in Mäusen vorliegenden protektiven Lipidprofil mit einem hohen Anteil von HDL-Cholesterin. Unter einer kombinierten Hochfett- und Hochcholesterin-Diät zeigen sich bei Wildtyp-Tiere Läsionen, die einem fatty streak entsprechen, sich aber nicht zur komplexen Läsion weiterentwickeln (Paigen et al. 1985, Bond und Jackson 2011).

Anfang der 1990er Jahre entwickelten Plump et al. sowie Piedrahita et al. ein Mausmodell für Atherosklerose, das auf einem homozygoten Knockout von Apolipoprotein E (ApoE) basiert. ApoE ist ein in der Leber synthetisiertes Protein und integraler Bestandteil von HDL-Partikeln. Es vermittelt die Endozytose des gesamten Partikels via LDL-Rezeptoren. Mäuse mit dem Genotyp ApoE ${ }^{-/-}$haben unter normaler Diät eine signifikante Hypercholesterinämie und weisen bereits nach 10 Wochen signifikante Läsionen in der proximalen Aorta auf. Dieser Effekt potenziert sich unter fett- und cholesterinreicher Diät (sog. westliche Diät) (Plump et al. 1992; Piedrahita et al. 1992). Die Prädilektionsstellen befinden sich ähnlich wie beim Menschen vorwiegend an Aufzweigungen des Gefäßsystems, vor allem in $\operatorname{der}$ A. brachiocephalica, sowie im Bereich von Ausflusstrakten, hier vor allem im Bereich der Aortenklappe. Die Entwicklung der atherosklerotischen Läsionen zeigt starke Ähnlichkeiten mit denen im menschlichen Körper in Bezug auf zeitliche Abfolge und Zusammensetzung. Fett- und cholesterinreiche Ernährung beschleunigt den Prozess signifikant (Nakashima et al. 1994). Ein Schlüsselereignis in der Atherosklerose ist die Plaqueruptur, die in der Regel eine Thrombusbildung und Ischämie in den distal gelegenen Versorgungsgebieten nach sich zieht. In der A. brachiocephalica von ApoE $^{-/}-$-Mäusen finden sich komplexe Läsionen, die mit zunehmenden Alter häufig Plaquerupturen zeigen. Anders als bei menschlichen Läsionen kommt es hier nicht zu thrombotischen Gefäßverschlüssen. Histologische Anzeichen für Plaquerupturen sind in der Plaque gelegene Hämorrhagien und später sog. buried fibrous caps als Zeichen verheilter Rupturen (Bond und Jackson 2011).

Zusätzlich zu den atherosklerotischen Läsionen im kardiovaskulären Bereich treten bei $\mathrm{ApoE}^{-/}$-Mäusen unter westlicher Diät Leberverfettung und Gallensteine auf. Weiterhin wurden Lipid-Ablagerungen im Bereich des Gastrointestinal-Trakts beobachtet (Zhang et al. 1994). Anders als in humanen Läsionen kommt es in den murinen AtheroskleroseModellen zu einer effektiven Kompensation der Stenose durch nach außen gerichteten Umbau des betroffenen Gefäßabschnitts sowie eine Vergrößerung der Media-Fläche (Van Craeyveld et al. 2012). 


\section{$1.4 \quad$ Fragestellung}

In den Jahren seit der Entdeckung von BRAP als Bindungspartner von BRCA-1 wurden mehrere Arbeiten zu seiner Funktion und Regulation publiziert. Die Wirkungsweise dieses Proteins ist weiterhin nicht ausreichend geklärt, allerdings sind drei Grundprinzipien erkennbar:

1. BRAP ist ein Modulator des MAPK-Signalwegs.

2. BRAP ist ein negativer Regulator der Translokation von Proteinen in den Zellkern.

3. BRAP ist ein Interaktionspartner von NFxB, und SNPs im Brap Gen sind mit einem erhöhten Risiko für Atherosklerose vergesellschaftet.

Die bisherigen Untersuchungen im atherosklerotischen Kontext beschränkten sich auf Zellkulturen und Genom-weite Assoziationsstudien. Auf Grund der Komplexität der Prozesse bei der Entstehung von atherosklerotischen Läsionen in vivo ist es schwierig, die Bedeutung eines Stoffwechselweges anhand von In vitro-Experimenten zu beurteilen. Die bisherige Evidenz, beginnend bei der Arbeit von Ozaki et al. (2009) deutet darauf hin, dass eine erhöhte Expression von BRAP zu einer stärkeren Ausprägung der Atherosklerose führt. Weiterhin wird bei Ozaki et al. und anderen Arbeitsgruppen postuliert, dass BRAP mit NF $\mathrm{B}$ interagiert, ein Signalweg, der sowohl atherogene als auch atheroprotektive Züge aufweist.

Zur Überprüfung des Zusammenhangs einer veränderten BRAP-Expression und dem Ausmaß der atherosklerotischen Belastung sollen in dieser Arbeit daher die Folgen eines heterozygoten BRAP-Knockouts in der $\mathrm{ApoE}^{-/-}$-Maus evaluiert werden. 


\section{Material und Methoden}

\subsection{Verwendete Materialien und Geräte}

\subsubsection{Reagenzien}

\begin{tabular}{|c|c|}
\hline Artikel & Firma \\
\hline Anilinblau & Carl Roth, Karlsruhe \\
\hline Antibody Diluent & Dako, Glostrup, DK \\
\hline Aquatex (wässriges Eindeckmittel) & Merck, Darmstadt \\
\hline Biebrich-Scarlett & Sigma-Aldrich, München \\
\hline Chloroform & Merck, Darmstadt \\
\hline Citrat-Puffer / Target retrieval solution & Dako, Glostrup, DK \\
\hline dNTPs $(100 \mathrm{mM})$ & Invitrogen, Darmstadt \\
\hline Eisen-III-Chlorid & Merck, Darmstadt \\
\hline Eisessig & Merck, Darmstadt \\
\hline Entellan (Einschlussmedium) & Merck, Darmstadt \\
\hline Ethanol & Chemie-Vertrieb Hannover, Hannover \\
\hline Ethylendiamintetraacetat (EDTA) & Serva, Heidelberg \\
\hline Formalin & Sigma-Aldrich, München \\
\hline Fuchsinsäure & Sigma-Aldrich, München \\
\hline Hämatoxylin & Sigma-Aldrich, München \\
\hline Hämatoxylin krist. & Merck, Darmstadt \\
\hline Hämatoxylin nach Mayer & Sigma-Aldrich, München \\
\hline Iod & Sigma-Aldrich, München \\
\hline Isofluran & Abbott, Wiesbaden \\
\hline Isotonische Kochsalzlösung & DiacoBiomedicali, Trieste, ITA \\
\hline Kaliumchlorid $[26,8 \mathrm{mM}]$ & Merck, Darmstadt \\
\hline Kaliumhydrogenphosphat $[14,7 \mathrm{mM}]$ & Merck, Darmstadt \\
\hline Kaliumiodid & Sigma-Aldrich, München \\
\hline Ketamin Inresa & Inresa Arzneimittel, Freiburg i. Br. \\
\hline Magnesiumchlorid $\left(\mathrm{MgCl}_{2}\right)$ & Merck, Darmstadt \\
\hline
\end{tabular}




\begin{tabular}{|c|c|}
\hline Natriumchlorid $[1,37 \mathrm{M}]$ & Carl Roth, Karlsruhe \\
\hline Natriumhydrogenphosphat [81mM] & Merck, Darmstadt \\
\hline Natriumhydroxid & Carl Roth, Karlsruhe \\
\hline Natriumthiosulfat & Merck, Darmstadt \\
\hline Normales Ziegenserum (NGS) & Dako, Glostrup, DK \\
\hline Paraformaldehyd & Sigma-Aldrich, München \\
\hline PBS & Sigma-Aldrich, München \\
\hline Phosphomolybdänsäure & Sigma-Aldrich, München \\
\hline Phosphotungstensäure & Sigma-Aldrich \\
\hline Pikrinsäure & Sigma-Aldrich, München \\
\hline Rinderserumalbumin (BSA) & Sigma-Aldrich, München \\
\hline Salzsäure, rauchend $(37 \%)$ & Merck, Darmstadt \\
\hline TritonX-100 & Merck, Darmstadt \\
\hline Universal-Agarose & Peqlab, Erlangen \\
\hline Wasserstoffperoxid (30\%) & Carl Roth, Karlsruhe \\
\hline Xylazin & Riemser Arzneimittel, Greifswald \\
\hline Xylol & Carl Roth, Karlsruhe \\
\hline Zink-Formalin & Thermo Fisher Scientific, Schwerte \\
\hline
\end{tabular}

\subsubsection{Materialien}

Artikel

\begin{tabular}{ll}
$15 \mathrm{ml}$ Tubes & Sarstedt, Nümbrecht \\
\hline $50 \mathrm{ml}$ Tubes & Sarstedt, Nümbrecht \\
\hline Auslaufpipetten $25 \mathrm{ml}$ & Sarstedt, Nümbrecht \\
\hline Deckgläser $(24 \times 48 \mathrm{~mm}, 24 \times 60 \mathrm{~mm})$ & Gerhard Menzel, Braunschweig \\
\hline Dumont \#5-45 Pinzette & F.S.T., Heidelberg \\
\hline Einbettkassetten & Medite, Burgdorf \\
\hline Fettstift Dako Pen & Dako, Glostrup, DK \\
\hline Glas- und Schliffwaren & Schott, Mainz \\
\hline Graefe Pinzette & F.S.T., Heidelberg \\
\hline Hitachi Sample Cups & Roche Diagnostics, Basel \\
\hline Kanülen BD Microlance 3 & Becton Dickinson, Heidelberg \\
\hline Labortücher & Kimberly-Clarke Deutschland, Mainz
\end{tabular}




\begin{tabular}{ll} 
Leukosilk & BSN medical, Hamburg \\
\hline Nahtmaterial 6/0 Seide & Resorba, Nürnberg \\
\hline Objektträger & Gerhard Menzel, Braunschweig \\
\hline Omnican 40 & B.Braun Melsungen, Melsungen \\
\hline Omnifix 40 Solo & B.Braun Melsungen, Melsungen \\
\hline Omnifix 5 ml / Luer Lock solo & B.Braun Melsungen, Melsungen \\
\hline Pipetten & Eppendorf, Hamburg \\
\hline Pipettenspitzen $(20 \mu \mathrm{l}, 200 \mu \mathrm{l}, 1000 \mu \mathrm{l})$ & Brand, Wertheim \\
\hline Präparierschere & Karl Hammacher, Solingen \\
\hline Rührspatel & Sarstedt, Nümbrecht \\
\hline Surgical Blade & Feather Safety Razor, Osaka, JPN \\
\hline Szintillationsflaschen $20 \mathrm{ml}$ & neoLabMigge Laborbedarf-Vertrieb, Heidelberg \\
\hline Venofix 25G & B.Braun Melsungen, Melsungen \\
\hline Wattestäbchen & Karl Riese, Barsbüttel \\
\hline
\end{tabular}

\subsubsection{Enzyme}

\section{Artikel}

Mango Taq DNA-Polymerase

Proteinase $\mathrm{K}$

\section{Firma}

Bioline, Luckenwalde

Carl Roth, Karlsruhe

\subsubsection{Geräte und Programme}

\section{Artikel}

\begin{tabular}{ll}
\hline Axio Vision 3.0 & Carl Zeiss, Oberkochen \\
\hline Axiovert 200 & Zeiss, Hamburg \\
\hline Centrifuge 5415 R & Eppendorf, Hamburg \\
\hline Einbettautomat & Leica, Wetzlar \\
\hline GraphPad PRISM 5 & GraphPad Software, San Diego, USA \\
\hline ImageJ v1.42 & National Institutes of Health, USA \\
\hline ImagePro Plus v4.1.00 & Media Cybernetics, La Jolla, USA \\
\hline Mikrotom JUNG RM 2035 & Leica, Wetzlar \\
\hline Olympus BX5 & Carl Zeiss, Oberkochen \\
\hline PCR-Gerät iQ 5 & Bio-Rad Laboratories, München \\
\hline Präzisionswaage ED153 & Sartorius, Göttingen \\
\hline
\end{tabular}




\subsubsection{Puffer und Lösungen}

\subsubsection{Färbelösungen}

\begin{tabular}{|c|c|c|}
\hline alkoholische Hämatoxylin-Lösung, 10\% & $\begin{array}{l}5 \mathrm{~g} \\
50 \mathrm{ml}\end{array}$ & $\begin{array}{l}\text { Hämatoxylin krist. } \\
\text { destilliertes Wasser }\end{array}$ \\
\hline \multirow[t]{3}{*}{ Anilinblau-Färbelösung } & $2,5 \mathrm{~g}$ & Anilinblau \\
\hline & $100 \mathrm{ml}$ & destilliertes Wasser \\
\hline & $2 \mathrm{ml}$ & Eisessig \\
\hline \multirow[t]{3}{*}{ Biebrich-Scharlachrot-Säurefuchsin-Lösung } & $90 \mathrm{ml}$ & $\begin{array}{l}\text { Biebrich-Scharlachrot, } 1 \% \text { (in destilliertes } \\
\text { Wasser) }\end{array}$ \\
\hline & $10 \mathrm{ml}$ & Säurefuchsin, 1\% (in destilliertes Wasser) \\
\hline & $1 \mathrm{ml}$ & Eisessig \\
\hline \multirow[t]{3}{*}{ Bouin's Fixative } & $750 \mathrm{ml}$ & gesättigte Pikrinsäure \\
\hline & $250 \mathrm{ml}$ & Formalin \\
\hline & $50 \mathrm{ml}$ & Eisessig \\
\hline \multirow[t]{2}{*}{ Eisenchlorid-Lösung, 10\% } & $5 \mathrm{~g}$ & Eisen-III-Chlorid \\
\hline & $50 \mathrm{ml}$ & destilliertes Wasser \\
\hline \multirow[t]{2}{*}{ Eisenchlorid-Lösung, 2\% } & $20 \mathrm{ml}$ & Eisenchlorid-Lösung, 10\% \\
\hline & $80 \mathrm{ml}$ & destilliertes Wasser \\
\hline \multirow[t]{2}{*}{ Eisessig, $1 \%$} & $99 \mathrm{ml}$ & destilliertes Wasser \\
\hline & $1 \mathrm{ml}$ & Eisessig \\
\hline \multirow[t]{2}{*}{ Natriumthiosulfat-Lösung, 5\% } & $5 g$ & Natriumthiosulfat \\
\hline & $100 \mathrm{ml}$ & destilliertes Wasser \\
\hline \multirow{3}{*}{$\begin{array}{l}\text { Phosphomolybdän-Phosphotungsten- } \\
\text { Lösung }\end{array}$} & $5 g$ & Phosphomolybdän \\
\hline & $5 \mathrm{~g}$ & Phosphotungsten \\
\hline & $200 \mathrm{ml}$ & destilliertes Wasser \\
\hline \multirow[t]{2}{*}{ Van-Gieson-Lösung } & $5 \mathrm{ml}$ & Säurefuchsin, 1\% (in destilliertes Wasser) \\
\hline & $80 \mathrm{ml}$ & destilliertes Wasser \\
\hline
\end{tabular}




\begin{tabular}{|c|c|c|}
\hline \multirow[t]{4}{*}{ Verhoeff'sche Jod-Lösung } & $2 \mathrm{~g}$ & Jod \\
\hline & $4 \mathrm{~g}$ & Kaliumiodid \\
\hline & & Durch kräftiges Schütteln vermischen \\
\hline & $100 \mathrm{ml}$ & $\begin{array}{l}\text { destilliertes Wasser in } 20 \quad \mathrm{ml} \text { Schritten } \\
\text { hinzufügen }\end{array}$ \\
\hline \multirow[t]{5}{*}{ Verhoeff'sche Elastika Färbelösung } & $50 \mathrm{ml}$ & 10\% alkoholische Hämatoxylin-Lösung \\
\hline & $50 \mathrm{ml}$ & 10\% Eisenchlorid-Lösung \\
\hline & $50 \mathrm{ml}$ & $100 \%$ Ethanol \\
\hline & & gründlich vermischen, dann \\
\hline & $50 \mathrm{ml}$ & Verhoeffsche Jod-Lösung \\
\hline \multirow[t]{8}{*}{ Weigert's-Eisen-Hämatoxylin-Lösung } & Lösung A & \\
\hline & $1 \mathrm{~g}$ & Hämatoxylin \\
\hline & $99 \mathrm{ml}$ & $95 \%$ Ethanol (in destilliertem Wasser) \\
\hline & Lösung B & \\
\hline & $4 \mathrm{ml}$ & Eisen-III-Chlorid, 29\% (in destilliertem Wasser) \\
\hline & $1 \mathrm{ml}$ & konzentrierte Salzsäure \\
\hline & $95 \mathrm{ml}$ & destilliertes Wasser \\
\hline & A:B & 1:1 (zeitnah ansetzen) \\
\hline
\end{tabular}

\subsubsection{Sonstige Lösungen}

\begin{tabular}{|c|c|c|}
\hline \multirow[t]{2}{*}{ Ethylendiamintetraacetat (EDTA) } & $1.800 \mathrm{mg}$ & Ethylendiamintetraacetat \\
\hline & $100 \mathrm{ml}$ & destilliertes Wasser \\
\hline \multirow[t]{6}{*}{ PBS } & $400 \mathrm{~g}$ & Natriumchlorid \\
\hline & $10 \mathrm{~g}$ & Kaliumchlorid \\
\hline & $55,5 \mathrm{~g}$ & Natriumhydrogenphosphat \\
\hline & $10 \mathrm{~g}$ & Kaliumhydrogenphosphat \\
\hline & $4.800 \mathrm{ml}$ & destilliertes Wasser \\
\hline & & $\begin{array}{l}\text { mit Natriumhydroxid auf } \mathrm{pH} 7,4 \text { einstellen und mit } \\
\text { destilliertem Wasser auf fünf Liter auffüllen }\end{array}$ \\
\hline
\end{tabular}




\subsubsection{Gebrauchsfertige Reaktionssysteme}

\begin{tabular}{ll} 
Artikel & Firma \\
\hline AEC Substrate Kit & Invitrogen, Karlsruhe \\
\hline DirectPCR Lysis TailReagent & Peqlab, Erlangen \\
\hline SuperPicture Kit (DAB, broad spectrum) & Invitrogen, Karlsruhe \\
\hline Vectastain Elite ABC Kit & VectorLabs, Burlingame, USA \\
\hline
\end{tabular}

\subsubsection{Verwendete Mauslinien}

Mauslinie

ApoE-//C57BL/6J

$\mathrm{IMP}^{-} /+/ \mathrm{C} 57 \mathrm{BL} / 6 \mathrm{~N}$

\section{Bezugsquelle}

Charles River WIGA, Sulzfeld

eigene Zucht, Universitätsmedizin Göttingen

Die Tiere wurden in einem zwölfstündigen Hell-Dunkel-Rhythmus bei $22{ }^{\circ} \mathrm{C}$ und $55 \pm$ $5 \%$ relativer Luftfeuchtigkeit gehalten. Trinkwasser und Nahrung standen immer zur freien Verfügung.

\subsection{Untersuchungen im Tiermodell}

\subsubsection{Versuchsablauf}

Für den Versuch wurden ApoE-defiziente Tiere mit dem genetischen Hintergrund C57BL/6J von der Firma Charles River WIGA GmbH (Sulzfeld, Deutschland) bezogen und in der Zentralen Tierexperimentellen Einrichtung (ZTE) der Universitätsmedizin Göttingen (UMG) gehalten. Um die Auswirkungen einer verminderten BRAP-Expression in diesem Atherosklerose-Tiermodell studieren zu können, wurden diese Tiere mit Mäusen verpaart, die einen heterozygoten Knock-out des brap Gens $\left(\mathrm{IMP}^{-/+}\right)$aufwiesen. Diese Knock-out-Linie wurde in unserem Labor von Dr. med. Tim Seidler und Dr. rer. nat. Cornelia Volland in Zusammenarbeit mit dem Max-Planck-Institut für Experimentelle Medizin, Göttingen, generiert. Die aus dieser Verkreuzung stammenden Tiere wurden für den Versuch verwendet.

Zur eindeutigen Identifikation wurde jedes Tier mit einem Ohrlochcode gemäß dem ZTESchema versehen. Weiterhin wurde bei jedem Tier eine Genotypisierung durchgeführt. Das dafür notwendige Gewebe wurde mittels Schwanzbiopsie gewonnen.

Alle Versuchstiere wurden im Alter von vier Wochen von ihren Elterntieren getrennt und - sofern sie nicht für die Weiterzucht ausgewählt wurden - in eine von zwei Gruppen eingeteilt. Die erste Gruppe wurde für die Dauer von sechs Monaten auf eine Hochfettdiät (D12451, Fa. ResearchDiets, USA; bezogen via Firma Brogaarden, Gentofte, DK) gesetzt. 
Die zweite Gruppe fungierte als Kontrollgruppe und erhielt die Normaldiät der ZTE (V1534-0, ssniff-Spezialdiäten, Soest) für sechs Monate. Die Zusammensetzung beider Diäten ist in Tabelle 2 gezeigt.

Tabelle 2: Zusammensetzung der Diäten

\begin{tabular}{lll} 
Bestandteil & $\begin{array}{l}\text { Anteil in kcal\% } \\
\text { (Normaldiät) }\end{array}$ & $\begin{array}{l}\text { Anteil in kcal\% } \\
\text { (Hochfettdiät) }\end{array}$ \\
\hline Protein & 33 & 20 \\
\hline Kohlenhydrate & 58 & 35 \\
\hline Fett & 9 & 45
\end{tabular}

Eine tierärztliche Betreuung durch die Mitarbeiter der ZTE war jederzeit gegeben, zusätzlich wurden alle Tiere während des Versuchs regelmäßig auf äußerliche Krankheitszeichen untersucht. Zeigte ein Tier deutliche Krankheitszeichen wie ausgeprägte Ekzeme oder einen kachektischen Ernährungszustand, so wurde dieses Tier aus dem Versuch genommen. Bei einer repräsentativen Auswahl von Tieren wurde ab Beginn der Hochfettdiät bis zur Gewebeentnahme wöchentlich das Gewicht im wachen Zustand protokolliert.

Die Gewebeentnahme erfolgte nach sechs Monaten Hochfettdiät unter tiefer Anästhesie. Die Betreuung der Tiere, die Entnahme sowie die weitere Behandlung der Proben und deren Auswertung erfolgten unter Verblindung bezüglich des jeweiligen Genotyps.

\subsubsection{Messung des Körpergewichts}

Das Gewicht der Tiere wurde vor der Tötung im anästhesierten Zustand mit einer Präzisionswaage (Sartorius, Göttingen) ermittelt.

\subsubsection{Gewebeentnahme}

Nach jeweils sechs Monaten Hochfettdiät wurden alle Tiere in tiefe Narkose versetzt und nach Abnahme einer Blutprobe durch die Entnahme von Herz mitsamt der proximalen Aorta und $\operatorname{der} A$. brachiocephalica getötet. Als weiteren Marker für den Ernährungszustand wurden die Leber und das abdominale Fettdepot entnommen und gewogen.

Für die Gewebeentnahme wurde folgendes Vorgehen gewählt: Nach Identifikation anhand des Ohrcodes wurde jede Maus mittels Peritonealanästhesie betäubt und der Narkoseerfolg durch Setzung eines Schmerzreizes (Kneifen in eine Extremität) überprüft. Für die Anästhesie wurde die sog. Hellabrunner Mischung aus Natriumchloridlösung $(0,9 \%)$, Xylazin $(20 \mathrm{mg} / \mathrm{ml})$ und Ketamin $(50 \mathrm{mg} / \mathrm{ml})$ im Verhältnis 2:1:1 in einer Dosierung von 3,125 $\mu \mathrm{l} / \mathrm{g}$ (Weibchen) bzw. 4,17 $\mu \mathrm{l} / \mathrm{g}$ (Männchen) Körpergewicht verabreicht. 
Nach Eintreten einer vollständigen Narkose (definiert als Fehlen jeglicher Reaktion auf Schmerzreiz) wurde die Maus auf dem Rücken platziert und mit Klebestreifen an den Extremitäten auf einer Styroporplatte fixiert. Dann wurden Thorax und Abdomen mit $70 \%$ Ethanol (in destilliertem Wasser) befeuchtet, um das Aufsuchen der korrekten Punktionsstelle zu erleichtern. Im nächsten Schritt erfolgte die kardiale Punktion für die Blutentnahme vom Rippenbogen aus, die mit einer EDTA-benetzten Insulinspritze durchgeführt wurde.

Von der entnommenen Blutprobe wurden $500 \mu \mathrm{l}$ in einem Eppendorfgefäß mit $5 \mu \mathrm{l}$ EDTA $(180 \mathrm{mg} / \mathrm{ml}$ in destilliertem Wasser) versetzt, um eine Gerinnung der Blutprobe zu verhindern. Alle Proben wurden der Abteilung für Klinische Chemie zur weiteren Analyse übergeben (siehe „2.3 Messungen in Vollblut und Serum“)

Der Rest der Probe wurde ohne Zusatz von gerinnungshemmenden Substanzen in ein zweites Eppendorfgefäß überführt und im Anschluss bei $3000 \mathrm{rpm}$ für 10 Minuten zentrifugiert. Der Überstand (Serum) wurde in ein neues Eppendorfgefäß pipettiert und bis zur weiteren Analyse in der Abteilung für Klinische Chemie bei $-80{ }^{\circ} \mathrm{C}$ gelagert.

Für die Entnahme der A. brachiocephalica wurde der Thorax unterhalb des Rippenbogens und entlang des Sternums eröffnet und die Maus über den linken Ventrikel mit PBS (phosphate-buffered saline) vorsichtig perfundiert. Zur Verhinderung des venösen Rückstroms wurde die Aorta vor Beginn der Perfusion auf Höhe des Zwerchfells durchtrennt. Im Anschluss erfolgte die bindegewebsfreie Darstellung der A. brachiocephalica von ihrem Abgang aus der Aorta ascendens bis zu ihrer Aufteilung in die A. subclavia und $A$. carotis communis sinistra, um sie im nächsten Schritt $5 \mathrm{~mm}$ (A. subclavia) bzw. $10 \mathrm{~mm}$ (A. carotis communis) distal dieser Übergange abzusetzen. Zur besseren Orientierung wurde am Arterienpräparat die $A$. carotis communis mit einem Faden markiert. Nach Entnahme wurden die Arterien in $10 \%$ Zink-Formalin über Nacht bei Raumtemperatur fixiert.

Das Herz wurde von umliegendem Gewebe befreit und unterhalb des Abgangs der $A$. brachiocephalica von der Aorta und vom Truncus pulmonalis abgetrennt. Für die histologische Aufarbeitung der Aortenklappe wurde das Herz kaudal der Ventilebene horizontal mit einer scharfen Klinge geteilt. Die Herzbasis wurde mit den darin befindlichen Klappen ebenfalls über Nacht in $10 \%$ Zink-Formalin bei Raumtemperatur, der verbleibende ventrikuläre Anteil in $4 \%$ Paraformaldehyd (PFA) über Nacht bei $4{ }^{\circ} \mathrm{C}$ fixiert.

Für die Entnahme des abdominalen Fettdepots wurde der Bauchraum komplett eröffnet und die darüber liegenden Gewebeschichten beiseite gezogen, um die Depots freizulegen. Diese wurden dann (unter Schonung der Ovarien bzw. Testes) entnommen und unmittelbar danach gewogen.

\subsubsection{Gewebefixierung und -einbettung}

Alle Gewebe wurden in der jeweiligen Formalin-Lösung über Nacht fixiert, die Herzbasisund die Arterien-Präparate wurden danach in $70 \%$ Ethanol bis zur Einbettung in Paraffin 
gelagert, die Ventrikelpräparate in destilliertem Wasser. Die Entwässerung und Einbettung der Herzpräparate in Paraffin wurde mit einem Einbettautomat (Leica, Wetzlar) nach folgendem Protokoll durchgeführt:

$\begin{array}{ll}70 \% \text { Ethanol } & 1 \mathrm{~h} 30 \mathrm{~min} \\ 80 \% \text { Ethanol } & 1 \mathrm{~h} 30 \mathrm{~min} \\ 96 \% \text { Ethanol } & 1 \mathrm{~h} 30 \mathrm{~min} \\ 100 \% \text { Ethanol } & 2 \times 1 \mathrm{~h} 30 \mathrm{~min} \\ \text { Chloroform } & 2 \times 1 \mathrm{~h} 30 \mathrm{~min} \\ \text { Paraffin } & 3 \times 1 \mathrm{~h} 30 \mathrm{~min}\end{array}$

Für die Arterien-Präparate wurde auf Grund ihrer geringen Größe folgendes Protokoll verwendet:

$\begin{array}{ll}70 \% \text { Ethanol } & 5 \mathrm{~min} \\ 80 \% \text { Ethanol } & 35 \mathrm{~min} \\ 96 \% \text { Ethanol } & 60 \mathrm{~min} \\ 100 \% \text { Ethanol } & 2 \times 30 \mathrm{~min} \\ \text { Chloroform } & 2 \times 60 \mathrm{~min} \\ \text { Paraffin } & 3 \times 25 \mathrm{~min}\end{array}$

Im Anschluss wurden alle Präparate in einer auf $65^{\circ} \mathrm{C}$ vorgewärmten und zur Hälfte mit Paraffin gefüllten Ausgussform platziert. Nach der optimalen Positionierung wurde die Form zur Gänze aufgefüllt und zum Auskühlen auf eine Kälteplatte verbracht. Bis zur weiteren Verwendung wurden die Paraffinblöcke bei $4{ }^{\circ} \mathrm{C}$ gelagert.

\subsubsection{Genotypisierung der transgenen Mäuse}

Zur Genotypisierung der transgenen Mäuse wurde das DirectPCR ${ }^{\circledR}$ Lysis TailReagent (peglab, Erlangen) verwendet. Zu einer Schwanzbiopsie wurde jeweils $200 \mu$ l Lysepuffer, versetzt mit $2 \mu$ Proteinase K-Lösung $(20 \mathrm{mg} / \mathrm{ml})$ in das Reaktionsgefäß gegeben und der Ansatz über Nacht bei $55^{\circ} \mathrm{C}$ in einem Reaktionsgefäß inkubiert. Nach Hitzebehandlung $\left(85^{\circ} \mathrm{C}\right.$ für 45 Minuten) zur Inaktivierung der Proteinase K (peglab, Erlangen) wurden alle Reaktionsgefäße bei $4{ }^{\circ} \mathrm{C}$ gelagert bis sich die verbliebenen Feststoffe am Boden abgesetzt 
hatten. Anschließend wurden die Überstände (= Lysate) für die PCR mit transgenspezifischen Primern versetzt.

\subsubsection{Genehmigung der Studie}

Die Tierversuchsvorhaben wurden von der Tierschutzkommission der Universitätsmedizin Göttingen sowie vom Niedersächsischen Landesamt für Verbraucherschutz und Lebensmittelsicherheit (LAVES) (Aktenzeichen T10.10 und G81.9) genehmigt und entsprechend durchgeführt.

\subsection{Messungen in Vollblut und Serum}

\subsubsection{Maschinelles Blutbild}

Die hierfür notwendigen Messungen wurden am COULTER Ac-T5 DIFF (BeckmannCoulter, Krefeld) in EDTA-Blut von der Abteilung für Klinische Chemie (Universitätsmedizin Göttingen) gemäß den geltenden Verfahrensanweisungen durchgeführt.

\subsubsection{Bestimmung von Cholesterin, low density lipoprotein (LDL), high density lipoprotein (HDL) und Triglyzeriden in Serum}

Die bei $-80{ }^{\circ} \mathrm{C}$ gelagerten Serum-Proben wurden aufgetaut und in spezielle Sammelgefäße (Hitachi Cups, Roche Diagnostics) überführt. Die Messungen wurden von der Abteilung für Klinische Chemie mit Hilfe eines automatisierten Analysegeräts der COBAS-Serie (Roche Diagnostics, Basel, Schweiz) durchgeführt. Folgende Werte wurden dabei angefordert: Cholesterin, HDL-Cholesterin, LDL-Cholesterin und Triglyzeride.

\subsection{Histologische Analysen}

\subsubsection{Erstellung von Paraffin-Schnitten}

Die bei $4{ }^{\circ} \mathrm{C}$ gelagerten Paraffin-Blöcke wurden in das Mikrotom (JUNG RM 2035, Leica, Wetzlar) eingespannt und die Schnittdicke auf $5 \mu \mathrm{m}$ eingestellt. Die erzeugten Schnitte wurden zunächst vorsichtig in ein Wasserbad (Raumtemperatur) transferiert und dann auf einen Objektträger aufgezogen. Anschließend wurden die Objektträger in einem weiteren Wasserbad auf $37^{\circ} \mathrm{C}$ erwärmt, um die Schnitte zu glätten. Die Objektträger wurden jeweils mit Angaben zum Tierstamm, -nummer und Erstellungsdatum versehen. Des Weiteren wurden pro Präparat alle Objektträger fortlaufend nummeriert. Alle genannten Angaben sowie Auffälligkeiten und bereits sichtbare Merkmale der einzelnen Schnitte wurden in einem Protokoll vermerkt. Zur Trocknung und weiteren Fixierung der Schnitte wurden diese für eine Stunde bei $55^{\circ} \mathrm{C}$ inkubiert. 


\subsubsection{Gewebefärbungen}

\subsubsection{Entparaffinierung}

Für die Färbungen mit den nachfolgenden Färbeverfahren mussten die ausgewählten Schnitte zunächst gewässert werden. Hierfür wurden sie mit Xylol (zweimal für je fünf Minuten) entparaffiniert und in einer absteigenden Ethanolreihe (100\%, $96 \%$, $70 \%$ und $50 \%$ in destilliertem Wasser, jeweils zwei Minuten) gewässert.

\subsubsection{Elastikafärbung nach Verhoeff / Verhoeff's Elastica Stain (VES)}

Um die atherosklerotischen Veränderungen $\operatorname{der}$ A. brachiocephalica und der Aortenklappe einer quantitativen, morphometrischen Auswertung zugänglich zu machen, wurde die Elastikafärbung nach Verhoeff (auch als Verhoeff's Elastica Stain, VES, beschrieben) verwendet. Hierunter färben sich die elastischen Fasern und Zellkerne schwarz, Kollagen rot und die restlichen Strukturen gelblich.

Von den Schnitten einer Aortenklappe wurde jeder zweite Schnitt aus dem Bereich gefärbt, der eine plan geschnittene (alle drei Klappensegel sichtbar) Aortenklappe vermuten ließ. Von den Schnitten eines Arterienpräparats wurde über die gesamte Strecke im Abstand von $75 \mu \mathrm{m}$ immer jeweils ein Schnitt zur Färbung ausgewählt.

Nach erfolgter Entparaffinierung und Wässerung wurden die Schnitte für 15 Minuten in die Verhoeff'sche Elastika-Färbelösung getaucht. Anschließend wurde die Färbelösung durch laufendes, lauwarmes Leitungswasser (20 Minuten) aus der Färbeschale entfernt und ein weiterer Waschschritt mit destilliertem Wasser für fünf Minuten durchgeführt. Als nächstes erfolgte ein Differenzierungsschritt mit $2 \%$ Eisenchlorid für zweieinhalb Minuten und unmittelbar danach eine Behandlung mit Natriumthiosulfat für eine Minute. Nun wurden die Schnitte erneut gewaschen, zunächst in Leitungswasser, dann in destilliertem Wasser (jeweils für fünf Minuten). Es folgte die Gegenfärbung mit der Van-Gieson-Lösung für eine Minute, bevor die Schnitte durch eine aufsteigende Alkoholreihe $96 \%$ und $100 \%$ in destilliertes Wasser für jeweils zwei Minuten) und Xylol (zweimal à fünf Minuten) dehydriert wurden. Die Eindeckung erfolgte mit einem harzigen Einschlussmedium (Entellan ${ }^{\circledR}$, Merck, Darmstadt)

Aus den VES-gefärbten Schnitten eines Aortenklappen-Präparats wurden drei aufeinanderfolgende Schnitte für die Auswertung ausgewählt. Kriterium für die Auswahl war, dass sich die Aortenklappe mit drei gleich großen Klappensegeln darstellte. Waren mehr als drei Schnitte vorhanden, die dieses Kriterium erfüllten, so wurden der Schnitt mit der größten Plaquefläche unter den Klappensegeln sowie jeweils der vorhergehende und der nachfolgende Schnitt für die Auswertung verwendet.

Bei den entsprechend gefärbten Schnitten der Arterienpräparate wurden alle Schnitte, die eine atherosklerotische Plaque aufwiesen, in die Auswertung mit einbezogen. 
Für die Auswertung wurden die nach den obenstehenden Kriterien ausgewählten Schnitte bei 40facher (Aortenklappe) bzw. 100facher Vergrößerung (A. brachiocephalica) fotografiert (Olympus BX5, Carl Zeiss) und mit Hilfe einer Bildverarbeitungssoftware (Image-Pro Plus, MediaCybernetics) ausgewertet.

- Auf jedem Aortenklappenschnitt wurde zunächst die Fläche der Aortenwurzel ( $\left.A_{\text {Aortenwurzel }}\right)$ vermessen und anschließend die Größe der vorhandenen atherosklerotischen Läsionen $\left(A_{\text {Plaque }}\right)$ ermittelt. Aus diesen beiden Werten wurde dann der Grad der Lumenstenose errechnet.

$$
\text { Lumenstenose in }[\%]=\frac{A_{\text {Plaque }} \times 100}{A_{\text {Membrana elastica interna }}}
$$

- Auf den Schnitten der Arterien wurden die Fläche des Lumens $\left(A_{\text {Lumen }}\right)$, die Fläche innerhalb der Membrana elastica interna ( $A_{\text {Membrana elastica interna }}$ ) und die Fläche innerhalb der Membrana elastica externa ( $A_{\text {Membrana elastica externa }}$ ) in $\mu \mathrm{m}^{2}$ ermittelt. Aus diesen Werten wurden folgende Parameter errechnet:

- Größe der atherosklerotischen Plaque in $\mu \mathrm{m}^{2}$ :

$$
A_{\text {Plaque }}=A_{\text {Membrana elastica interna }}-A_{\text {Lumen }}
$$

- Lumenstenose in \%:

$$
\text { Lumenstenose in }[\%]=\frac{A_{\text {Plaque }} \times 100}{A_{\text {Membrana elastica interna }}}
$$

- Fläche der Media in $\mu \mathrm{m}^{2}$ :

$$
A_{\text {Media }}=A_{\text {Membrana elastica externa }} A_{\text {Membrana elastica interna }}
$$

- Intima-Media-Verhältnis:

$$
\text { Intima }- \text { Media }- \text { Verhältnis }=\frac{A_{\text {Plaque }}}{A_{\text {Media }}}
$$

- Gesamtfläche:

$$
\text { Gesamtfläche }=A_{\text {Membrana elastica externa }}
$$


Es wurden aus den einzelnen Messwerten jeweils die Mittelwerte pro Präparat (und damit pro Maus) ermittelt. Im Mittel wurden drei mit VES gefärbte Schnitte pro Maus erhoben.

\subsubsection{Masson-Trichrom-Färbung (MTC)}

Zur Quantifizierung des Kollagengehalts in den atherosklerotischen Plaques sowie zur Beurteilung der Plaquestabilität wurde die Masson-Trichrom-Färbung verwendet.

Nach Durchlaufen der Alkoholreihe wurden die Schnitte zur Reinigung fünf Minuten in destilliertem Wasser gelagert, bevor sie über Nacht in Bouin's Fixative nachfixiert wurden. Am darauffolgenden Morgen wurden die Fixierungslösung unter laufendem Leitungswasser ausgespült und die Objektträger nochmals zur Reinigung für fünf Minuten in destilliertes Wasser gegeben. Anschließend erfolgte die Anfärbung der Muskulatur mit Biebrich-Scharlachrot-Säurefuchsin für 15 Minuten. Nach Spülung für fünf Minuten in destilliertem Wasser wurde die Färbung 15 Minuten in PhosphomolybdicPhosphotungstic-Lösung differenziert, bevor die Kollagenfärbung mit Anilinblau-Lösung für acht Minuten durchgeführt wurde. Zur Entfernung der Färbelösung wurden die Objektträger erneut in destilliertem Wasser fünf Minuten lang gespült, bevor eine weitere Differenzierung in $1 \%$ Essigsäure für fünf Minuten folgte. Zur Dehydrierung wurden die Schnitte vor der Einbettung je zweimal für zwei Minuten mit $95 \%$ und $100 \%$ sowie zweimal für fünf Minuten mit Xylol behandelt. Die Einbettung erfolgte mit einem harzigen Einschlussmedium.

Die gefärbten Schnitte wurden bei 100facher Vergrößerung fotografiert (Olympus BX5, Fa. Carl Zeiss) und mit der Software Image-Pro Plus ausgewertet. Hierfür wurde die Grenze der atherosklerotischen Plaque markiert und der Anteil des blau gefärbten Kollagens an der Plaquefläche ermittelt.

\subsubsection{Evaluation der Vulnerabilität von atherosklerotischen Läsionen}

Für die Beurteilung der Plaque-Vulnerabilität wurden MTC- und VES-gefärbte Schnitte der A. brachiocephalica, die eine atherosklerotische Plaque aufwiesen, herangezogen und in Hinblick auf folgende indirekte Instabilitäts-Kriterien (nach Dellas et al. 2007) beurteilt:

- Vorliegen einer frischen, noch nicht verheilten Ruptur, definiert als das extravaskuläre Auftreten von Erythrozyten innerhalb der Plaque unabhängig vom Vorliegen eines sichtbaren Defekts der Plaqueoberfläche. Hierfür wurden MTC-gefärbte Schnitte verwendet, auf denen sich Erythrozyten rötlich darstellen.

- Vorliegen von Hinweisen auf abgelaufene, bereits verheilte Rupturen, sog. buried fibrous caps. Hierbei handelt es sich um Elastin-reiche Regionen innerhalb der Plaque, die sich durch die VES-Färbung sichtbar machen lassen. Sie stellen Residuen von Plaquerupturen dar, die im Zuge der Heilung durch weiteres Plaquematerial überwachsen wurden. 
- Vorliegen von Rupturen der Lamina elastica media mit Ausdehnung der intimalen Plaque in die Tunica media. Die Analyse erfolgte in VES-gefärbten Schnitten.

- Dicke der an glatten Muskelzellen reichen Plaquekappe im Verhältnis zur Tiefenausdehnung der gesamten Plaque. Die Tiefenausdehnung wurde als die Strecke von Plaqueoberfläche bis zur Lamina elastica interna definiert. Die Analyse erfolgte an MTCgefärbten Schnitten.

Die Befunde wurden durch Prof. Dr. med. Katrin Schäfer und PD Dr. med. Tim Seidler validiert. Alle Untersucher waren bezüglich des Genotyps und des Geschlechts der Versuchstiere verblindet.

\subsubsection{Immunhistochemische Färbungen}

\subsubsection{Protokoll für die Vorbereitung zur immunhistochemischen Färbung}

Alle Schnitte wurden zunächst mit Xylol (zweimal für je fünf Minuten) entparaffiniert und in einer absteigenden Ethanolreihe (100\%, $95 \%, 80 \%, 70 \%, 50 \%$ und $25 \%$ in destilliertem Wasser, jeweils zwei Minuten) gewässert bevor sie - mindestens für fünf Minuten, maximal über Nacht - in destilliertem Wasser gereinigt wurden. Zur Demaskierung der durch die Formalin-Fixierung verdeckten Epitope wurden die Schnitte in Citrat-Puffer (Dako, Glostrup, DK) gegeben und für sechs Minuten bei $800 \mathrm{~W}$ in der Mikrowelle erhitzt. Nach einer Abkühlungsphase von 20 Minuten wurden die Schnitte zweimal für fünf Minuten mit PBS gewaschen. Zur Blockierung der endogenen PeroxidaseAktivität folgte eine Behandlung mit $3 \%$ Wasserstoffperoxid in PBS für zehn Minuten. Danach wurden die Schnitte erneut dreimal für fünf Minuten in PBS gewaschen. Währenddessen wurden die zu färbenden Schnitte mit einem hydrophoben Schreibstift umkreist, um einem Abfließen der später aufzutragenden Antikörperlösungen vorzubeugen. Je nach Notwendigkeit schlossen sich vor der Antikörper-Inkubation nun weitere vorbereitende Schritte an (siehe die spezifischen Färbeprotokolle).

Danach folgte die Inkubation mit dem primären Antikörper (für alle Inkubationszeiten siehe das jeweilige Färbeprotokoll). Mit einem dreifachen Waschschritt in PBS (à fünf Minuten) wurde der primäre Antikörper entfernt und anschließend ein passender sekundärer Antikörper aufgetragen. Nach erneutem Waschen (in PBS, dreimal à fünf Minuten) erfolgte die Anwendung eines entsprechenden Detektionssystems (DAB für PCNA, AEC für alle weiteren Färbungen) nach Herstellerangaben.

Die jeweilige Konzentration des primären Antikörpers wurde mit einem hintergrundreduzierenden Verdünnungsmedium (Fa. Dako Deutschland GmbH, Hamburg) hergestellt, die des sekundären Antikörpers (wenn nicht anders angegeben) mit $1 \%$ Rinderserumalbumin (BSA) in PBS. 
Zur Verhinderung einer Austrocknung der Schnitte fanden alle Antikörper-Inkubationen sowie die Anwendung der Detektionssysteme in einer feuchten Kammer bei Raumtemperatur und in Dunkelheit statt.

Bei jeder Färbung wurde ein Schnitt nur mit dem Verdünnungsmedium ohne Primärantikörper bedeckt und diente als negative Kontrolle.

Alle Schnitte wurden zur Gegenfärbung in Hämalaun nach Mayer getaucht und dann eingedeckt. Die Eindeckung erfolgte im Falle der Färbung von PCNA nach Durchlaufen einer aufsteigenden Alkoholreihe (80\%, $95 \%$ und $100 \%$ Ethanol in destilliertem Wasser für je zwei Minuten und zweimal Xylol, jeweils fünf Minuten) mit einem harzigen Medium, bei allen anderen hier beschriebenen Färbungen mit einem wässrigem Medium (Aquatex, Merck Millipore, Darmstadt).

Für die Auswertung wurden die Schnitte bei 100facher Vergrößerung fotografiert. Die Auswertung erfolgte mit Hilfe der Software ImagePro Plus (Media Cybernetics, La Jolla, USA). Hierfür wurde jeweils die Grenzen der Plaque markiert und der Anteil der immunpositiven Fläche daran ermittelt.

\subsubsection{Immunhistochemische Färbung von Makrophagen}

Makrophagen spielen eine Schlüsselrolle in der Entstehung und Aufrechterhaltung der Atherosklerose. Für die Markierung von Makrophagen in den Arterien wurde ein für das Antigen Mac-2 spezifischer Antikörper verwendet, für die Markierung in den Schnitten der Aortenklappe ein Mac-3 spezifischer. Sowohl bei Mac-2 als auch bei Mac-3 handelt es sich um Glykoproteine, die sich vorwiegend auf der Oberfläche von reifen Makrophagen befinden, aber auch im geringen Umfang auf Zellmembranen anderer Immunzellen und Fibroblasten auftreten können. Es konnte gezeigt werden, dass beide Antigene gleichermaßen die Präsenz von Makrophagen anzeigen (Inoue et al. 2005).

Zur Reduzierung von Bindungsstellen des Sekundärantikörpers im Gewebe wurden vor beiden Färbungen die Schnitte für 30 Minuten mit $10 \%$ normalen Ziegenserum inkubiert (NGS).

Für alle Antikörper (AK) wurde eine Inkubationszeit von 60 Minuten bei Raumtemperatur gewählt. Folgende Antikörper wurden in der angegebenen Verdünnung eingesetzt:

\begin{tabular}{llll}
\hline 1. AK & Rat anti-Mac-2 & $1: 100$ & CL8942AP Cedarlane, Burlington, Canada \\
\hline & Rat anti-Mac-3 & $1: 100$ & BD 550292, BD Pharmingen, Heidelberg \\
\hline 2. AK & Rabbit anti-rat (biotinyliert) & $1: 200$ & 61-9540, Invitrogen, Darmstadt \\
\hline
\end{tabular}

Zur Detektion der gebundenen Sekundärantikörper kam zunächst ein kommerzielles Kit (VectorLabs, Burlingame, USA) zum Einsatz, das Avidin in Verbindung mit Meerrettichperoxidase (horseradish peroxidase, HRP) beinhaltet. Im Anschluss wurde ein 
weiteres kommerziell erhältliches Kit (ebenfalls VectorLabs), welches Wasserstoffperoxid und das Chromogen 3-Amino-9-Ethylcarbazol (AEC) umfasst, entsprechend den Herstellervorgaben verwendet. Avidin hat eine hohe Affinität zu Biotin und bindet daher an den Biotin-gebundenen Sekundärantikörper. Die Avidin-gebundene Peroxidase setzt bei Kontakt mit Wasserstoffperoxid Protonen frei, welches das Chromogen zu einem rotbräunlichen Produkt oxidiert.

\subsubsection{Immunhistochemische Färbung von T-Lymphozyten}

Das Antigen CD3 ist ein transmembranäres Protein und ein integraler Bestandteil des TZellrezeptors. Es ist somit ein spezifischer Marker für T-Lymphozyten und lässt einen Rückschluss auf die Ausprägung von Inflammation in den untersuchten Gewebeproben zu. Vor Auftragen des Primärantikörpers wurden die Schnitte mit $10 \%$ NGS für 30 Minuten inkubiert, um potentielle Bindungsstellen für den Sekundärantikörper abzudecken und so mögliche Hintergrundfärbungen zu reduzieren.

Die Inkubation mit dem Primärantikörper wurde über Nacht bei $4{ }^{\circ} \mathrm{C}$ durchgeführt, die Inkubationszeit für den Sekundärantikörper betrug 60 Minuten bei Raumtemperatur.

\begin{tabular}{llll}
\hline 1. AK & Rabbit anti-mouse CD3 & $1: 25$ & ab16669, abcam, Cambridge, UK \\
\hline 2. AK & Goat anti-rabbit (biotinyliert) & $1: 100$ & B-2770, Invitrogen, Darmstadt \\
\hline
\end{tabular}

Als Detektionssystem wurde, wie unter 2.4.4.3 beschrieben, ein ABC-Kit und AEC-Kit verwendet.

\subsubsection{Immunhistochemische Färbung von glatten Muskelzellen}

Glatte Muskelzellen liefern einen entscheidenden Beitrag zum Größenwachstum, aber auch zur Stabilität einer atherosklerotischen Läsion. Für die Anfärbung der Muskelzellen wurde ein Antikörper ausgewählt, der spezifisch für die in glatten Muskelzellen vorkommende $\alpha$ Isoform von Aktin (SMA, smooth muscle a-actin) ist und eine ausreichende Reaktivität bei murinen Geweben zeigt.

Die Inkubationszeit für den Primärantikörper betrug 60 Minuten, die für den Sekundärantikörper 30 Minuten.

\begin{tabular}{llll}
\hline 1.AK & Mouse anti-human & $1: 25$ & M0851, Dako, Glostrup, DK \\
\hline 2.AK & Goat anti-mouse (biotinyliert) & $1: 100$ & B-2770, invitrogen, Darmstadt \\
\hline
\end{tabular}

Als Detektionssystem wurden die unter 2.4.4.3 beschriebenen kommerziellen Kits der Firma Invitrogen benutzt. 
2.4.4.5 Immunhistochemische Färbung von proliferierenden Zellen

Proliferating-cell-nuclear-antigen (PCNA) vermittelt zusammen mit dem Replikationsfaktor C (RF-C) in eukaryontischen Zellen die Ablösung der Polymerase- $\alpha$ und dann die Bindung der Polymerase- $\delta$ an die DNA (Rassow 2008). PCNA eignet sich daher als spezifischer Marker für DNA-Synthese und somit indirekt für proliferative Aktivität.

Bei dieser Färbung war auf Grund der intranukleären Lokalisation des Antigens vor Auftragen des Antikörpers ein Permeabilisierungsschritt (4 \% BSA und 0,1 \% TritonX-100 in PBS für 30 Minuten) notwendig. Des Weiteren wurde ein Blockierungsschritt mit $4 \%$ BSA in PBS für 60 Minuten eingefügt. Im Anschluss an beide Schritte wurden die Objektträger jeweils dreimal für fünf Minuten in PBS gewaschen.

Der mit $4 \%$ BSA in PBS verdünnte Primärantikörper wurde für 90 Minuten mit den Schnitten inkubiert. Als Sekundärantikörper kam ein HRP-Polymer-konjugierter Antikörper zum Einsatz. Als Detektionssystem kam das zugehörige DAB-Kit (3,3'Diaminobenzidin) zum Einsatz, da sich hier auf Grund der schwarz-braunen Anfärbung die immunpositiven Zellkerne besser erkennen ließen. Dieses Kit beinhaltete weiterhin eine 0,6 \% Wasserstoffperoxid- sowie eine Pufferlösung. Die Meerrettichperoxidase reagiert mit dem Wasserstoffperoxid unter Freisetzung von Protonen, die ihrerseits dann das Chromogen 3,3'-Diaminobenzidin zu einem braunen Produkt oxidieren. Alle Bestandteile des Kits wurden gemäß den Herstellervorgaben verwendet.

\begin{tabular}{|c|c|c|c|}
\hline 1. AK & Mouse anti-PCNA & $1: 1000$ & \#2586, New England Biolabs, Frankfurt a.M. \\
\hline 2. AK & SuperPicture ${ }^{\mathrm{TM}} \mathrm{Kit}$ & & 87-8963, Invitrogen, Darmstadt \\
\hline
\end{tabular}

\subsection{Statistische Auswertung}

Für die statistische Analyse der erhobenen Daten wurde die Software GraphPadPrism in der Version 5.0 verwendet. Mittels Student's t-test wurden Unterschiede zwischen zwei Gruppen auf ihre statistische Signifikanz hin überprüft. Waren Unterschiede zwischen mehr als zwei Gruppen zu überprüfen wurde der One-Way $A N O V A$ und anschließend der Bonferroni's multiple comparison test benutzt. Der Chi-Quadrat-Test wurde zur Auswertung von Häufigkeitsunterschieden bei der Merkmalsausprägung angewandt. Ein p<0,05 würde als statistisch signifikant erachtet.

Die Fehlerbalken in den Grafiken stehen - sofern es nicht anders im Abbildungstext vermerkt ist - für den Standardfehler (SEM). 


\section{Ergebnisse}

\subsection{Charakterisierung der $\mathrm{IMP}^{-/+} / \mathrm{ApoE}^{-/-}$-Maus}

Für die Generierung des Mausmodells wurden $\mathrm{IMP}^{-/+}$- und ApoE $\mathrm{E}^{-/-}$-Tiere miteinander verpaart, deren $\mathrm{IMP}^{-/+} / \mathrm{ApoE}^{-/-}-\mathrm{Nachkommen}$ wurden anschließend für 6 Monate entweder auf Hochfett- oder Normal-Diät gesetzt. Anschließend erfolgten nachstehende Analysen.

Zur besseren Lesbarkeit werden im Folgenden Tiere mit dem Genotyp $\mathrm{IMP}^{-/+} / \mathrm{ApoE}^{-/-}$als IMP-KO-Gruppe und deren Geschwistertiere mit dem Genotyp $\mathrm{IMP}^{+/+} / \mathrm{ApoE}^{-/-}$als Kontroll-Gruppe bezeichnet.

\subsubsection{Morphometrische Analyse der $\mathrm{IMP}^{-/+} / \mathrm{ApoE}^{-/-}$-Maus}

Alle Mäuse wurden vor der Tötung zur Gewebeentnahme und nach Verabreichung der intraperitonealen Anästhesie gewogen. Unmittelbar nach der Präparation wurden das Gewicht der Leber und des abdominalen Fettdepots als weitere Marker für den Ernährungszustand ermittelt.

Die nachfolgenden Ergebnisse werden getrennt nach den Genotypen dargestellt, eine geschlechtsspezifische Auswertung ergab keine abweichenden Ergebnisse.

Tabelle 3: Geschlechterverteilung unter Normaldiät

\begin{tabular}{|c|c|c|}
\hline $\begin{array}{c}\text { Geschlechterverteilung } \\
\text { unter Normaldiät }\end{array}$ & Kontroll-Gruppe & IMP-KO-Gruppe \\
\hline Männlich & 14 & 10 \\
\hline Weiblich & 10 & 9 \\
\hline
\end{tabular}

Tabelle 4: Geschlechterverteilung unter Hochfettdiät

\begin{tabular}{|c|c|c|}
\hline $\begin{array}{c}\text { Geschlechterverteilung } \\
\text { unter Hochfettdiät }\end{array}$ & Kontroll-Gruppe & IMP-KO-Gruppe \\
\hline Männlich & 21 & 25 \\
\hline Weiblich & 25 & 23 \\
\hline
\end{tabular}


3.1.1.1 Körpergewicht zum Zeitpunkt der Tötung

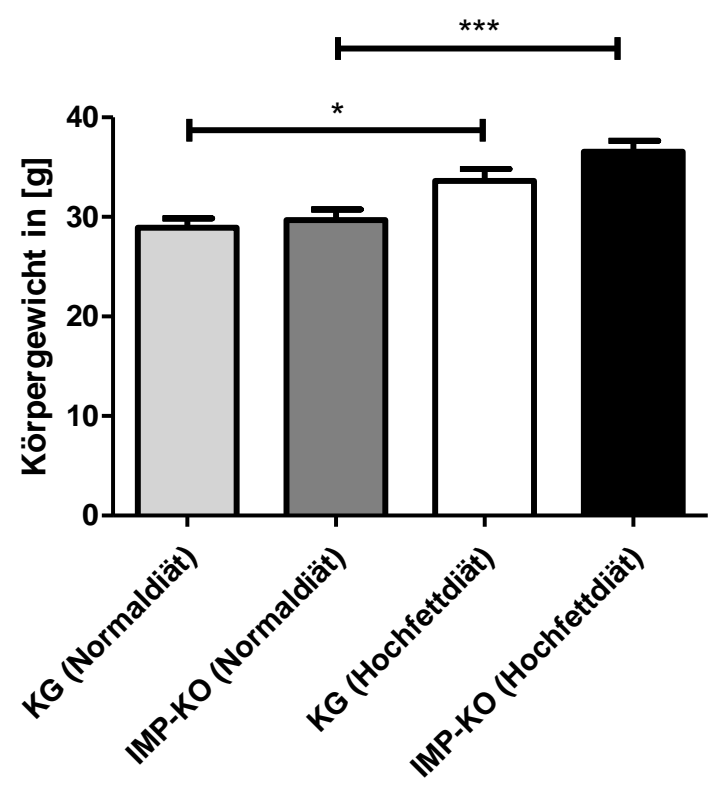

\begin{tabular}{|c|c|c|c|}
\hline Körpergewicht & Kontroll-Gruppe & IMP-KO-Gruppe & $\mathbf{p}$ \\
\hline Normaldiät / 6 Monate & $28,9 \pm 0,9 \mathrm{~g}, \mathrm{n}=24$ & $29,7 \pm 1,1 \mathrm{~g}, \mathrm{n}=19$ & 0,61 \\
\hline Hochfettdiät / 6 Monate & $33,6 \pm 1,2 \mathrm{~g}, \mathrm{n}=46$ & $36,6 \pm 1,1 \mathrm{~g}, \mathrm{n}=48$ & 0,07 \\
\hline $\mathbf{P}$ & $<0,001$ & 0,01 & \\
\hline
\end{tabular}

Abbildung 3: Körpergewicht in der Kontroll- und IMP-KO-Gruppe, jeweils unter Normal- und

Hochfettdiät. Es ergab sich kein statistisch signifikanter Unterschied zwischen Kontroll- und IMP-KOGruppe. Unter Hochfettdiät ergab sich jeweils ein signifikant höheres Körpergewicht gegenüber der Normaldiät (Normaldiät $\mathrm{p}=0,01$, unter Hochfettdiät $\mathrm{p}=<0,001$ ).

Somit zeigte sich ein signifikant größeres Körpergewicht für beide Genotypen unter Hochfettdiät. Zudem zeigte sich ein statistisch nicht signifikanter Trend zu höherem Körpergewicht in der IMP-KO- im Vergleich zur Kontroll-Gruppe. 


\subsubsection{Lebergewicht}

Die Leber wurde jedem Tier nach der Tötung entnommen und anschließend gewogen.

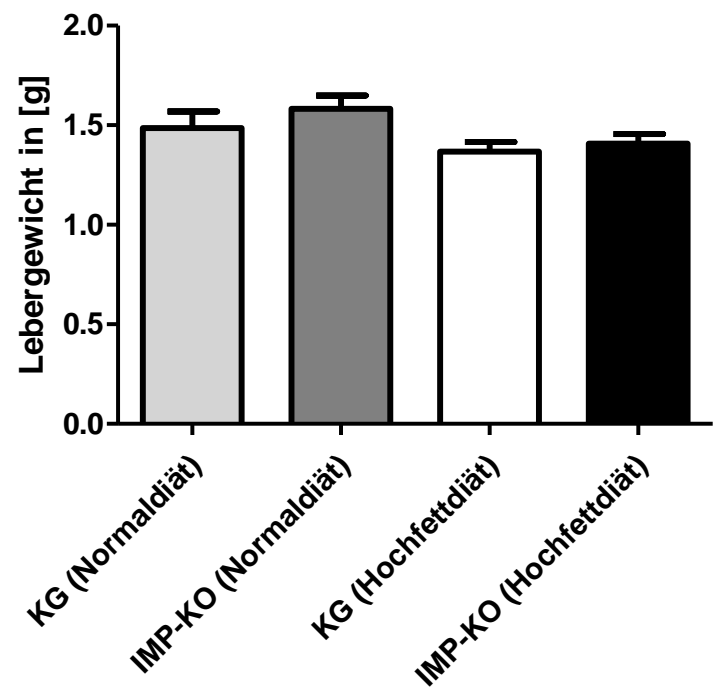

\begin{tabular}{|c|c|c|c|}
\hline Lebergewicht & Kontroll-Gruppe & IMP-KO-Gruppe & $\mathbf{p}$ \\
\hline Normaldiät / 6 Monate & $1,37 \pm 0,05 \mathrm{~g}, \mathrm{n}=24$ & $\begin{array}{c}1,41 \pm 0,05 \mathrm{~g}, \\
\mathrm{n}=18\end{array}$ & 0,57 \\
\hline Hochfettdiät / 6 Monate & $1,49 \pm 0,08 \mathrm{~g}, \mathrm{n}=47$ & $\begin{array}{c}1,58 \pm 0,07 \mathrm{~g}, \\
\mathrm{n}=48\end{array}$ & 0,36 \\
\hline $\mathbf{p}$ & 0,13 & 0,33 & \\
\hline
\end{tabular}

Abbildung 4: Lebergewicht in der Kontroll- und IMP-KO-Gruppe, jeweils unter Normal- und Hochfettdiät. Es ergab sich kein statistisch signifikanter Unterschied.

Es zeigte sich bei beiden Genotypen unter Hochfettdiät keine signifikante Zunahme des Lebergewichts gegenüber der Normaldiät. Das Lebergewicht der IMP-KO-Gruppe war gegenüber der Kontroll-Gruppe weder unter Normal- noch unter Hochfettdiät erhöht. 


\subsubsection{Quotient aus Leber- und Körpergewicht}

Um einen möglichen Einfluss des Gesamtgewichts auf das Organgewicht zu eliminieren, wurde zusätzlich der Quotient aus Leber- und Körpergewicht berechnet.

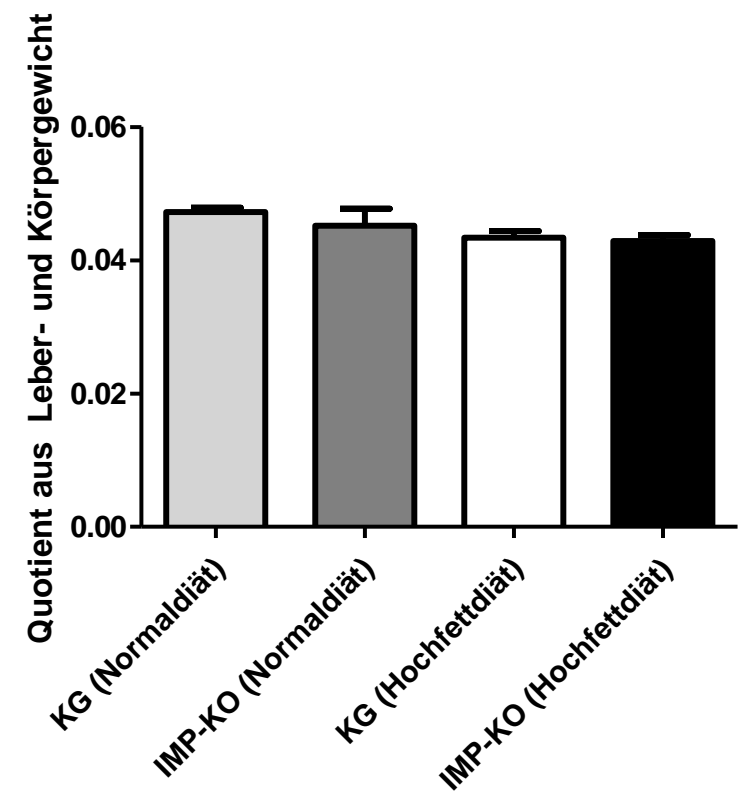

\begin{tabular}{|c|c|c|c|}
\hline $\begin{array}{c}\text { Quotient aus Leber- } \\
\text { und Körpergewicht }\end{array}$ & Kontroll-Gruppe & IMP-KO-Gruppe & $\mathbf{p}$ \\
\hline Normaldiät / 6 Monate & $0,047 \pm 0,001, \mathrm{n}=24$ & $\begin{array}{l}0,048 \pm 0,001, \\
\mathrm{n}=18\end{array}$ & 0,63 \\
\hline Hochfettdiät / 6 Monate & $0,043 \pm 0,001, \mathrm{n}=46$ & $\begin{array}{l}0,043 \pm 0,001, \\
\mathrm{n}=48\end{array}$ & 0,70 \\
\hline $\mathbf{p}$ & $<0,01$ & $<0,01$ & \\
\hline
\end{tabular}

Abbildung 5: Quotient aus Leber- und Körpergewicht in der Kontroll- und IMP-KO-Gruppe, jeweils unter Normal- und Hochfettdiät. Jeweils signifikant niedrigerer Quotient für beide Genotypen unter Hochfettdiät gegenüber der Normaldiät.

Hier zeigte sich ein statistisch signifikant niedrigerer Quotient für beide Genotypen unter Hochfett- gegenüber der Normaldiät. 


\subsubsection{Gewicht des abdominalen Fettdepots}

Das abdominale Fettdepot ist ein Marker für den Ernährungszustand und korreliert mit dem Gesamtkörperfettanteil. Die Entnahme erfolgte nach der Tötung im Anschluss an die Organentnahme.

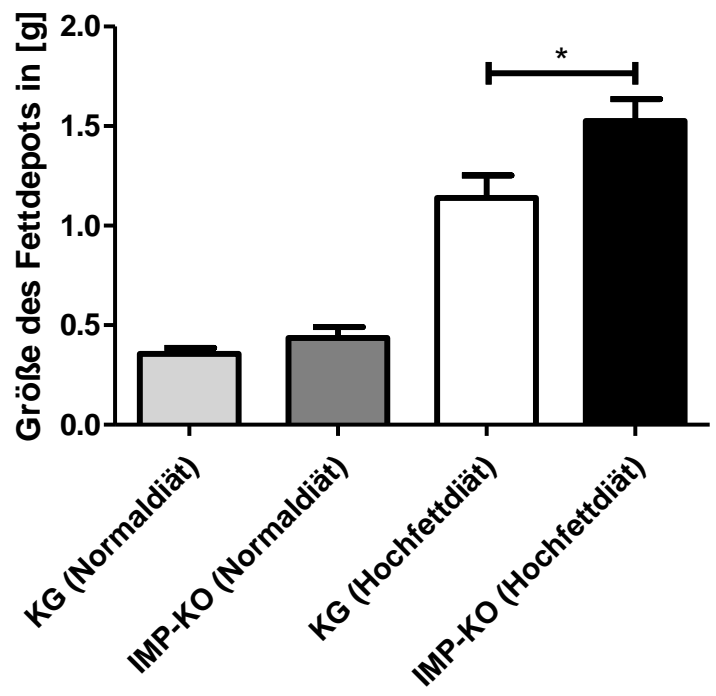

\begin{tabular}{|c|c|c|c|}
\hline $\begin{array}{c}\text { Gewicht des abdominalen } \\
\text { Fettdepots }\end{array}$ & Kontroll-Gruppe & IMP-KO-Gruppe & $\mathbf{p}$ \\
\hline Normaldiät / 6 Monate & $0,36 \pm 0,03 \mathrm{~g}, \mathrm{n}=24$ & $\begin{array}{c}0,44 \pm 0,05 \mathrm{~g}, \\
\mathrm{n}=18\end{array}$ & 0,18 \\
\hline Hochfettdiät / 6 Monate & $1,14 \pm 0,11 \mathrm{~g}, \mathrm{n}=45$ & $\begin{array}{c}1,53 \pm 0,11 \mathrm{~g}, \\
\mathrm{n}=47\end{array}$ & 0,02 \\
\hline $\mathbf{p}$ & $<0,0001$ & $<0,0001$ & \\
\hline
\end{tabular}

Abbildung 6: Gewicht der abdominalen Fettdepots in der Kontroll- und IMP-KO-Gruppe, jeweils unter Normal- und Hochfettdiät. Unter Hochfettdiät zeigte sich ein signifikant höheres Gewicht der abdominalen Fettdepots in der IMP-KO-Gruppe gegenüber der Kontroll-Gruppe $(p=<0,02)$. Weiterhin zeigte sich ein signifikant höheres Gewicht des abdominalen Fettdepots bei beiden Genotypen unter Hochfettdiät gegenüber der Normaldiät $(\mathrm{p}=<0,0001)$.

Es zeigte sich unter Hochfettdiät ein signifikant höheres Gewicht der abdominalen Fettdepots in der IMP-KO-Gruppe gegenüber der Kontrollgruppe $(p=<0,02)$. Weiterhin zeigte sich ein signifikant höheres Gewicht der abdominalen Fettdepots bei beiden Genotypen unter Hochfettdiät gegenüber der Normaldiät. 


\subsubsection{Verhältnis von abdominalem Fettdepot und Körpergewicht}

Zusätzlich wurde der Quotient aus dem Gewicht des Fettdepots und dem Körpergewicht berechnet.

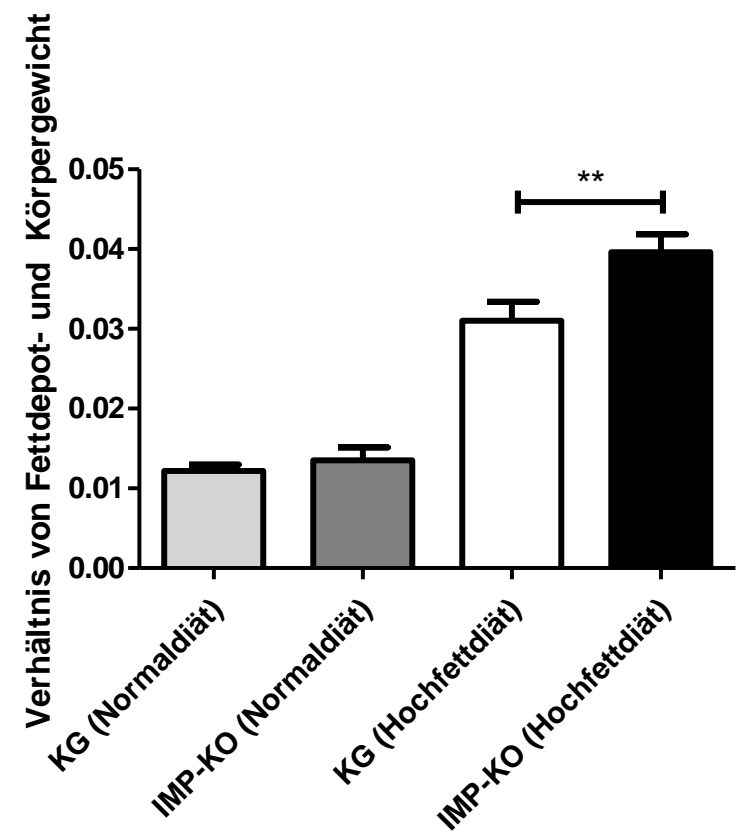

\begin{tabular}{|c|c|c|c|}
\hline $\begin{array}{c}\text { Verhältnis von } \\
\text { Fettdepot und } \\
\text { Körpergewicht }\end{array}$ & Kontroll-Gruppe & IMP-KO-Gruppe & $\mathbf{p}$ \\
\hline Normaldiät / 6 Monate & $0,012 \pm 0,001, \mathrm{n}=24$ & $\begin{array}{c}0,014 \pm 0,002, \\
\mathrm{n}=19\end{array}$ & 0,43 \\
\hline Hochfettdiät / 6 Monate & $0,031 \pm 0,002, \mathrm{n}=44$ & $0,04 \pm 0,002, \mathrm{n}=47$ & $<0,01$ \\
\hline p & $<0,0001$ & $<0,0001$ & \\
\hline
\end{tabular}

Abbildung 7: Quotient aus dem Gewicht der abdominalen Fettdepots und Körpergewicht in der Kontroll- und IMP-KO-Gruppe, jeweils unter Normal- und Hochfettdiät. Unter Hochfettdiät zeigt sich ein signifikant erhöhter Quotient in der IMP-KO-Gruppe gegenüber der Kontroll-Gruppe $(\mathrm{p}=<0,01)$.

Es zeigte sich ein signifikant erhöhter Quotient in der IMP-KO-Gruppe gegenüber der Kontrollgruppe $(p=<0,01)$. Weiterhin zeigte sich für beide Genotypen ein signifikant erhöhter Quotient unter Hochfettdiät gegenüber der Normaldiät. 


\subsubsection{Automatisierte Quantifizierung der korpuskulären Blutbestandteile}

Tabelle 5: Die korpuskulären Blutbestandteile nach sechs Monaten Normaldiät

\begin{tabular}{|c|c|c|c|c|}
\hline Parameter & Einheit & Kontroll-Gruppe & IMP-KO-Gruppe & $\mathbf{p}$ \\
\hline Leukozyten & {$\left[10^{3} / \mu \mathrm{l}\right]$} & $6,1 \pm 0,6, \mathrm{n}=13$ & $5,8 \pm 0,5, \mathrm{n}=9$ & 0,77 \\
\hline Neutrophile & Anteil in \% & $15,1 \pm 1,8, \mathrm{n}=13$ & $17,1 \pm 3,0, \mathrm{n}=9$ & 0,55 \\
\hline Lymphozyten & Anteil in \% & $69,5 \pm 2,5, \mathrm{n}=13$ & $66,5 \pm 3,5, \mathrm{n}=9$ & 0,49 \\
\hline Monozyten & Anteil in \% & $11,7 \pm 1,1, \mathrm{n}=13$ & $11,6 \pm 1,1, \mathrm{n}=9$ & 0,96 \\
\hline Eosinophile & Anteil in \% & $1,7 \pm 0,3, \mathrm{n}=13$ & $1,9 \pm 0,7, \mathrm{n}=9$ & 0,26 \\
\hline Basophile & Anteil in \% & $2,6 \pm 0,5, \mathrm{n}=13$ & $2,9 \pm 0,8, \mathrm{n}=9$ & 0,72 \\
\hline Erythrozyten & {$\left[10^{6} / \mu \mathrm{l}\right]$} & $7,9 \pm 0,2, \mathrm{n}=13$ & $7,9 \pm 0,6, \mathrm{n}=9$ & 1,00 \\
\hline Hämoglobin & {$[\mathrm{g} / \mathrm{dl}]$} & $11,8 \pm 0,4,=13$ & $11,8 \pm 0,9, \mathrm{n}=9$ & 0,93 \\
\hline Hämatokrit & Anteil in \% & $37,7 \pm 1,4, \mathrm{n}=13$ & $37,5 \pm 3,0, \mathrm{n}=9$ & 0,93 \\
\hline MCV & {$[\mathrm{fl}]$} & $47,9 \pm 0,5, \mathrm{n}=12$ & $46,9 \pm 0,6, \mathrm{n}=7$ & 0,19 \\
\hline MCH & {$[\mathrm{pg}]$} & $15,0 \pm 0,1, \mathrm{n}=10$ & $14.9 \pm 0,2, \mathrm{n}=8$ & 0,78 \\
\hline MCHC & {$[\mathrm{g} / \mathrm{dl}]$} & $31,4 \pm 0,3 \mathrm{n}=13$ & $31,6 \pm 0,4, \mathrm{n}=9$ & 0,69 \\
\hline EVB & Abweichung in $\%$ & $13,2 \pm 0,3, \mathrm{n}=13$ & $13,3 \pm 0,5, \mathrm{n}=9$ & 0,81 \\
\hline Thrombozyten & {$\left[10^{3} / \mu \mathrm{l}\right]$} & $646,5 \pm 48,7, \mathrm{n}=13$ & $639,1 \pm 68,0, \mathrm{n}=9$ & 0,93 \\
\hline MTV & {$[\mathrm{fl}]$} & $6,1 \pm 0,1, \mathrm{n}=13$ & $6,2 \pm 0,1, \mathrm{n}=9$ & 0,67 \\
\hline
\end{tabular}

$\mathrm{MCV}=$ mittleres korpuskuläres Volumen; $\mathrm{MCH}=$ Mittleres korpuskuläres Hämoglobin; $\mathrm{MCHC}=$ Mittlere korpuskuläre Hämoglobinkonzentration; EVB = Erythrozytenverteilungsbreite, Angabe der Abweichung vom MCV in \%; MTV = Mittleres thrombozytäres Volumen.

Bei der Untersuchung der korpuskulären Blutbestandteile ergaben sich unter Normaldiät keine statistisch signifikanten Unterschiede zwischen Kontroll- und IMP-KO-Gruppe. 
Tabelle 6: Die korpuskulären Blutbestandteile nach sechs Monaten Hochfettdiät

\begin{tabular}{|c|c|c|c|c|}
\hline Parameter & Einheit & Kontroll-Gruppe & IMP-KO-Gruppe & $\mathbf{p}$ \\
\hline Leukozyten & {$\left[10^{3} / \mu \mathrm{l}\right]$} & $4,5 \pm 0,5, \mathrm{n}=28$ & $5,7 \pm 0,4, \mathrm{n}=31$ & 0,10 \\
\hline Neutrophile & Anteil in \% & $20,9 \pm 1,5, \mathrm{n}=27$ & $18,0 \pm 1,4, \mathrm{n}=30$ & 0,16 \\
\hline Lymphozyten & Anteil in \% & $59,1 \pm 2,0, \mathrm{n}=27$ & $60,4 \pm 2,0, \mathrm{n}=30$ & 0,65 \\
\hline Monozyten & Anteil in \% & $14,4 \pm 1,4, \mathrm{n}=27$ & $10,9 \pm 1,1, \mathrm{n}=30$ & $\mathbf{0 , 0 5}$ \\
\hline Eosinophile & Anteil in \% & $2,5 \pm 0,8, \mathrm{n}=27$ & $4,9 \pm 0,9, \mathrm{n}=30$ & 0,06 \\
\hline Basophile & Anteil in \% & $3,1 \pm 0,8, \mathrm{n}=27$ & $5,9 \pm 1,0, \mathrm{n}=30$ & $\mathbf{0 , 0 4}$ \\
\hline Erythrozyten & {$\left[10^{6} / \mu \mathrm{l}\right]$} & $7,1 \pm 0,2, \mathrm{n}=28$ & $6,5 \pm 0,3, \mathrm{n}=31$ & 0,16 \\
\hline Hämoglobin & {$[\mathrm{g} / \mathrm{dl}]$} & $10,8 \pm 0,4, \mathrm{n}=28$ & $10,2 \pm 0,5, \mathrm{n}=31$ & 0,27 \\
\hline Hämatokrit & Anteil in \% & $34,2 \pm 1,3, \mathrm{n}=28$ & $31,9 \pm 1,8,=31$ & 0,32 \\
\hline MCV & {$[\mathrm{fl}]$} & $48,2 \pm 0,5, \mathrm{n}=28$ & $46,6 \pm 1,3 \mathrm{n}=31$ & 0,27 \\
\hline MCH & {$[\mathrm{pg}]$} & $15,4 \pm 0,1, \mathrm{n}=28$ & $16,3 \pm 0,6, \mathrm{n}=30$ & 0,12 \\
\hline MCHC & {$[\mathrm{g} / \mathrm{dl}]$} & $31,9 \pm 0,3, \mathrm{n}=28$ & $33,2 \pm 0,6, \mathrm{n}=30$ & 0,07 \\
\hline EVB & Abweichung in \% & $15,8 \pm 0,3, \mathrm{n}=28$ & $15,7 \pm 0,4, \mathrm{n}=31$ & 0,77 \\
\hline Thrombozyten & {$\left[10^{3} / \mu \mathrm{l}\right]$} & $620.4 \pm 32,9, \mathrm{n}=28$ & $668.8 \pm 41,9, \mathrm{n}=30$ & 0,37 \\
\hline MTV & {$[\mathrm{fl}]$} & $6,3 \pm 0,1, \mathrm{n}=28$ & $6,3 \pm 0,1, \mathrm{n}=30$ & 0,64 \\
\hline
\end{tabular}

$\mathrm{MCV}=$ Mittleres korpuskuläres Volumen; $\mathrm{MCH}=$ Mittleres korpuskuläres Hämoglobin; MCHC $=$ Mittlere korpuskuläre Hämoglobinkonzentration; EVB = Erythrozytenverteilungsbreite, Angabe der Abweichung vom MCV in \%; MTV = Mittleres thrombozytäres Volumen.

In der Untersuchung der korpuskulären Blutbestandteile fanden sich unter Hochfettdiät mit Ausnahme des erhöhten Anteils von basophilen Granulozyten $(3,1 \pm 0,8 \%, \mathrm{n}=27$ in der Kontroll-Gruppe vs. 5,9 \pm 1,0\%, $\mathrm{n}=30$ in der IMP-KO-Gruppe - $\mathrm{p}=0,04)$ keine statistisch signifikanten Unterschiede.

Statistisch nicht signifikante Trends fanden sich bei dem Anteil der Eosinophilen $(2,5 \pm$ 0,8 \%, $\mathrm{n}=27$ in der Kontroll-Gruppe vs. 4,9 $\pm 0,9 \%, \mathrm{n}=30$ in der IMP-KO-Gruppe $\mathrm{p}=0,06)$ und dem Anteil der Monozyten $(14,4 \pm 1,4 \%, \mathrm{n}=27$ in der Kontroll-Gruppe vs.10,9 $\pm 1,1 \%, \mathrm{n}=30$ in der IMP-KO-Gruppe $-\mathrm{p}=0,05)$.

\subsubsection{Bestimmung von Lipoproteinen im Serum}

Die nachfolgenden Bestimmungen wurden von der Abteilung für Klinische Chemie (Universitätsmedizin Göttingen) durchgeführt. Zur Evaluation der verwendeten Diäten sowie zur Untersuchung auf Störungen des Lipoprotein-Stoffwechsels wurde das GesamtCholesterin inklusive der HDL- und LDL-Fraktion sowie die Konzentration an Triglyzeriden im Serum bestimmt. Anschließend wurden die Quotienten aus LDL- und HDL-Cholesterin sowie dem Gesamt-Cholesterin und HDL-Cholesterin berechnet. 
3.1.3.1 Bestimmung des Gesamtcholesterins im Serum

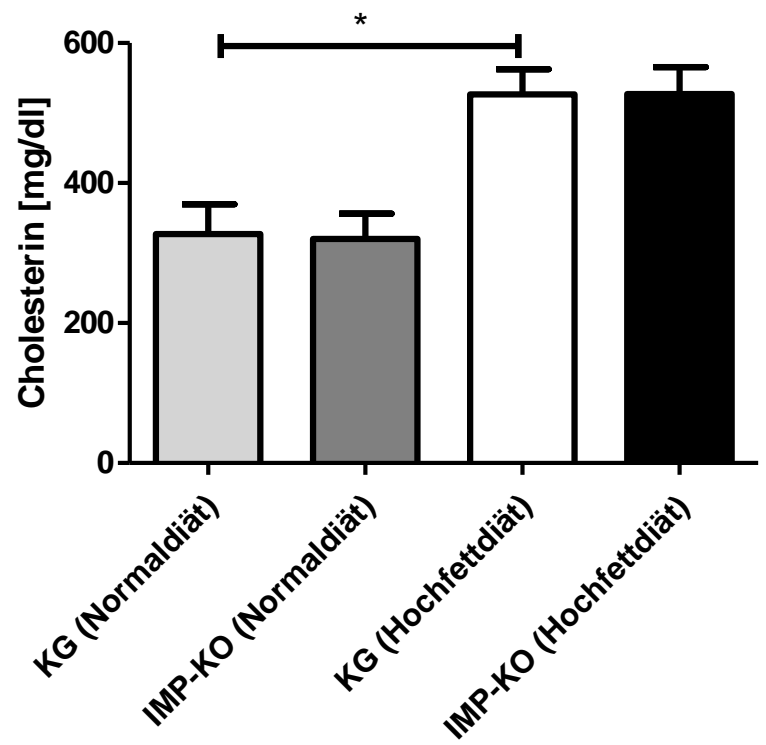

\begin{tabular}{|c|c|c|c|}
\hline & Kontroll-Gruppe & IMP-KO-Gruppe & $\mathbf{p}$ \\
\hline Normaldiät / 6 Monate & $327,3 \pm 42,5, \mathrm{n}=6$ & $320,0 \pm 36,5, \mathrm{n}=3$ & 0,92 \\
\hline Hochfettdiät / 6 Monate & $526,9 \pm 3,1, \mathrm{n}=22$ & $527,1 \pm 38,6, \mathrm{n}=26$ & 1,00 \\
\hline p & 0,01 & 0,09 & \\
\hline
\end{tabular}

Abbildung 8: Bestimmung des Gesamtcholesterins im Serum der Kontroll- und IMP-KO-Gruppe, jeweils nach sechs Monaten Normal- bzw. Hochfettdiät. Unter Hochfettdiät zeigt sich in der Kontrollgruppe gegenüber der Normaldiät ein signifikant höherer Cholesteringehalt im Serum $(p=<0,05)$.

Unter Hochfettdiät zeigte sich in der Kontrollgruppe gegenüber der Normaldiät ein signifikant erhöhter Gesamtcholesterinspiegel im Serum gegenüber der Normaldiät. Unterschiede zwischen den Genotypen traten nicht auf. 
3.1.3.2 Bestimmung des HDL-Cholesterins im Serum

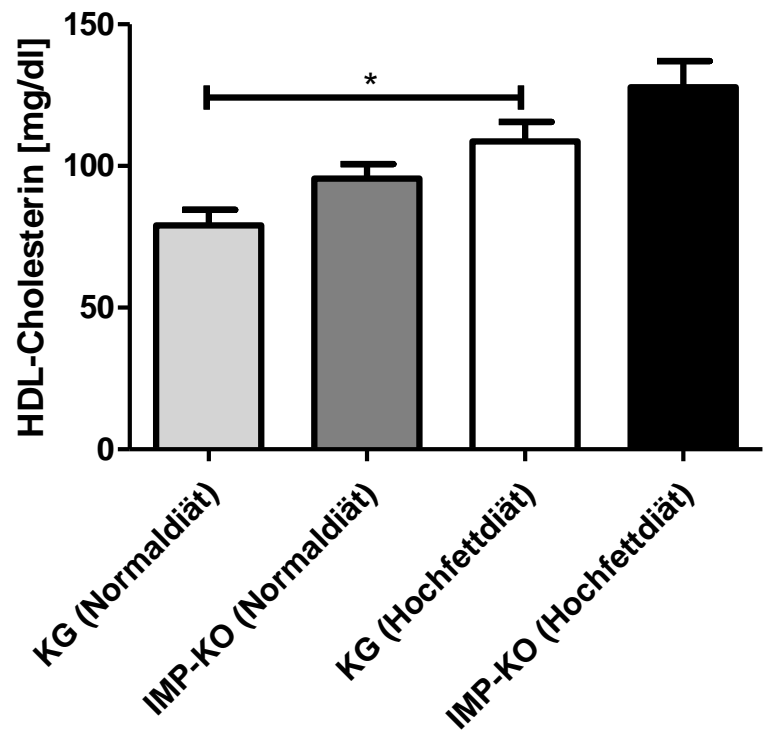

\begin{tabular}{|c|c|c|c|}
\hline & Kontroll-Gruppe & IMP-KO-Gruppe & $\mathbf{p}$ \\
\hline Normaldiät / 6 Monate & $79,0 \pm 5,5, \mathrm{n}=6$ & $95,5 \pm 5,2, \mathrm{n}=4$ & 0,08 \\
\hline Hochfettdiät / 6 Monate & $108,7 \pm 6,8, \mathrm{n}=22$ & $127,8 \pm 9,3, \mathrm{n}=26$ & 0,12 \\
\hline p & 0,04 & 0,19 & \\
\hline
\end{tabular}

Abbildung 9: Bestimmung des HDL-Cholesterins im Serum der Kontroll- und IMP-KO-Gruppe, jeweils nach sechs Monaten Normal- bzw. Hochfettdiät. Unter Hochfettdiät zeigte sich in der Kontrollgruppe gegenüber der Normaldiät ein signifikant höherer HDL-Cholesteringehalt im Serum $(\mathrm{p}=<0,05)$.

Unter Hochfettdiät zeigte sich in der Kontrollgruppe gegenüber der Normaldiät ein signifikant erhöhter HDL-Cholesterin-Spiegel im Serum. Unterschiede zwischen den Genotypen traten nicht auf, wenngleich sich in der IMP-KO-Gruppe sowohl unter Normal- als auch unter Hochfettdiät ein Trend zu höheren HDL-Cholesterin-Spiegeln gegenüber der jeweiligen Kontrollgruppe andeutete. 
3.1.3.3 Bestimmung des LDL-Cholesterins im Serum

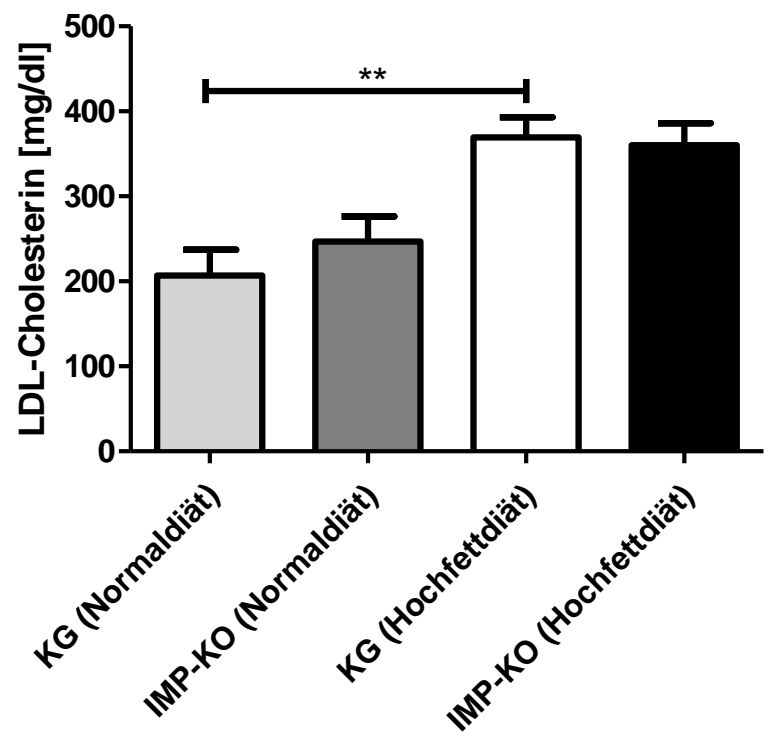

\begin{tabular}{|c|c|c|c|}
\hline & Kontroll-Gruppe & IMP-KO-Gruppe & $\mathbf{p}$ \\
\hline Normaldiät / 6 Monate & $206,8 \pm 30,4, \mathrm{n}=6$ & $246,8 \pm 29,7, \mathrm{n}=4$ & 0,40 \\
\hline Hochfettdiät / 6 Monate & $369,5 \pm 23,7, \mathrm{n}=22$ & $\begin{array}{c}360,3 \pm 25,7, \\
\mathrm{n}=26\end{array}$ & 0,80 \\
\hline P & 0,002 & 0,10 & \\
\hline
\end{tabular}

Abbildung 10: Bestimmung des LDL-Cholesterins im Serum der Kontroll- und IMP-KO-Gruppe, jeweils nach sechs Monaten Normal- bzw. Hochfettdiät. Unter Hochfettdiät zeigte sich in der Kontrollgruppe gegenüber der Normaldiät ein signifikant höherer LDL-Cholesteringehalt im Serum $(\mathrm{p}=<0,01)$.

Unter Hochfettdiät zeigte sich in der Kontrollgruppe gegenüber der Normaldiät ein signifikant erhöhter LDL-Cholesterin-Spiegel im Serum. Unterschiede zwischen den Genotypen traten nicht auf. 
3.1.3.4 Bestimmung der Triglyzeride im Serum

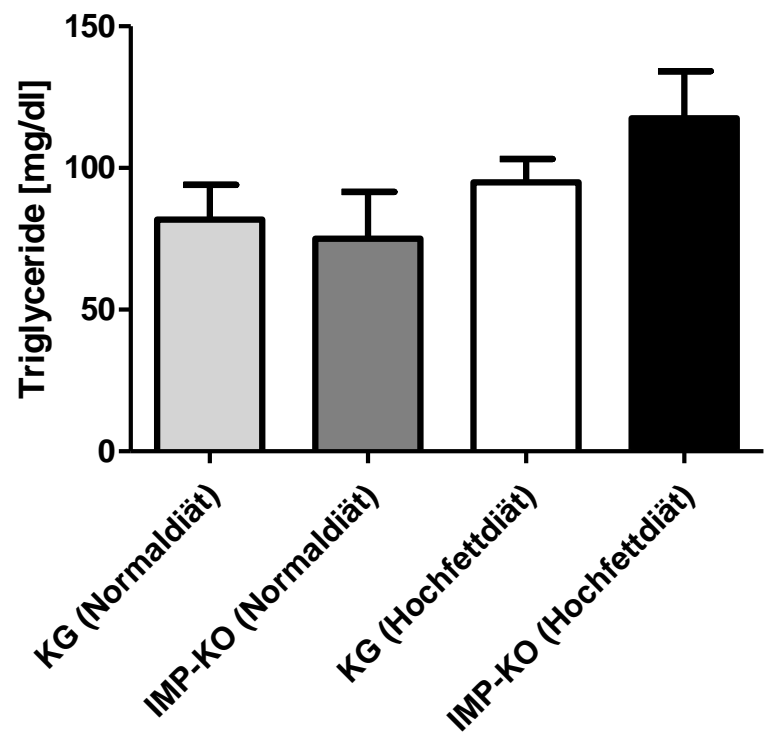

\begin{tabular}{|c|c|c|c|}
\hline & Kontroll-Gruppe & IMP-KO-Gruppe & p \\
\hline Normaldiät / 6 Monate & $81,8 \pm 12,2, \mathrm{n}=6$ & $75,0 \pm 16,5, \mathrm{n}=3$ & 0,75 \\
\hline Hochfettdiät / 6 Monate & $95,0 \pm 8,3 \mathrm{n}=22$ & $\begin{array}{c}117,6 \pm 16,6, \\
\mathrm{n}=26\end{array}$ & 0,25 \\
\hline p & 0,45 & 0,40 & \\
\hline
\end{tabular}

Abbildung 11: Bestimmung der Triglyzeride im Serum der Kontroll- und IMP-KO-Gruppe, jeweils nach sechs Monaten Normal- bzw. Hochfettdiät. Es zeigte sich kein statistisch signifikanter Unterschied.

Bei der Bestimmung der Triglyzeride im Serum zeigte sich kein statistisch signifikanter Unterschied zwischen den Genotypen und den Diätgruppen. 
3.1.3.5 Berechnung des Quotienten aus LDL- und HDL-Cholesterin

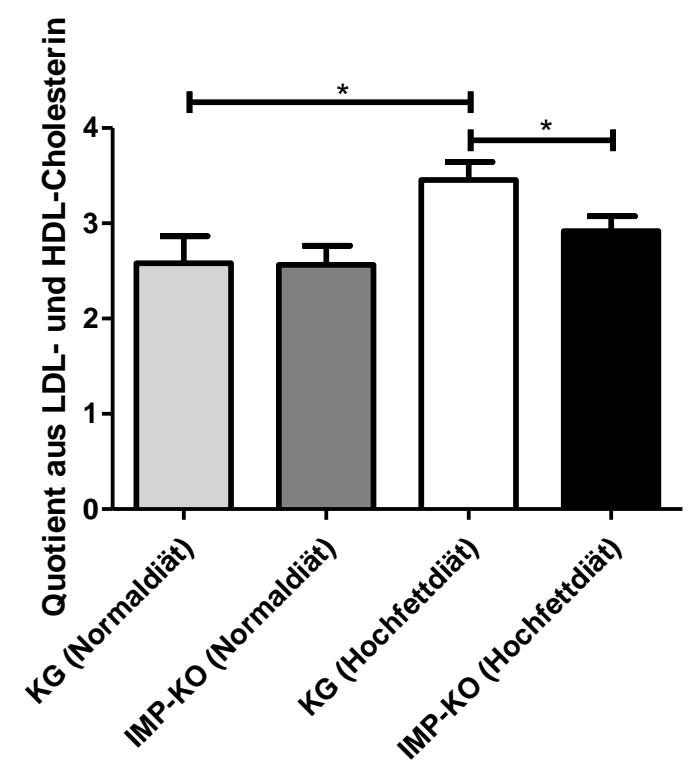

\begin{tabular}{|c|c|c|c|}
\hline & Kontroll-Gruppe & IMP-KO-Gruppe & $\mathbf{p}$ \\
\hline Normaldiät / 6 Monate & $2,6 \pm 0,3, \mathrm{n}=6$ & $2,6 \pm 0,2, \mathrm{n}=4$ & 1,00 \\
\hline Hochfettdiät / 6 Monate & $3,5 \pm 0,2, \mathrm{n}=22$ & $2,9 \pm 0,2 \mathrm{n}=26$ & 0,03 \\
\hline $\mathbf{p}$ & 0,04 & 0,40 & \\
\hline
\end{tabular}

Abbildung 12: Berechnung des Quotienten aus LDL- und HDL-Cholesterin, jeweils nach sechs Monaten Normal- bzw. Hochfettdiät. Es zeigten sich signifikante Unterschiede zwischen Normal- und Hochfettdiät in der Kontrollgruppe $(\mathrm{p}=<0,05)$ sowie zwischen Kontrollgruppe und IMP-KO-Gruppe unter Hochfettdiät $(\mathrm{p}=<0,05)$.

Unter Hochfettdiät zeigte sich in der Kontrollgruppe gegenüber der Normaldiät ein signifikant höherer LDL/HDL-Quotient. Weiterhin trat unter Hochfettdiät in der IMPKO-Gruppe ein signifikant niedrigerer LDL/HDL-Quotient gegenüber der Kontrollgruppe auf. 
3.1.3.6 Berechnung des Quotienten aus Cholesterin und HDL-Cholesterin

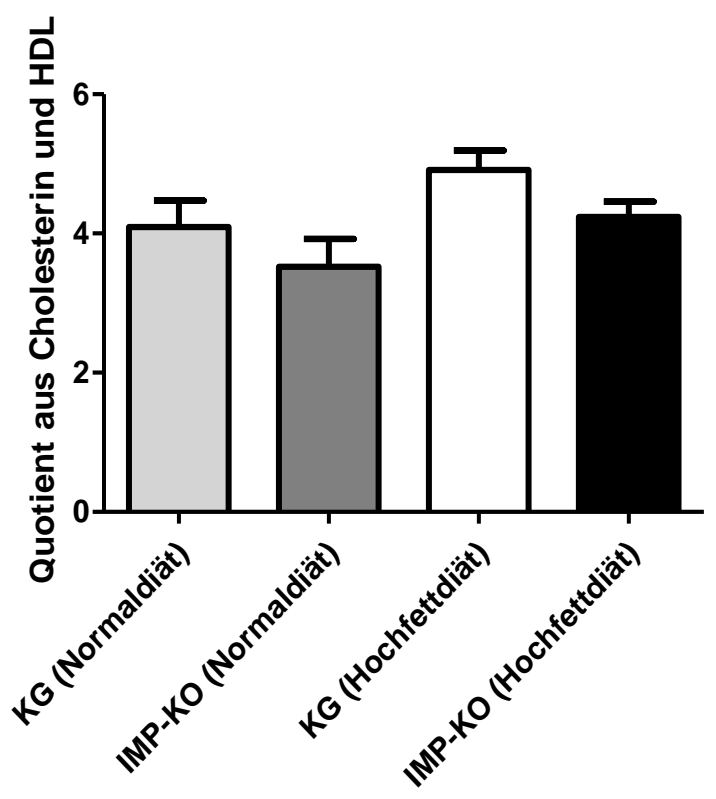

\begin{tabular}{|c|c|c|c|}
\hline & Kontroll-Gruppe & IMP-KO-Gruppe & $\mathbf{p}$ \\
\hline Normaldiät / 6 Monate & $4,1 \pm 0,4, \mathrm{n}=6$ & $3,5 \pm 0,4 \mathrm{n}=3$ & 0,38 \\
\hline Hochfettdiät / 6 Monate & $4,9 \pm 0,3 \mathrm{n}=22$ & $4,2 \pm 0,2 \mathrm{n}=26$ & 0,06 \\
\hline p & 0,17 & 0,29 & \\
\hline
\end{tabular}

Abbildung 13: Berechnung des Quotienten aus Gesamtcholesterin und HDL-Cholesterin, jeweils nach sechs Monaten Normal- bzw. Hochfettdiät. Es zeigte sich kein statistisch signifikanter Unterschied.

Bei der Berechnung des Gesamtcholesterin/HDL-Cholesterin-Quotienten zeigte sich kein statistisch signifikanter Unterschied.

\subsection{Morphometrie der atherosklerotischen Läsionen}

\subsubsection{Ausprägung atherosklerotischer Läsionen im Bereich der Aortenwurzel unter Hochfett- und Normaldiät}

Es wurden jeweils drei geeignete konsekutive Schnitte der Aortenwurzel wie unter 2.4.3.2 beschrieben ausgewählt und mit Verhoeffs Elastica Stain behandelt. Anschließend wurde die prozentuale Reduktion des durchflossenen Gefäßdurchschnitts mit Hilfe einer Bildbearbeitungssoftware bestimmt. Hierfür wurde der Anteil der atherosklerotischen Läsionen an der Fläche des Gefäßlumens planimetrisch bestimmt und die Gefäßstenose in Prozent angegeben. 


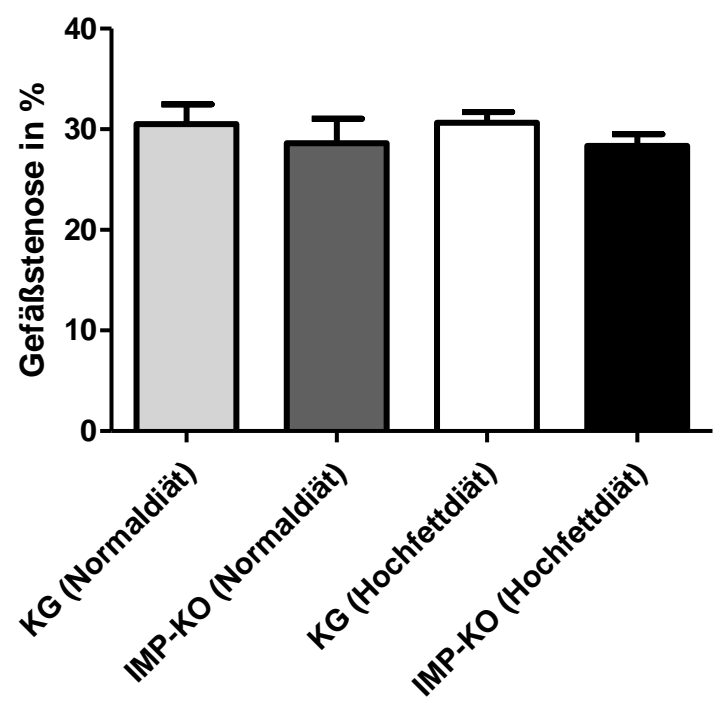

Abbildung 14: Prozentuale Reduktion des durchflossenen Gefäßdurchschnitts im Bereich der Aortenwurzel in der Kontroll- und IMP-KO-Gruppe, jeweils nach sechs Monaten Normal- bzw. Hochfettdiät. Die Unterschiede zwischen den Gruppen waren statistisch nicht signifikant.
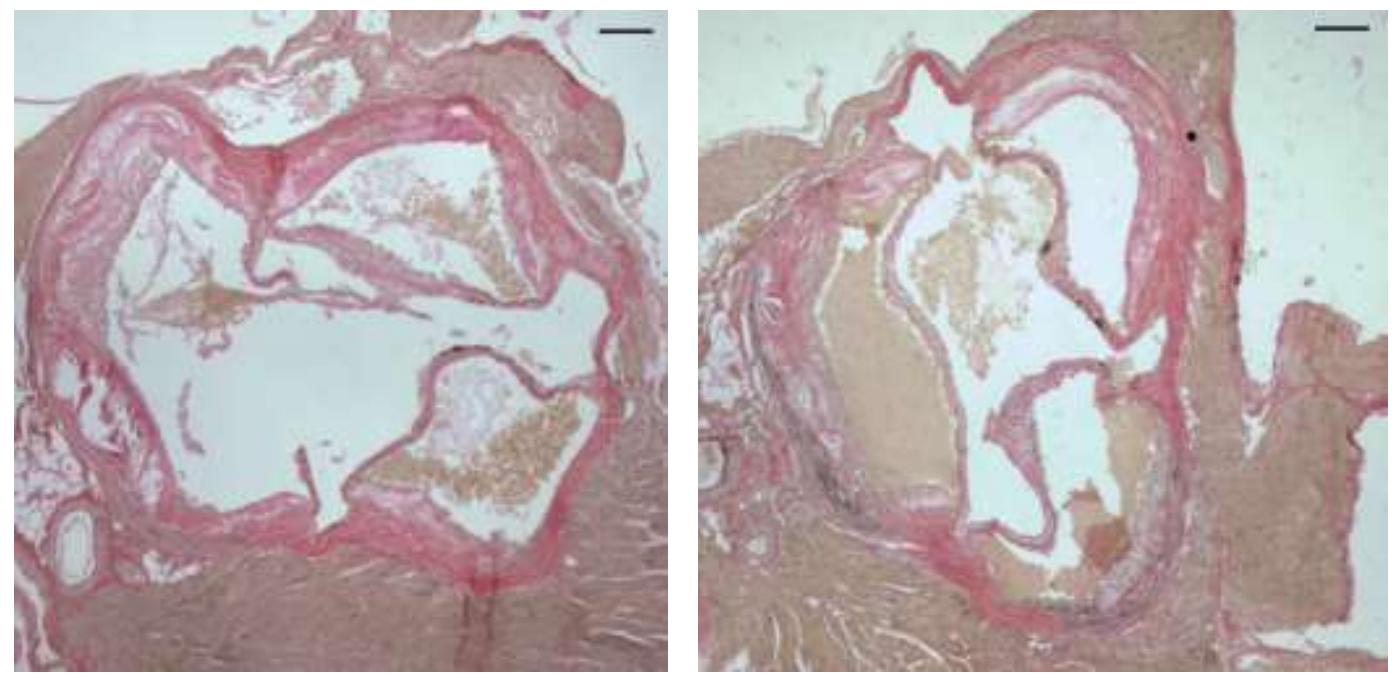

Abbildung 15: Beispiel von atherosklerotischen Plaques in der Aortenwurzel nach sechs Monaten Hochfettdiät. Linke Abbildung: Kontrollgruppe, rechte Abbildung: IMP-KO-Gruppe. Die Färbung erfolgte mit Verhoeff's Elastica Stain. Der Eichbalken entspricht $100 \mu \mathrm{m}$.

Nach sechs Monaten Normaldiät betrug die prozentuale Reduktion des durchflossenen Gefäßdurchschnitts 30,5 $\pm 2,0 \%, \mathrm{n}=9$, in der Kontrollgruppe vs. $28,6 \pm 2,4 \%, \mathrm{n}=9$ in der IMP-KO-Gruppe $(p=0,55)$.

Nach sechs Monaten Hochfettdiät betrug die prozentuale Reduktion des durchflossenen Gefäßdurchschnitts 30,7\% $\pm 1,1 \%, n=24$, in der Kontrollgruppe vs. $28,4 \pm 1,2 \%, n=28$ in der IMP-KO-Gruppe $(\mathrm{p}=0,16)$. 


\subsubsection{Ausprägung der Läsionen im Bereich der Arteria brachiocephalica unter Hochfettdiät}

Eine weitere bedeutsame Prädilektionsstelle für das Auftreten atherosklerotischer Läsionen in der Maus ist die A. brachiocephalica. Für die Analyse wurden sämtliche Schnitte eines Präparats mit Verhoeff's Elastica Stain gefärbt und anschließend solche, die eine Plaque aufwiesen, in die Auswertung einbezogen. Die Messung und Berechnung der prozentualen Reduktion des durchflossenen Gefäßdurchschnitts sowie der anderen Parameter (Fläche der Media, Verhältnis von Intima zu Media und die Fläche des Gesamtquerschnitts) erfolgten, wie in Kapitel 2.4.3.2 beschrieben, mit Hilfe einer Bildbearbeitungssoftware.

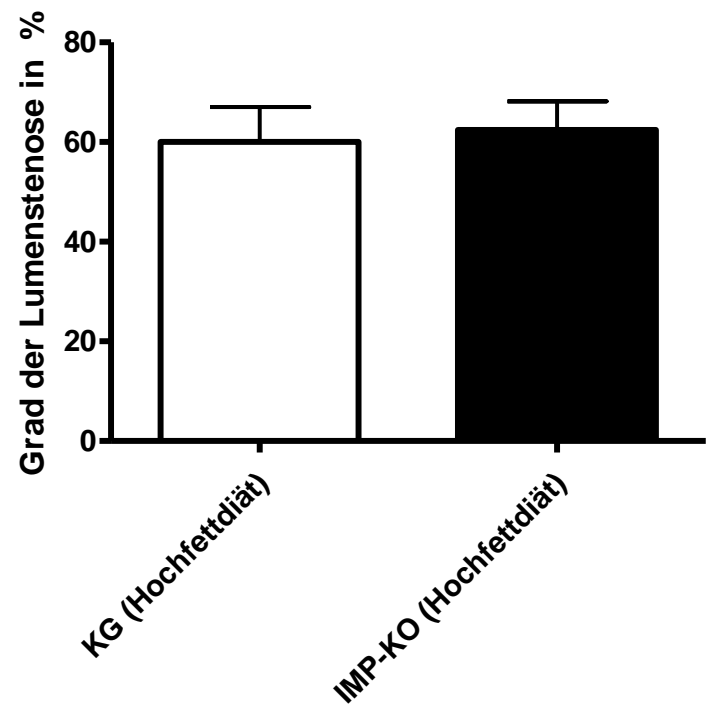

Abbildung 16: Prozentuale Reduktion des durchflossenen Gefäßdurchschnitts im Bereich der A. brachiocephalica nach sechs Monaten Hochfettdiät in der Kontroll- und IMP-KO-Gruppe. Es zeigte sich kein statistisch signifikanter Unterschied.
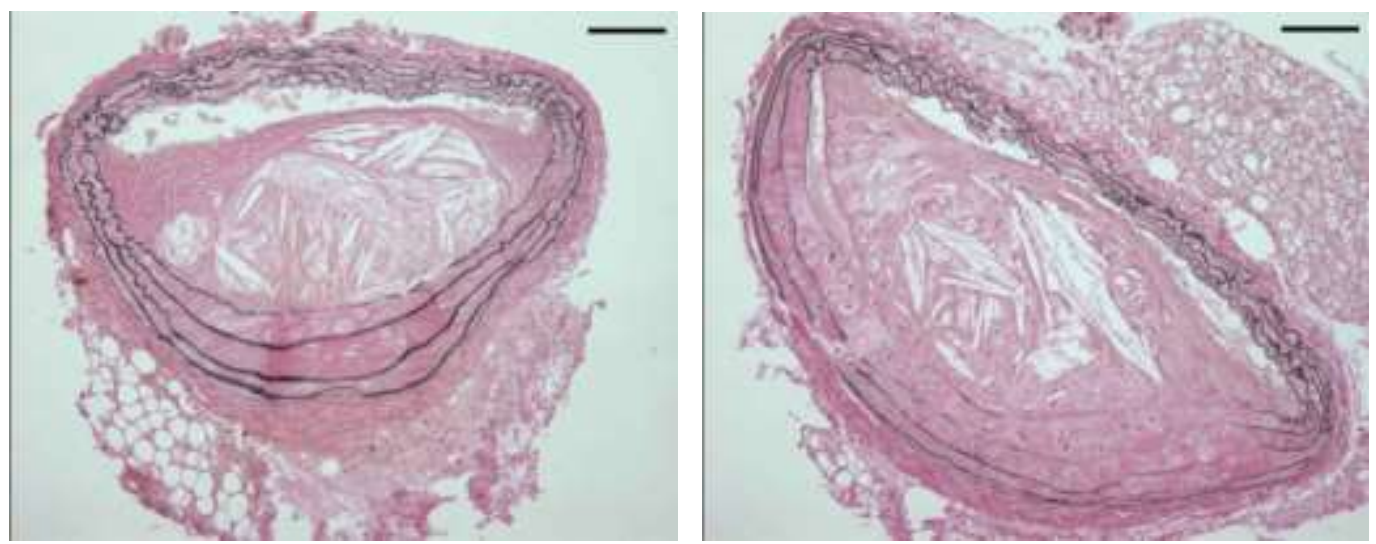

Abbildung 17: Ausprägung der atherosklerotischen Plaques in der A. brachiocephalica nach sechs Monaten Hochfettdiät. Linke Abbildung: Kontrollgruppe, rechte Abbildung: IMP-KO-Gruppe. Verhoff's Elastica Stain. Der Eichbalken entspricht $100 \mu \mathrm{m}$. 
Die prozentuale Reduktion des durchflossenen Gefäßdurchschnitts betrug nach sechs Monaten Hochfettdiät 60,0 $\pm 7,0 \%, \mathrm{n}=20$, in der Kontrollgruppe vs. $62,4 \pm 5,8 \%, \mathrm{n}=17$, in der IMP-KO-Gruppe $(\mathrm{p}=0,8)$.

Die durchschnittliche Media-Fläche betrug nach sechs Monaten Hochfettdiät $74.930 \pm$ $4.937 \mu \mathrm{m}^{2}, \mathrm{n}=20$ in der Kontrollgruppe vs. $79.120 \pm 5.689 \mu \mathrm{m}^{2}, \mathrm{n}=17$, in der IMP-KOGruppe $(p=0,58)$.

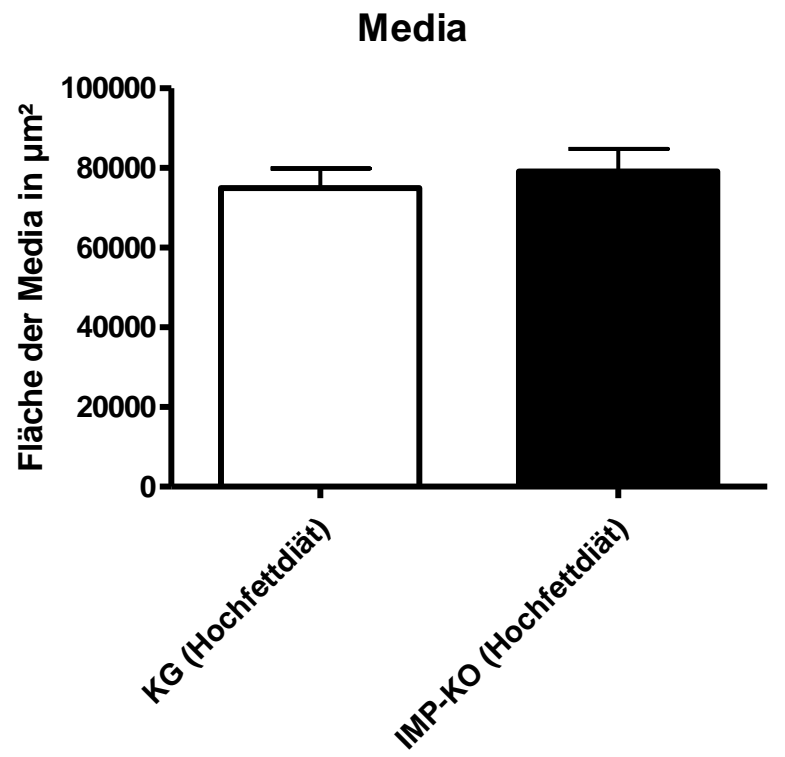

Abbildung 18: Die Media-Fläche der A. brachiocephalica auf Höhe der Lumenstenose nach sechs Monaten Hochfettdiät in der Kontroll- und IMP-KO-Gruppe. Es zeigte sich kein statistisch signifikanter Unterschied.

Das Verhältnis von Intima- zu Media-Fläche betrug nach sechs Monaten Hochfettdiät $0,852 \pm 0,119, \mathrm{n}=20$, in der Kontroll-Gruppe vs. $0,867 \pm 0,093, \mathrm{n}=17$, in der IMP-KOGruppe $(p=0,92)$. 


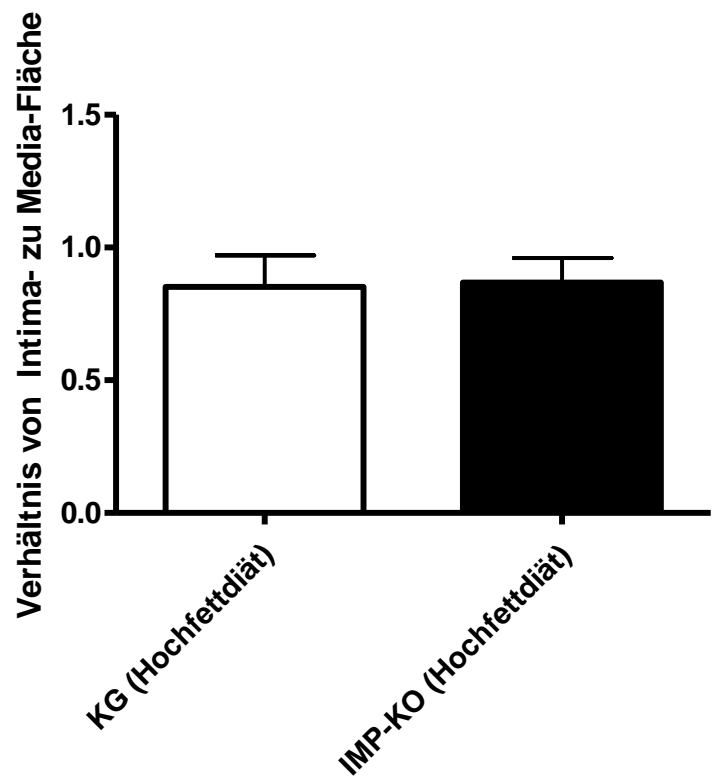

Abbildung 19: Verhältnis von Intima- zu Media-Fläche der A. brachiocephalica auf Höhe der Lumenstenose nach sechs Monaten Hochfettdiät in der Kontroll- und IMP-KO-Gruppe. Es zeigte sich kein statistisch signifikanter Unterschied.

Die Fläche des Gesamtquerschnitts der A. brachiocephalica ( $A_{\text {Membrana elastica externa) }}$ betrug nach sechs Monaten $186.500 \pm 12.650 \mu \mathrm{m}^{2}, \mathrm{n}=17$, in der IMP-KO-Gruppe vs. $181.600 \pm 15.150 \mu \mathrm{m} 2, \mathrm{n}=20$, in der Kontroll-Gruppe $(\mathrm{p}=0,81)$.

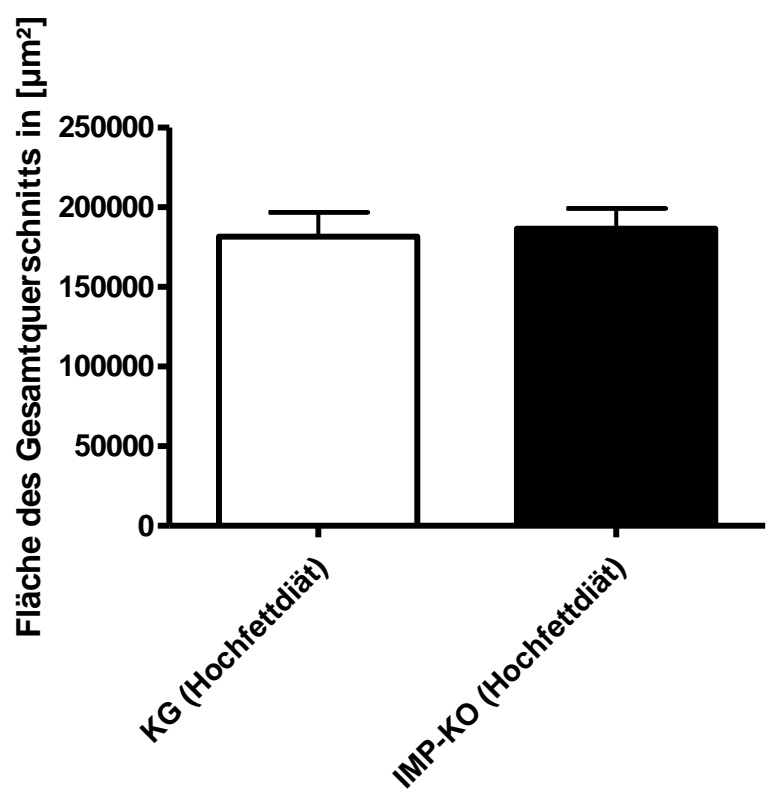

Abbildung 20: Die Fläche des Gesamtquerschnitts der A. brachiocephalica nach sechs Monaten Hochfettdiät in der Kontroll- und IMP-KO-Gruppe. Es zeigte sich kein statistisch signifikanter Unterschied. 


\subsection{Zusammensetzung und Stabilität der atherosklerotischen} Läsionen

Für die Entstehung und Progression einer atherosklerotischen Läsion ist die Präsenz und Interaktion von Makrophagen, T-Lymphozyten sowie glatten Muskelzellen von entscheidender Bedeutung. Qualitative oder quantitative Veränderungen bei diesen Zelltypen haben somit unmittelbare Auswirkung auf die Ausprägung der Läsionen, unabhängig von ihrer Größe.

Makrophagen stammen aus dem Monozyten-Pool in der Blutbahn und werden durch oxidierte Lipoproteine in die subendotheliale Schicht rekrutiert, wo sie eine zentrale Rolle in der Plaqueentstehung einnehmen. Eine Beeinflussung dieser Zellpopulation führt in der Regel zu einer Veränderung der atherosklerotischen Belastung (Moore und Tabas 2011).

T-Lymphozyten sind, verglichen mit Makrophagen, zahlenmäßig weniger stark in einer atherosklerotischen Läsion vertreten, haben aber einen wesentlichen Einfluss auf die Plaqueprogression, da sie proatherogene Mediatoren produzieren (Hansson und Hermansson 2011).

Glatte Muskelzellen nehmen wie Makrophagen Lipide auf und entwickeln sich zu Schaumzellen. Obwohl sie im ApoE-Mausmodell eine geringere Rolle spielen als im Menschen sind sie für die Initiation und Progression atherosklerotischer Läsionen sowie für die Plaquestabilität in späteren Stadium relevant (Allahverdian et al. 2012). 


\subsubsection{Zelluläre Zusammensetzung der Läsionen im Bereich der Aortenwurzel unter Hochfettdiät}

\subsubsection{Immunhistochemische Färbung von Makrophagen}

Nach immunhistochemischer Anfärbung von Mac3-positiven Zellen betrug der Anteil der immunpositiven Fläche an der Gesamtplaquefläche 36,12 \pm 3,38, $n=5$, in der KontrollGruppe vs. 36,15 $\pm 4,41, \mathrm{n}=5$, in der IMP-KO-Gruppe $(\mathrm{p}=0,99)$.

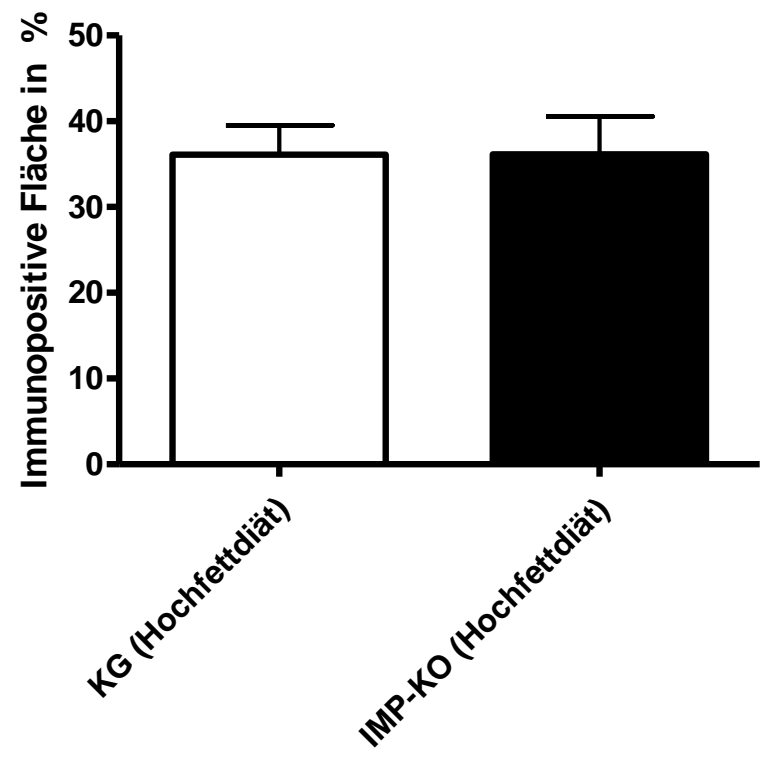

Abbildung 21: Anteil der Mac3-positiven Fläche an der Gesamtplaquefläche. Die Unterschiede zwischen den Gruppen waren statistisch nicht signifikant.
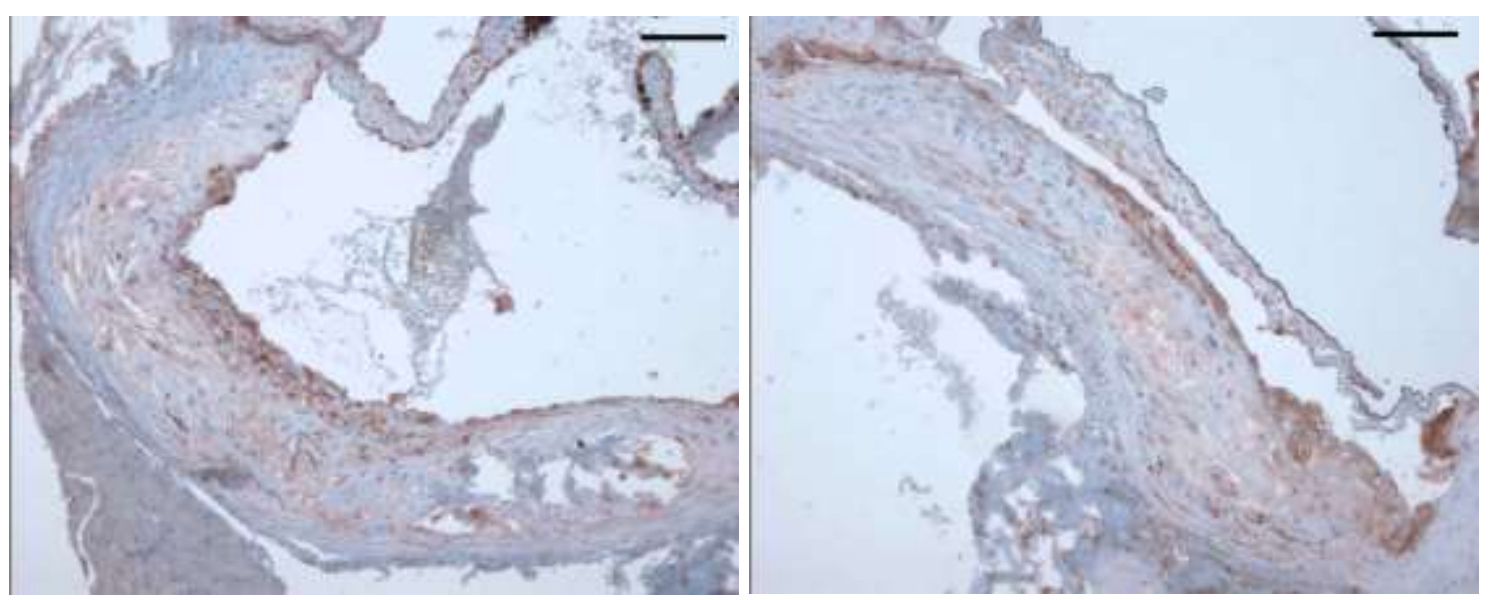

Abbildung 22: Immunhistochemische Färbung von Makrophagen. Die Abbildungen zeigen jeweils einen bei 100facher Vergrößerung fotografierten, repräsentativen Ausschnitt. Linke Abbildung: Kontroll-Gruppe; rechte Abbildung: IMP-KO-Gruppe. Der Eichbalken entspricht $100 \mu \mathrm{m}$. 


\subsubsection{Immunhistochemische Färbung von T-Lymphozyten}

Nach immunhistochemischer Anfärbung von $\mathrm{CD}^{+}$-positiven Zellen betrug der Anteil der immunpositiven Fläche an der Gesamtplaquefläche $6,9 \pm 0,7 \%, \mathrm{n}=9$, in der Kontrollgruppe vs. $6,6 \pm 1,1 \%, \mathrm{n}=9$, in der IMP-KO-Gruppe $(\mathrm{p}=0,82)$.

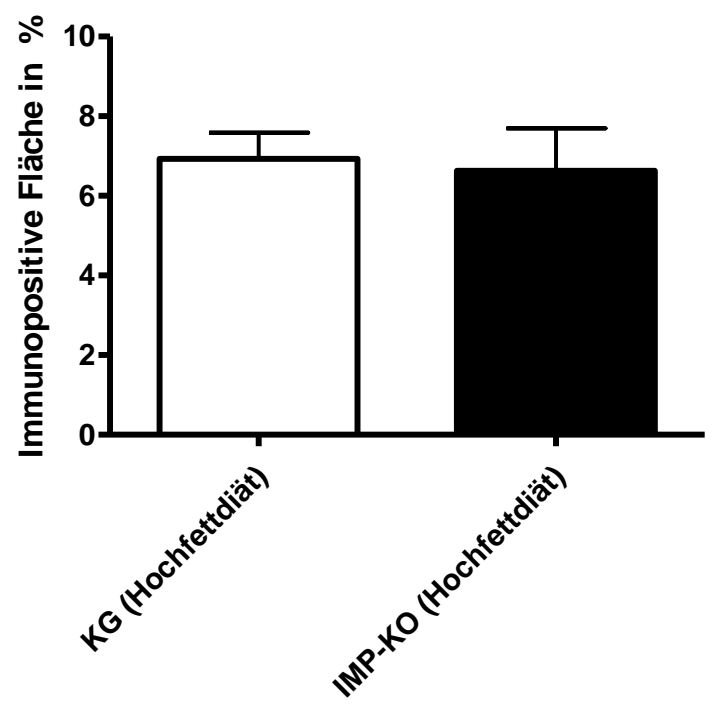

Abbildung 23: Anteil der CD3-positiven Fläche an der Gesamtplaquefläche. Die Unterschiede zwischen den Gruppen waren statistisch nicht signifikant.
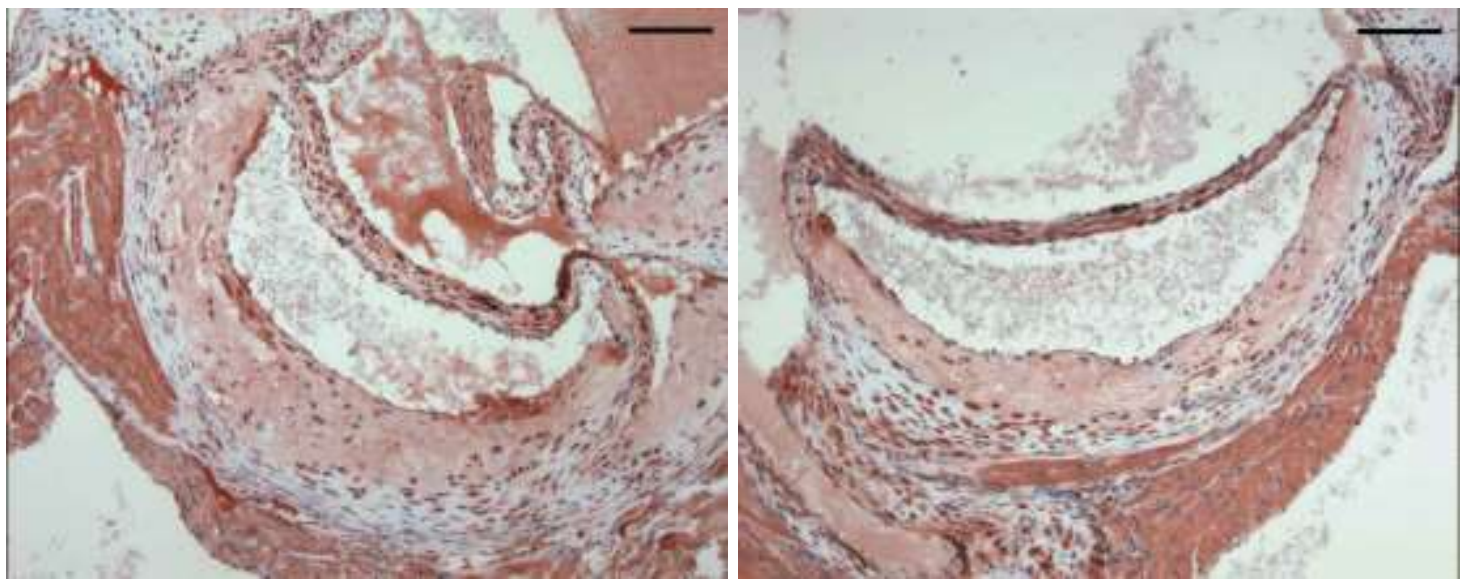

Abbildung 24: Immunhistochemische Färbung von T-Lymphozyten. Die Abbildungen zeigen jeweils einen bei 100facher Vergrößerung fotografierten, repräsentativen Ausschnitt. Linke Abbildung: KontrollGruppe, rechte Abbildung: IMP-KO-Gruppe. Der Eichbalken entspricht $100 \mu \mathrm{m}$. 


\subsubsection{Immunhistochemische Färbung von glatten Muskelzellen}

Nach immunhistochemischer Anfärbung von SMA-positiven Zellen betrug der Anteil der immunpositiven Fläche an der Gesamtplaquefläche 22,7 \pm 4,4 \%, $\mathrm{n}=5$, in der KontrollGruppe vs. 22,9 $\pm 3,3 \%, \mathrm{n}=5$, in der IMP-KO-Gruppe $(\mathrm{p}=0,97)$.

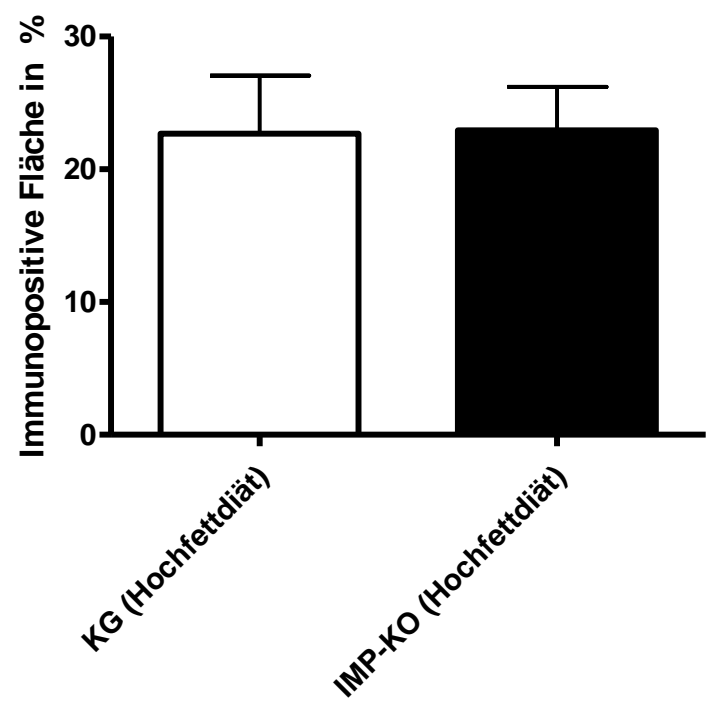

Abbildung 25: Anteil der SMA-positiven Fläche an der Gesamtplaquefläche. Die Unterschiede zwischen den Gruppen waren statistisch nicht signifikant.
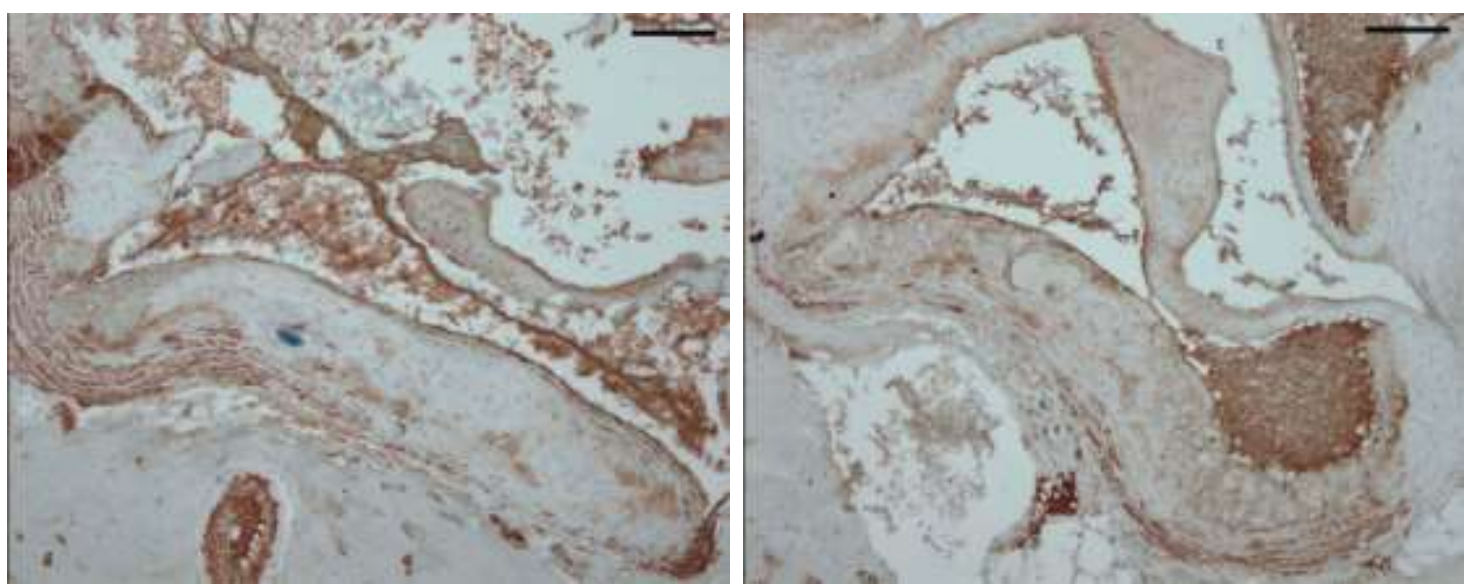

Abbildung 26: Immunhistochemische Färbung von SMA-positiven Zellen. Die Abbildungen zeigen jeweils einen bei 100 facher Vergrößerung fotografierten, repräsentativen Ausschnitt. Linke Abbildung: Kontroll-Gruppe, rechte Abbildung IMP-KO-Gruppe. Der Eichbalken entspricht $100 \mu \mathrm{m}$. 


\subsubsection{Immunhistochemische Färbung von proliferierenden Zellen}

Bedingt durch den hohen Zellumsatz in atherosklerotischen Läsionen sind Veränderungen in der Proliferationsaktivität ebenfalls von Bedeutung für die Progression atherosklerotischer Läsionen. Hierfür wurde PCNA als Surrogat-Parameter gewählt.

Nach immunhistochemischer Anfärbung von PCNA-positiven Zellen betrug der Anteil der immunpositiven Fläche an der Gesamtplaquefläche 61,7 \pm 3,5 \%, $\mathrm{n}=5$, in der KontrollGruppe $67,8 \pm 3,4 \%, \mathrm{n}=5$, in der IMP-KO-Gruppe $(\mathrm{p}=0,25)$.

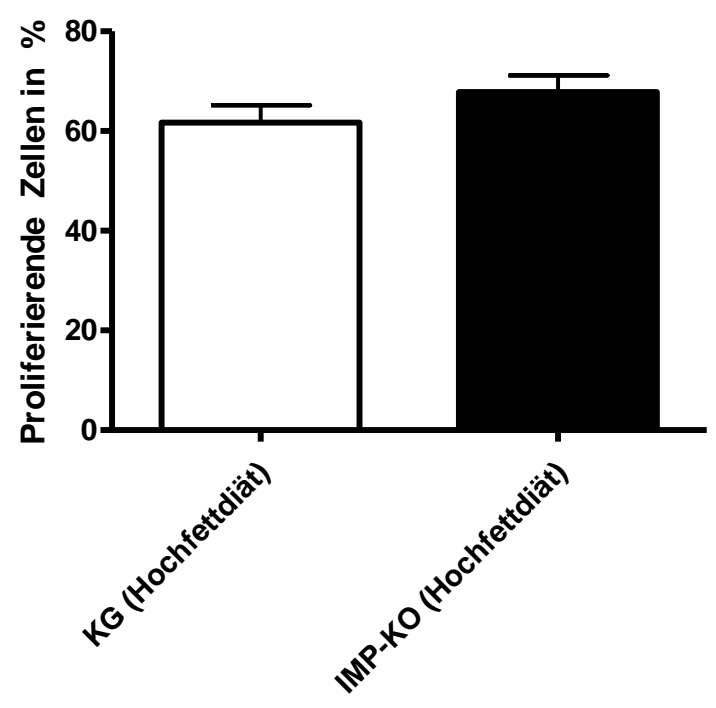

Abbildung 27: Anteil der PCNA-positiven Fläche an der Gesamtplaquefläche. Die Unterschiede zwischen den Gruppen waren statistisch nicht signifikant.
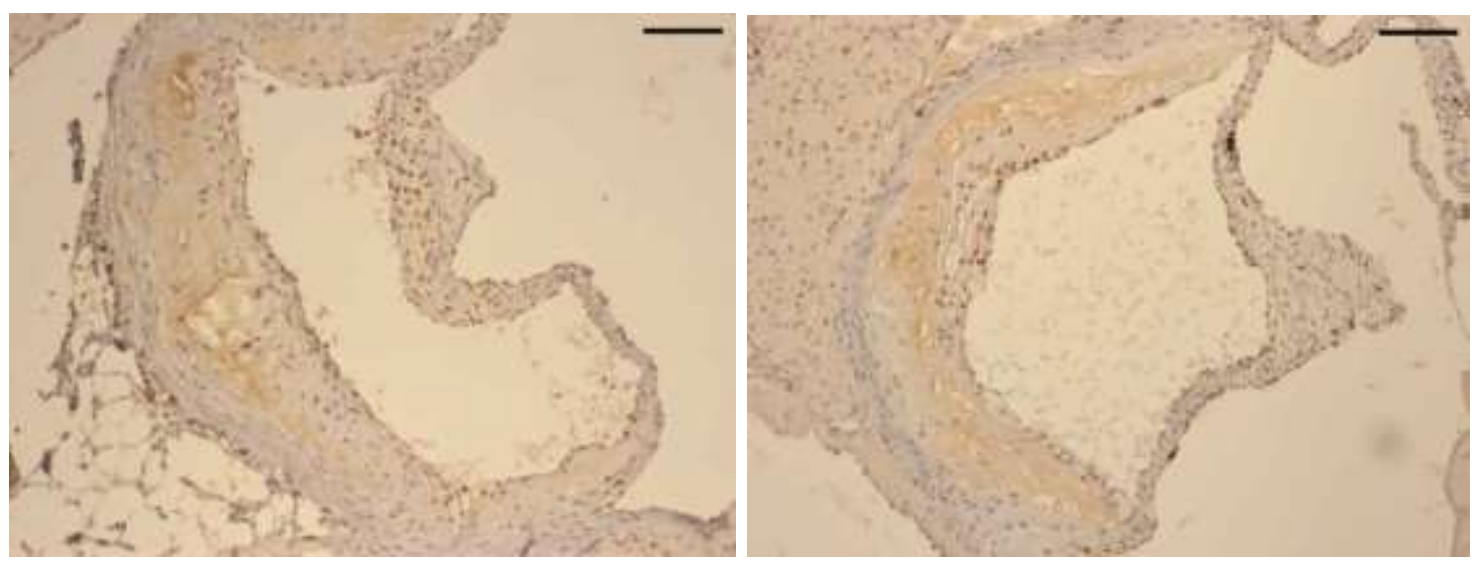

Abbildung 28: Immunhistochemische Färbung von PCNA-positiven Zellen. Die Abbildungen zeigen jeweils einen bei 100facher Vergrößerung fotografierten, repräsentativen Ausschnitt. Linke Abbildung Kontroll-Gruppe, rechte Abbildung IMP-KO-Gruppe. Der Eichbalken entspricht $100 \mu \mathrm{m}$. 


\subsubsection{Zusammensetzung der Läsionen im Bereich der A. brachiocephalica unter Hochfettdiät}

\subsubsection{Immunhistochemische Färbung von Makrophagen}

Nach immunhistochemischer Anfärbung von Mac2-positiven Zellen betrug der Anteil der immunpositiven Fläche an der Gesamtplaquefläche 15,4 \pm 5,9\%, $\mathrm{n}=6$, in der IMP-KOGruppe vs. $14,0 \pm 2,3 \%, n=7$, in der Kontroll-Gruppe $(p=0,83)$.

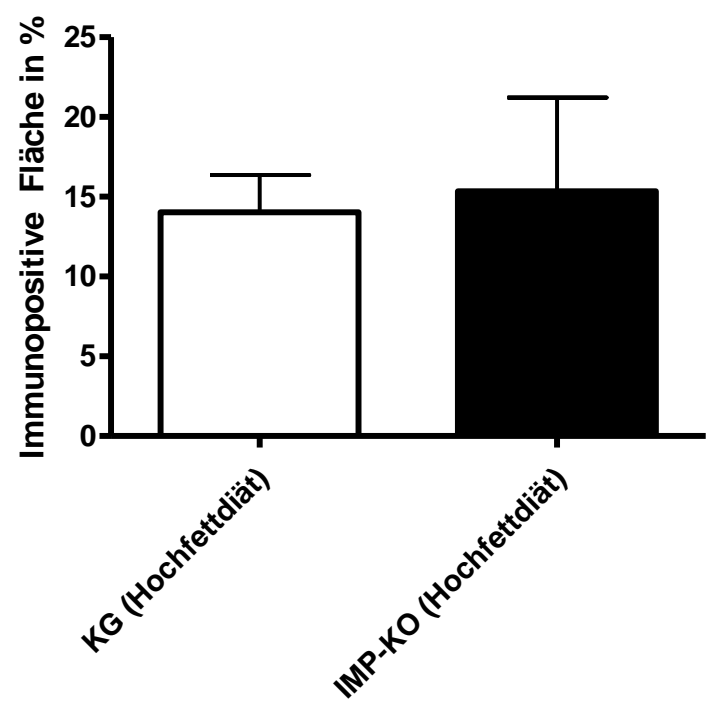

Abbildung 29: Anteil der Mac2-positiven Fläche an der Gesamtplaquefläche. Die Unterschiede zwischen den Gruppen waren statistisch nicht signifikant.
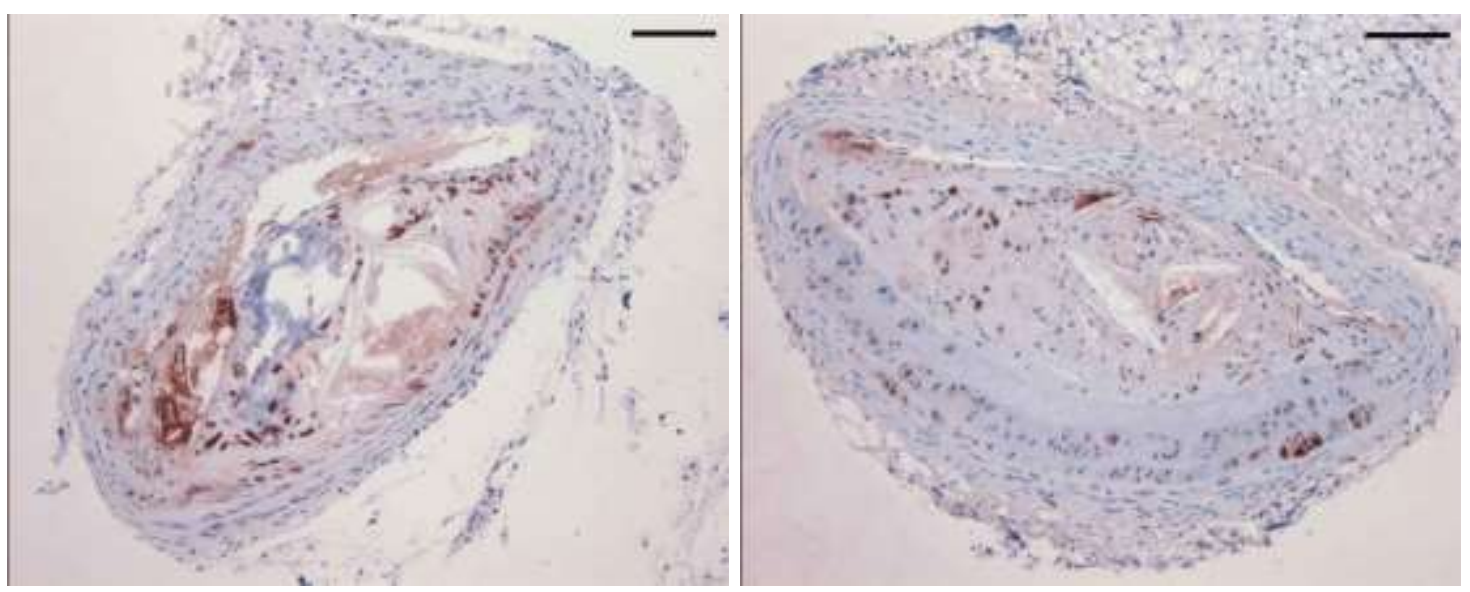

Abbildung 30: Immunhistochemische Färbung von Makrophagen. Linke Abbildung Kontroll-Gruppe, rechte Abbildung IMP-KO-Gruppe. Der Eichbalken entspricht $100 \mu \mathrm{m}$. 


\subsubsection{Immunhistochemische Färbung von T-Lymphozyten}

Nach immunhistochemischer Anfärbung von CD3-positiven Zellen betrug der Anteil der immunpositiven Fläche an der Gesamtplaquefläche 4,1 $\pm 1,4 \%, n=8$ in der KontrollGruppe vs. 4,1 $\pm 1,5 \%, \mathrm{n}=5$, in der IMP-KO-Gruppe $(\mathrm{p}=0,99)$.

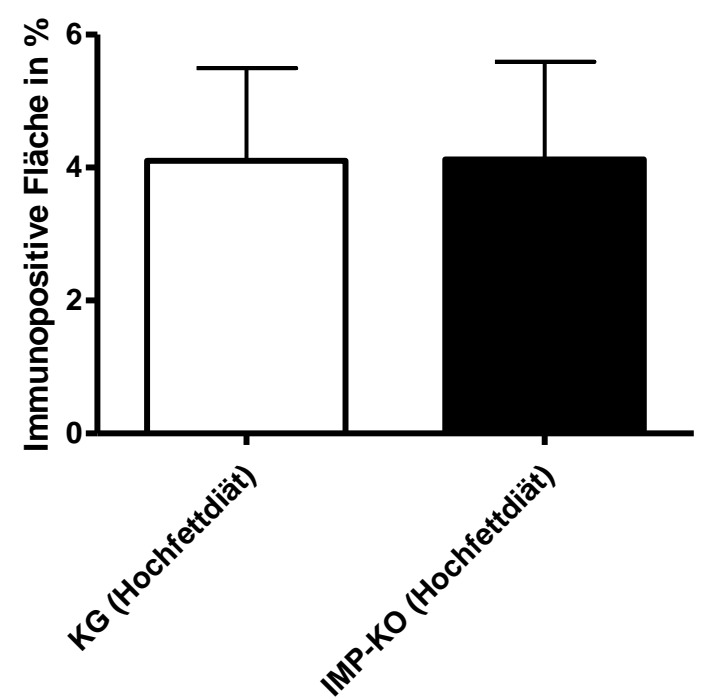

Abbildung 31: Anteil der CD3-positiven Fläche an der Gesamtplaquefläche. Die Unterschiede zwischen den Gruppen waren statistisch nicht signifikant.
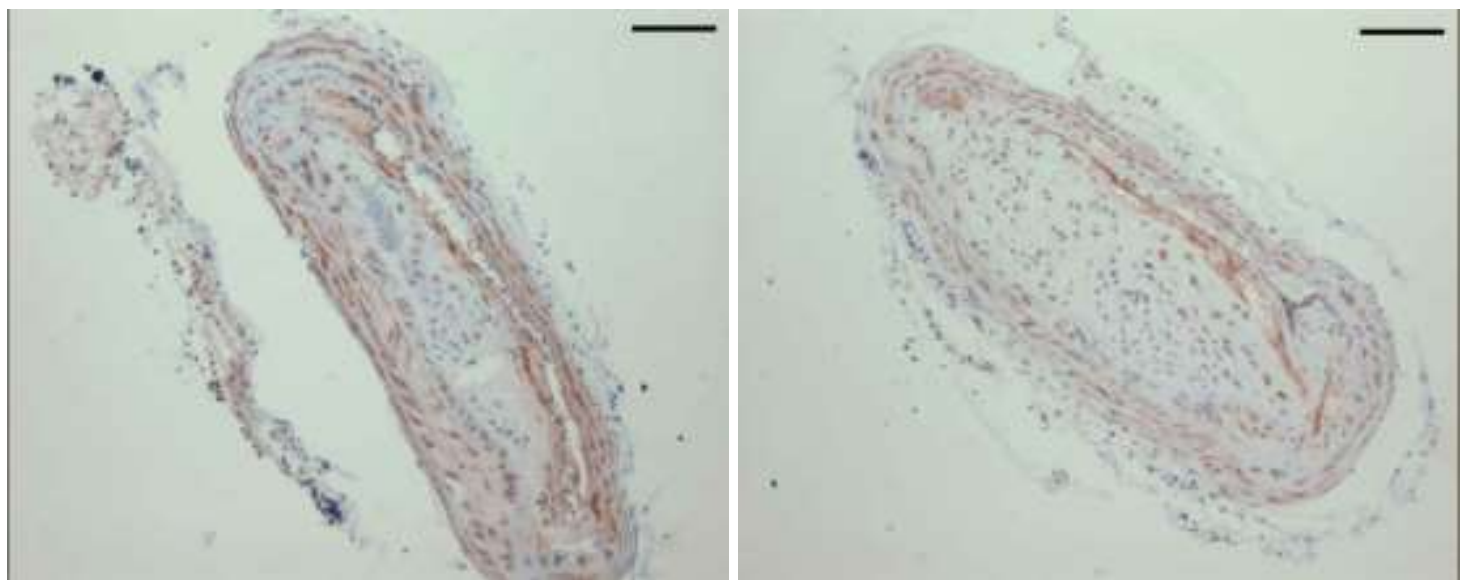

Abbildung 32: Immunhistochemische Färbung von CD3-positiven Lymphozyten. Linke Abbildung Kontroll-Gruppe, rechte Abbildung IMP-KO-Gruppe. Der Eichbalken entspricht $100 \mu \mathrm{m}$. 
3.3.2.3 Immunhistochemische Färbung von glatten Muskelzellen

Nach immunhistochemischer Anfärbung von SMA-positiven Zellen betrug der Anteil der immunpositiven Fläche an der Gesamtplaquefläche 3,9 $\pm 1,6 \%, \mathrm{n}=8$, in der KontrollGruppe vs. 4,0 $\pm 0,7 \%, \mathrm{n}=7$, in der IMP-KO-Gruppe $(\mathrm{p}=0,94)$.

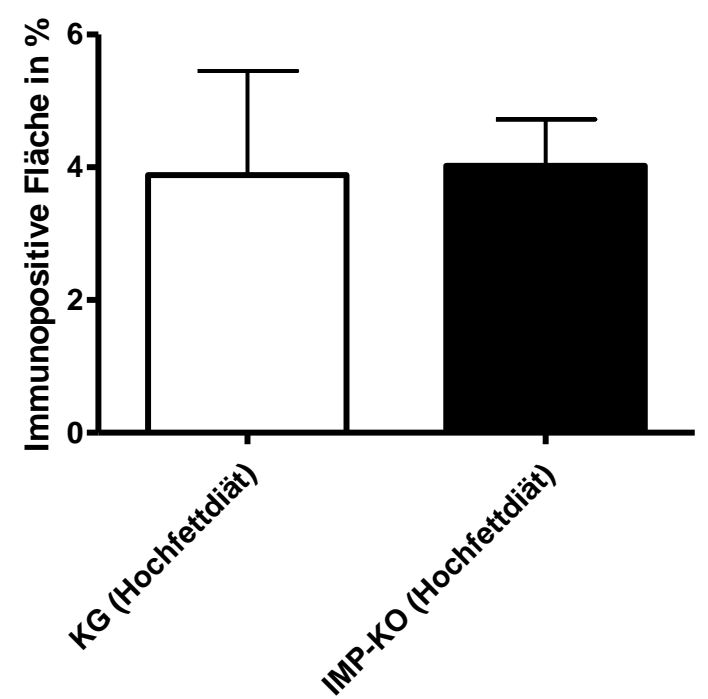

Abbildung 33: Anteil der SMA-positiven Fläche an der Gesamtplaquefläche. Die Unterschiede zwischen den Gruppen waren statistisch nicht signifikant.
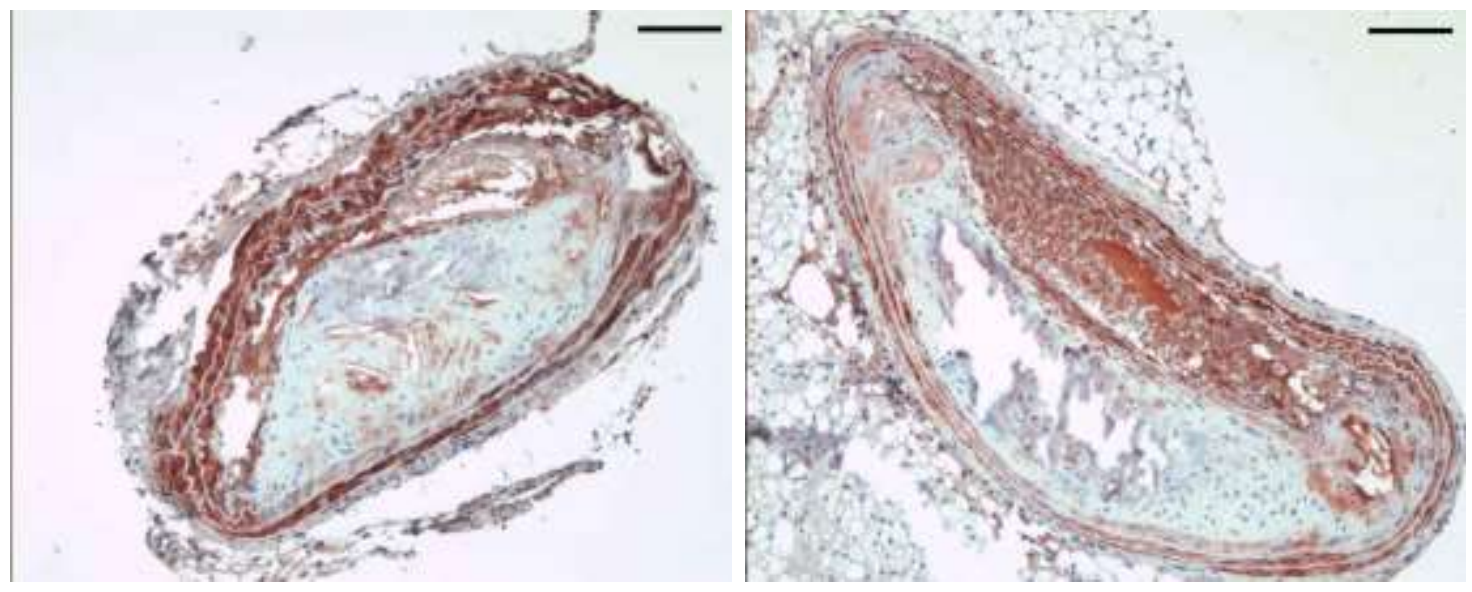

Abbildung 34: Immunhistochemische Färbung von SMA-positiven Zellen. Linke Abbildung KontrollGruppe, rechte Abbildung IMP-KO-Gruppe. Der Eichbalken entspricht $100 \mu \mathrm{m}$. 


\subsubsection{Färbung von Kollagen / Masson-Trichrom-Färbung}

Der Kollagenanteil an der Gesamtplaquefläche betrug 29,2 \pm 6,1 \%, $\mathrm{n}=7$, in der KontrollGruppe vs. 22,1 $\pm 7,1 \%, \mathrm{n}=6$, in der IMP-KO-Gruppe $(\mathrm{p}=0,46)$.

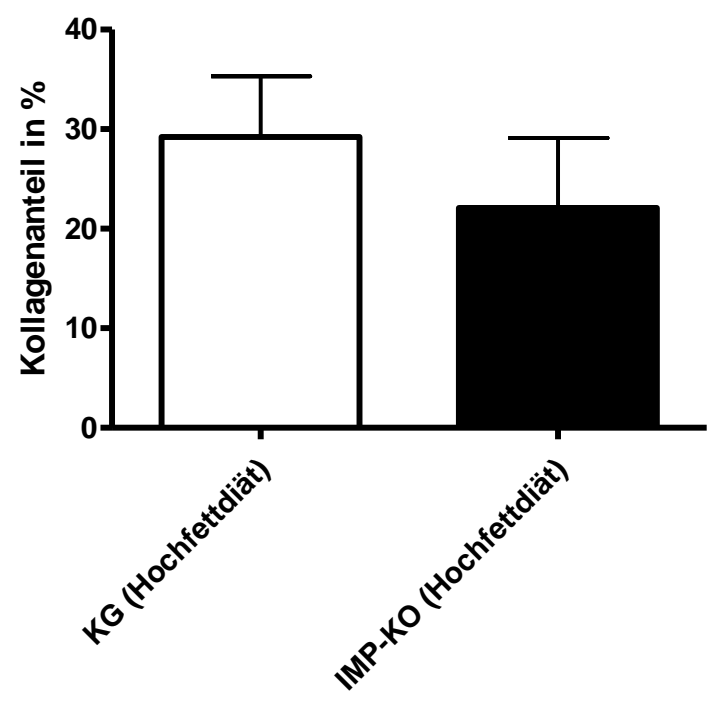

Abbildung 35: Kollagenanteil an der Gesamtplaquefläche. Die Unterschiede zwischen den Gruppen waren statistisch nicht signifikant.
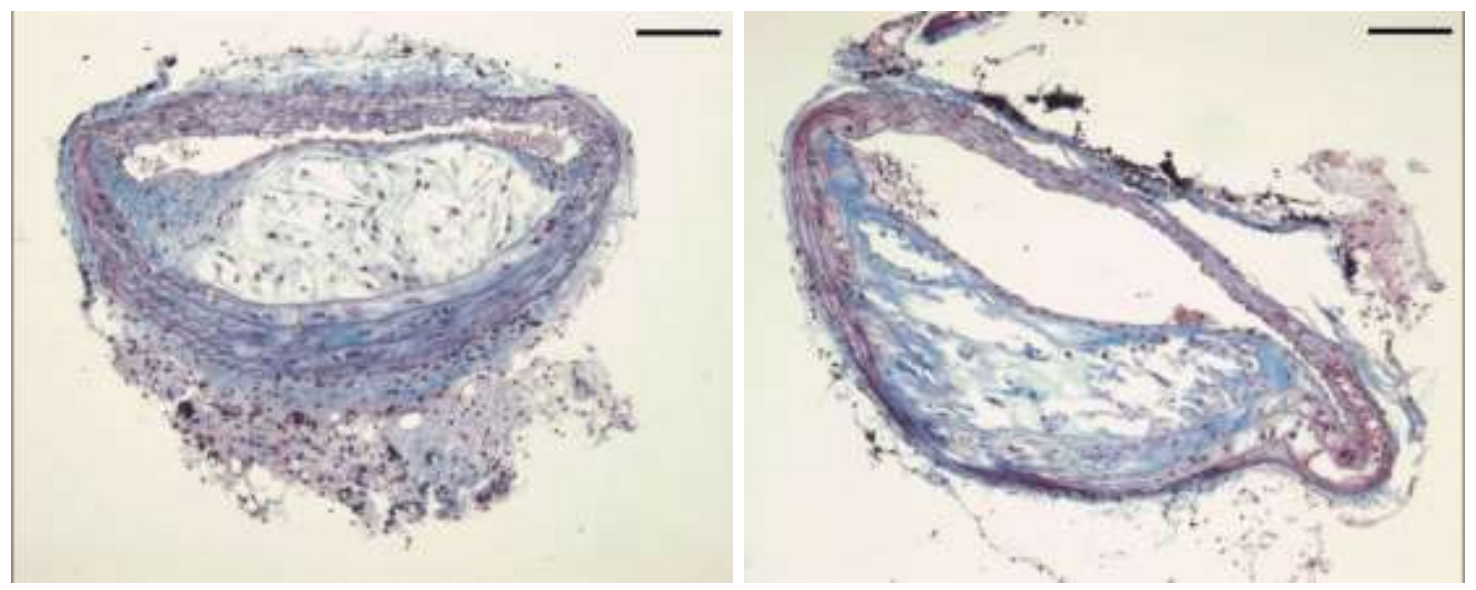

Abbildung 36: Färbung von Kollagen. Linke Abbildung Kontroll-Gruppe, rechte Abbildung IMP-KOGruppe. Der Eichbalken entspricht $100 \mu \mathrm{m}$. 


\subsubsection{Vulnerabilität der atherosklerotischen Läsionen in der A. brachiocephalica unter Hochfettdiät}

Neben der progredienten Stenose ist die Ruptur der atherosklerotischen Plaque bestimmend für die klinische Manifestation. Abweichend vom Menschen, kommt es im Mausmodell im Regelfall nicht zu thrombosierenden Rupturen, so dass in dieser Arbeit die folgenden Surrogatparameter als Hinweisgeber für die Instabilität einer Plaque herangezogen wurden.

\subsubsection{Analyse von Hinweisen auf das Vorliegen einer frischen Plaqueruptur}

Hinweise auf das Vorliegen einer akuten Plaqueruptur (extravaskuläre Erythrozytenansammlungen in der Plaque, vgl. Kapitel 2.4.4) fanden sich in 66,7 \% (4/6) der Fälle in der Kontroll-Gruppe vs. 57,1 \% (4/7) der Fälle in der IMP-KO-Gruppe $(\mathrm{p}=0,73)$.

\subsubsection{Analyse von Hinweisen auf alte, abgelaufene Plaquerupturen}

Die Anzahl der sog. buried fibrous caps als Hinweis auf abgelaufene Plaquerupturen betrug pro Läsion 2,4 \pm 0,6 $(\mathrm{n}=10)$, in der Kontroll-Gruppe vs. 2,8 $\pm 0,4(\mathrm{n}=11)$, in der IMP-KOGruppe $(p=0,56)$.

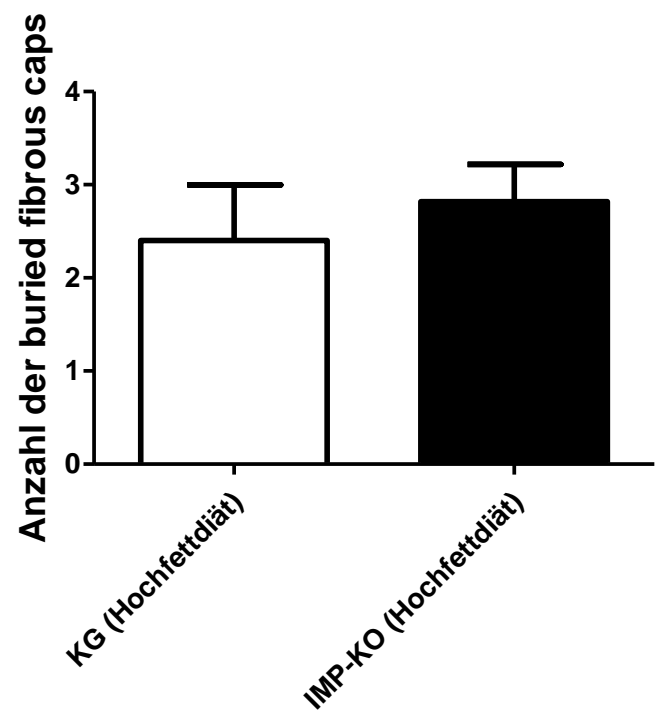

Abbildung 37: Anzahl der buried fibrous caps unter Hochfettdiät in atherosklerotischen Plaques der A. brachiocephalica als Hinweis auf abgelaufene Plaquerupturen. Die Unterschiede zwischen den Gruppen waren statistisch nicht signifikant. 
3.3.3.3 Analyse der Ausdehnung der Plaques in die Tunica Media

Eine Ausdehnung der Plaque in die Tunica Media zeigte sich in 20,0 \% (2/10) der Fälle in der Kontroll-Gruppe vs. 45,5 \% (5/11) der Fälle in der IMP-KO-Gruppe ( $\mathrm{p}=0,41)$.

3.3.3.4 Analyse des Verhältnis von Plaquekappe zum Gesamtplaque (cap-to-intima-ratio)

Das Verhältnis von Plaquekappe zu Gesamtplaque als Ausdruck der Stabilität der Plaque betrug $0,06 \pm 0,01, \mathrm{n}=7$, in der Kontroll-Gruppe vs. $0,05 \pm 0,01, \mathrm{n}=5$, in der IMP-KOGruppe $(\mathrm{p}=0,54)$.

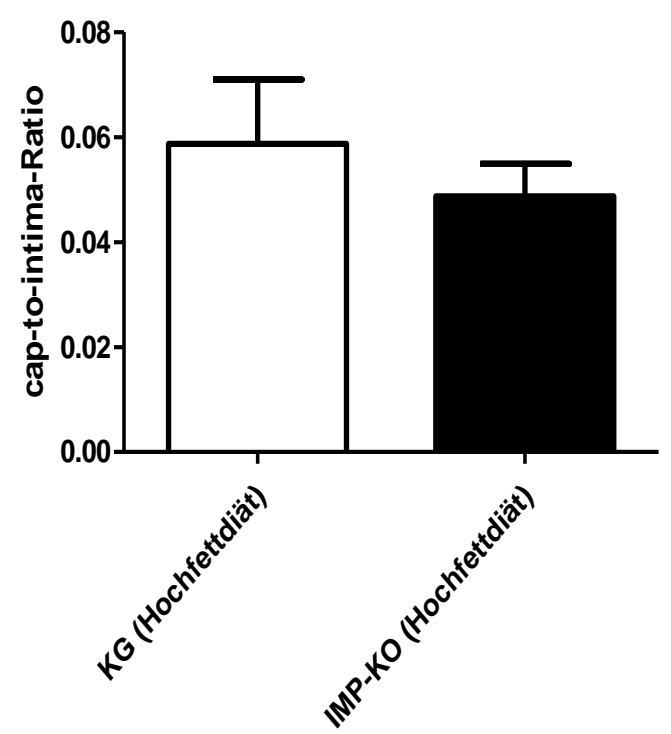

Abbildung 38: Verhältnis von Plaquekappe zu Gesamtplaque („cap-to-intima-Ratio“). Die Unterschiede zwischen den Gruppen waren statistisch nicht signifikant.

In der Analyse der oben genannten Faktoren zeigte sich weder in der Kontroll- noch in der IMP-KO-Gruppe ein Anhalt für eine Plaqueinstabilität. 


\section{Diskussion}

\subsection{Zusammenfassung der Ergebnisse}

Atherosklerose ist eine systemische Erkrankung mit Manifestation an allen Orten der arteriellen Strombahn, deren Ursachen bislang nur teilweise bekannt sind. Zunehmend geraten dabei genetische Faktoren in das Blickfeld der Untersuchungen, wobei nur eine Minderheit von identifizierten Genen über die Mechanismen klassischer Risikofaktoren wie beispielsweise Bluthochdruck, Dyslipidämien oder Diabetes mellitus wirkt. Genomweite Assoziationsstudien (GWAS) haben diverse Gen-Loci identifiziert, die mit dem Auftreten von Atherosklerose oder entsprechenden Komplikationen wie beispielsweise myokardialer Infarzierung assoziiert sind (Holdt und Teupser 2013). BRAP ist ein mutmaßliches Regulationsprotein für den Zellzyklus, für das mehrere SNPs bekannt sind. Mehrere GWAS zeigten, dass ein bestimmter SNP mit einem erhöhten Risiko für Atherosklerose assoziiert ist. Darüber hinaus zeigt die Studie von Ozaki et al., dass dieser SNP wahrscheinlich zu einer vermehrten BRAP-Expression führt (Ozaki et al. 2009). Die Zielsetzung der hier vorliegenden Arbeit war es, die Auswirkungen einer verminderten

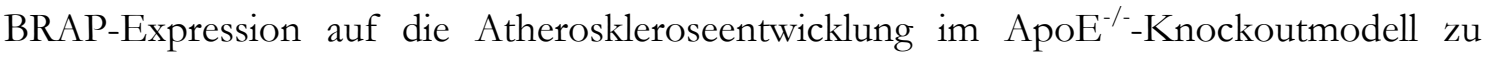
untersuchen. Die Versuche wurden jeweils unter Normal- und Hochfettdiät durchgeführt, um eine robuste Atherosklerose zu provozieren und zusätzlich einen Einfluss der Ernährung sichtbar zu machen. Im ersten Teil der Arbeit wurde der Phänotyp der IMP' ${ }^{/+} / \mathrm{ApoE}^{-/}$-Maus (IMP-KO), welche auf Grund einer heterozygoten Deletion eine um die Hälfte reduzierte BRAP-Expression in einem $\mathrm{ApoE}^{-/-}$-Hintergrund aufwies, unter Normalund Hochfettdiät untersucht.

Unter Hochfettdiät erhöhten sich gegenüber der Normaldiät das Körpergewicht und das Gewicht der abdominalen Fettdepots, während es beim Lebergewicht und den korpuskulären Blutbestandteile $\mathrm{zu}$ keinen signifikanten Veränderungen durch die Ernährung kam. Wenn das Lebergewicht allerdings in Verhältnis zum Gesamtkörpergewicht betrachtet wurde, traten auch hier signifikante Unterschiede in Form eines verringerten Leber-Körpergewicht-Quotienten unter Hochfettdiät zutage.

Bei der Untersuchung der Parameter unter dem Aspekt des Genotyps fiel unter Hochfettdiät ein erhöhtes Gewicht der abdominalen Fettdepots in der IMP-KO-Gruppe gegenüber der Kontrolle auf, wobei sich dieser Effekt weiter verstärkte, wenn diese Werte relativ zum Körpergewicht betrachtet wurden. Ein ähnlicher, statistisch aber nicht signifikanter Trend war im Vergleich der Körpergewichte erkennbar. Unter Normaldiät hingegen waren diese Effekte zwischen IMP-KO- und Kontrollgruppe in Bezug auf die 
Gewichte nicht nachweisbar. In der Analyse der korpuskulären Blutbestandteile wiesen die Werte der IMP-KO-Tiere mit Hochfettdiät einen signifikant höheren Anteil von basophilen Granulozyten auf, einen ähnlichen, wenn auch nicht signifikanten Trend zeigte die Analyse der eosinophilen Granulozyten. Die Zahl der Monozyten war tendenziell in der IMP-KO-Gruppe unter Hochfettdiät vermindert.

Im zweiten Teil der Arbeit wurde die Ausprägung der Atherosklerose der IMP-KO-Maus im Vergleich zur Kontrolle evaluiert. Exemplarisch wurden dafür die atherosklerotischen Plaques in der Aortenwurzel und in $\operatorname{der}$ A. brachiocephalica analysiert, die häufig untersuchte Prädilektionsstellen im Mausmodell darstellen. Hier ergab sich kein feststellbarer Effekt der Hochfettdiät gegenüber der Normaldiät in Bezug auf den Grad der Stenose; beide Diäten induzierten gleichermaßen zuverlässig eine ausgeprägte Atherosklerose an den benannten Stellen. Bei der Betrachtung der Genotypen zeigte sich im Bereich der Aortenwurzel sowohl unter Normal- als auch unter Hochfettdiät kein signifikanter Unterschied zwischen der Kontroll- und der IMP-KO-Gruppe hinsichtlich des Grads der Stenose. Bei den folgenden Untersuchungen wurde daher auf eine weitere Analyse von Proben unter Normaldiät verzichtet. Im Bereich der $A$. brachiocephalica wurden aus demselben Grund nur noch Tiere unter Hochfettdiät untersucht. Hier ergab sich ebenfalls kein Unterschied im Stenosegrad zwischen Kontroll- und IMP-KO-Gruppe. Zum Ausschluss einer kompensierten Stenose, beispielsweise durch ein outward arterial remodeling, wurden weitere Parameter der Gefäßstruktur wie Größe der Media, der äußere Gefäßdurchmesser sowie zugehörige Quotienten erfasst (siehe auch Kapitel 3.2.2). Auch hier zeigte sich kein Anhalt für eine kompensierte Stenose oder eine anderweitige Veränderungen der Gefäßwand.

Im dritten Teil der Arbeit wurden daher die Zusammensetzung und die Stabilität der atherosklerotischen Plaques evaluiert. Die Ruptur einer instabilen, vulnerablen atherosklerotischen Läsion mit nachfolgendem thrombotischem Verschluss des betroffenen Gefäßes hat in der Regel gravierende Konsequenzen wie Apoplex oder Herzinfarkt, die bei einem stenosierten Gefäß nicht oder nur in abgemilderter Form auftreten. Die Stabilität der Plaque wird maßgeblich von ihrer zellulären Zusammensetzung beeinflusst. Im Rahmen dieser Arbeit wurde der relative Anteil von Makrophagen, $\mathrm{CD}^{+}{ }^{+}$ T-Lymphozyten, glatten Muskelzellen sowie die proliferative Aktivität der Zellen in den Plaques im Bereich der Aortenwurzel erfasst. Hierbei ergab sich kein Unterschied zwischen der IMP-KO- und der Kontrollgruppe. Im Bereich der A. brachiocephalica wurde neben den genannten Parametern der Kollagenanteil anstelle der proliferativen Aktivität in der Plaque ermittelt. Hier war ebenfalls kein Unterschied feststellbar. 


\subsection{Einfluss einer reduzierten BRAP-Expression auf den Phänotyp der $\mathrm{ApoE}^{-/-}$-Maus unter Hochfettdiät}

Die MAPK-Signalkaskaden sind evolutionär gut konservierte Signalwege, die integrative Schaltstellen zwischen extrazellulären Signalen und zentralen intrazellulären Vorgängen wie Zellwachstum, -differenzierung, -proliferation und Apoptose, aber auch Zellmigration darstellen (Dhillon et al. 2007). Im Allgemeinen gilt es als gesichert, dass alle MAPKSignalwege (p38, JNK und Erk) eine Schlüsselrolle im Energiestoffwechsel spielen und insbesondere bei Überaktivierung an einer Aggravierung von assoziierten Krankheitsbildern wie Adipositas und Diabetes mellitus beteiligt sind. Allerdings konzentrieren sich die bisher bekannten Arbeiten auf die Analyse einzelner Faktoren der MAPK-Signalkaskade - meist in Zusammenhang mit der Adipogenese oder intrazellulären Insulinwirkung - und sind daher in ihren Ergebnissen zum Teil noch nicht sehr kongruent (Gehart et al. 2010). Gute Evidenz gibt es hingegen für die Rolle des MAPK-ErkSignalwegs in der Adipogenese. So führt beispielsweise ein Fehlen von Erk in PräAdipozyten zu einer Hemmung der weiteren Differenzierung (Sale et al. 1995). Der Effekt von Erk ist aber zeitabhängig und kann - abhängig von dem Zeitpunkt der Aktivierung sowohl eine Förderung als auch eine Hemmung der Adipogenese zur Folge haben. Eine Erk-Aktivierung in einer frühen Phase begünstigt die Adipogenese, zu einem späteren Zeitpunkt zeigt sich eine gegenteilige Wirkung (Prusty 2002). Hierbei wird der proadipogene Transkriptionsfaktor peroxisome proliferator activated receptor gamma (PPAR $\gamma$ ) durch Erk-abhängige Phosphorylierung inaktiviert (Hu et al. 1996). Die Arbeit von Bost et al. konnte darüber hinaus zeigen, dass der frühe pro-adipogene Effekt von Erk1 und nicht von Erk2 getragen wird. Erk1 ${ }^{-/}$-Mäuse weisen dabei weniger differenzierte Adipozyten auf und sind unter Hochfettdiät resistent gegenüber einer Adipositasentwicklung. Weiterhin fanden sich Hinweise auf einen gegenüber $\mathrm{Erk}^{+/+}$-Tieren post-prandial gesteigerten Energieumsatz. Bei Erk2 war all dies nicht der Fall (Bost et al. 2005). Umgekehrt kam es durch adenoviral vermittelte Erk-Aktivierung zu einer Verringerung des Stoffwechsels und einer gesteigerten intra-hepatischen Glykogenakkumulation sowie einer erhöhten Lipolyserate. Zusätzlich fand sich in der Interventionsgruppe ein erhöhtes Lebergewicht auf Grund einer durch Erk bedingten Hemmung der Glykogenolyse (Jiao et al. 2013).

Die bisherigen Ergebnisse zu BRAP zeigen, dass BRAP durch Bindung an KSR die Formierung des Raf-MEK-Erk-Komplexes hemmt und so die Antwort des MAPK-ErkSignalweges in seiner Stärke limitiert. Eine verringerte Expression von BRAP führte bei Aktivierung des MAPK-Erk-Signalweges zu einer höheren Antwortamplitude bei gleicher Antwortdauer, d. h. einer vermehrten Aktivierung von Erk (Matheny et al. 2004). Die Ergebnisse der hier vorgelegten Arbeiten zeigen, dass es nach sechs Monaten Hochfettdiät in Mäusen mit reduzierter BRAP-Expression zu einer signifikanten Zunahme der abdominalen Fettdepots mit tendenziell ebenfalls erhöhtem Körpergewicht kommt. Dies lässt sich möglicherweise auf eine erhöhte Erk-Aktivität infolge einer verminderten 
Regulation durch BRAP zurückführen. Es ist wahrscheinlich, dass dieser Effekt durch die verwendete Hochfettdiät noch weiter verstärkt und dadurch überhaupt erst sichtbar wird. Jiao et al. fanden in ihrer Arbeit eine erhöhte Erk-Aktivität in Mäusen auf Hochfettdiät (Jiao et al. 2013). In einer anderen Arbeit war dieser Effekt jedoch nicht nachweisbar (Bost et al. 2005). Passend dazu konnten Avery et al. in einer Meta-Analyse mehrerer Populationsstudien einen SNP (rs11065987) nachweisen, der 9,9 kb upstream des brap Lokus liegt, der mit atherogener Dyslipidämie, Bluthochdruck und stammbetonter Adipositas assoziiert ist (Avery et al 2011). Die Effekte des in einer nicht-kodierenden Region des Chromosoms 12q24 liegenden SNPs auf die Expression oder Funktion von BRAP sind allerdings bislang nicht bekannt (Daly 2010).

Wie oben erwähnt beschrieben Jiao et al. unter konstitutiver Erk-Aktivierung eine signifikante Erhöhung des Lebergewichts auf Grund von Glykogenanreicherung in hepatischen Zellen (Jiao et al. 2013). Eine entsprechende Veränderung des Lebergewichts ließ sich im Rahmen dieser Arbeit nicht reproduzieren, hier zeigte sich kein Unterschied von einer reduzierten BRAP-Expression zur Kontrollgruppe. Es ist jedoch einschränkend anzumerken, dass auf Grund der Ausrichtung der Arbeit weder die Erk-Aktivierung noch der Glykogen-Gehalt überprüft wurden. Weiterhin ist es bemerkenswert, dass auch die Art des Futters keinen Einfluss auf das Lebergewicht zu haben scheint. Bezüglich des Lebergewichts ist es jedoch denkbar, dass Kompensationsmechanismen existieren und eine reduzierte BRAP-Expression im IMP-KO-Modell nicht ausreichend war, um einen entsprechenden Phänotyp hervorzurufen. Auch ist nicht auszuschließen, dass ein höheres Lebergewicht erst zu einem späteren Lebenszeitpunkt auftritt. So ermittelten Jiao et al. die Lebergewichte nach 38 Wochen Hochfettdiät, während die Gewichte in dieser Arbeit schon nach 24 Wochen ermittelt wurden.

Ein weiterer, maßgeblicher Faktor für die Untersuchung des metabolischen Syndroms sowie assoziierter Erkrankungen im Mausmodell ist die Zusammensetzung des verwendeten Futters. Hier zeigen sich Parallelen zum Menschen, wo ein enger Zusammenhang von aufgenommener Energiemenge und Häufigkeit von Adipositas besteht (Hariri und Thibault 2010). Mäuse in der freien Wildbahn konsumieren üblicherweise eine fettarme Diät, die ungefähr 4-6\% Fett und weniger als 0,02\% Cholesterin enthält (Getz und Reardon 2006). In einer Metaanalyse mehrerer Studien fanden Buettner et al. dass eine Hochfettdiät mit einem Fettanteil von mindestens $40 \mathrm{kcal} \%$ an tierischen und pflanzlichen Fettsäuren (bezogen auf den Energieanteil) Adipositas und Insulinresistenz im Mausmodell induziert. In den entsprechenden Mausstämmen führt eine solche Hochfettdiät zur Ausprägung von atherosklerotischen Plaques (Buettner et al. 2007). Besonders geeignet und daher häufig in diesem Kontext verwendet ist der Stamm C57BL/6J (Surwit et al. 1995). Es dabei aber zu berücksichtigen, dass die Vergleichbarkeit der einbezogenen Studien durch die Vielzahl an verwendeten Diäten eingeschränkt ist. Dazu kann unter anderem die Verwendung von nicht aufgereinigten Futterbestandteilen, infolge unterschiedlicher geografischer Herkunft und Komposition der 
Nahrungsbestandteile sowie intransparenter Darstellung der verwendeten Futterformeln beitragen (Buettner et al. 2007). Für die Untersuchung der Atherosklerose kann durch eine Erhöhung des Cholesterinanteils die Effektivität der Diät erhöht werden, allerdings treten hierbei Verschiebungen in der Verteilung der Lipoproteine im Blutplasma auf (Subramanian et al. 2008). Auch kommt es in LDL-Rezeptor-negativen (LDLR ${ }^{-/}$) Mäusen ab einem Cholesterin-Anteil von 0,15 \% zu einer Erhöhung der Lipidkonzentration in der Leber sowie zu einer zusätzlichen, Cholesterin-abhängigen Erhöhung des Körpergewichts (Teupser et al. 2003). Es ist jedoch nicht gesichert, inwiefern diese Ergebnisse auf das ApoE-KO-Mausmodell übertragbar sind. Entsprechend genetisch modifizierte Tiere neigen im Vergleich aber generell unter Normaldiät $\mathrm{zu}$ einer stärker ausgeprägten Atherosklerose und höheren Cholesterinspiegeln im Plasma (Getz und Reardon 2006; Ishibashi et al. 1994). Im Allgemeinen reichen Cholesterinspiegel von mindestens $300 \mathrm{mg} / \mathrm{dl}$ aus, um einen ausreichenden atherosklerotischen Effekt zu hervorzurufen (Getz und Reardon 2006). Neben seiner Rolle im Lipidstoffwechsel führt Cholesterin zu einer breiten Expression von inflammatorischen Genen und einer Aktivierung der angeborenen Immunität, was den proatherogenen Effekt unterstützt (Vergnes et al. 2003; Tall und Yvan-Chervet 2015). Ein extrem erhöhter Cholesterinspiegel kann so Effekte eines veränderten Immunsystems überdecken (Reardon et al. 2001). Allerdings ist auch für eine Hochfettdiät ohne Cholesterinzusatz eine immunsuppressive Wirkung beschrieben worden (Crevel et al. 1992). Teupser et al. (2003) empfehlen daher für die Plaqueanalysen, wie sie auch im Rahmen dieser Arbeit durchgeführt wurden, einen Cholesterinanteil von 0,02\% sowie einen eher geringen Fettanteil, um störende Einflüsse durch die Hochfettdiät auszuschließen.

Die in dieser Arbeit verwendete Hochfettdiät wird als Futter für die Diät-induzierte Fettleibigkeit vertrieben und enthält bei einem Fettanteil von $45 \mathrm{kcal} \%$ einen Cholesterinanteil von 0,02\% (D12451, Fa. ResearchDiets, siehe auch Kapitel 2.2.1). Als Kontroll-Diät wurde das Standard-Futter der ZTE Göttingen (V1534, Fa. Ssniff Spezialdiäten) verwendet, das einen Fettanteil von $9 \mathrm{kcal} \%$ (Cholesterinanteil nicht ausgewiesen) enthält. In der hier vorgelegten Arbeit zeigt sich nach 24 Wochen Versuchsdauer ein um $14 \%$ (Kontrollgruppe) bzw. 19\% (IMP-KO-Gruppe) erhöhtes Körpergewicht im Vergleich zu der Normaldiät-Gruppe. Dies ist im Einklang mit den Daten anderer publizierter Studien (Petro et al. 2004, Masuzaki et al. 2001). Die gemessenen Cholesterinspiegel liegen mit 526,9 \pm 3,1 mg/dl (Kontrollgruppe, $\mathrm{n}=22$ ) bzw. $527,1 \pm 38,6 \mathrm{mg} / \mathrm{dl}$ (IMP-KO-Gruppe, $\mathrm{n}=26$ ) im Durchschnitt deutlich über den von Getz und Reardon (2006) angegebenen Grenzwerten und sind daher als ausreichend für eine aussagekräftige Atherosklerose-Induktion anzusehen. Dies wird durch die vorgefundene Ausprägung der atherosklerotischen Plaques bestätigt, die im Erwartungsbereich lag (s. Kapitel 4.4). Es ist aber möglich, dass ein höherer CholesterinAnteil in der Hochfettdiät zu einem stärker ausgebildeten Phänotyp geführt hätte. So konnte für LDL-Rezeptor-negative $\left(\mathrm{LDLR}^{-/}\right)$Mäuse gezeigt werden, dass es bei einer 
Steigerung von $0,5 \%$ auf 1,25\% Cholesterin zu höheren Cholesterin- und TriglyzeridSpiegeln im Plasma kommt (Lichtman et al. 1999). In der Analyse der HDL- und LDLCholesterinfraktion zeigte sich unter Hochfettdiät ebenfalls ein erwartungsgemäßer Anstieg der einzelnen Parameter. Auffallend hierbei ist ein Trend zu höheren HDLKonzentrationen in der IMP-KO-Gruppe unter Hochfettdiät, der bei Berechnung des LDL/HDL-Quotienten statistische Signifikanz erreicht. HDL-Cholesterin wird gemeinhin als atheroprotektiv angesehen, niedrige HDL-Werte gehen mit einem höherem Risiko für Atherosklerose bzw. koronare Herzkrankheit (KHK) einher (Gordon et al. 1977). So fand sich für $\mathrm{ApoE}^{-/}$-Mäuse eine negative Korrelation von HDL-Werten im Serum mit der Ausprägung der atherosklerotischen Belastung (VanderLaan et al. 2009). Es ist jedoch nicht ausgeschlossen, dass die Induktion durch das verwendete Futter zu stark war und dadurch subtilere Effekte verdeckt wurden oder dass die Analyse zu einem Zeitpunkt stattfand, an dem akute Reaktionen wie beispielsweise die Monozytenrekrutierung abgeschlossen war, daraus folgende Komplikation aber noch nicht ausgebildet wurden. Die Analyse der Triglyzeride ergab keinen wegweisenden Befund, hier ist allerdings kritisch anzumerken, dass die verwendeten Tiere vor der Probenentnahme nicht nüchtern waren und so die Ergebnisse durch unterschiedliche Nahrungsaufnahme in der Nacht davor verändert sein können. Eine weitere Schwierigkeit bei der statistischen Beurteilung ergibt sich durch die geringe Anzahl an eingeschlossenen Proben von Tieren unter Normaldiät (IMP-KOGruppe: $n=6$, Kontroll-Gruppe: $n=3-4$. Siehe auch Kapitel 3.1.3). Dies war bedingt durch einen Wechsel des Analyseverfahrens in der Abteilung für Klinische Chemie. Die Ergebnisse von nach dem Stichtag eingeschickten Proben waren nicht hinreichend vergleichbar mit den vorher gewonnenen Daten, so dass auf eine Verwendung verzichtet wurde. Eine weitere, mögliche Störvariable bei diesem Versuchsaufbau könnte die Verwendung des normalen Futters der ZTE als Kontrolldiät darstellen. Hier kann die Möglichkeit nicht ausgeschlossen werden, dass es durch die Verwendung von nicht aufgereinigten Nahrungsbestandteilen zu natürlichen Schwankungen im Verhältnis von Fett, Kohlenhydraten und Proteinen gekommen ist. Auch die Energiedichte sowie Geschmack und Geruch können bei nicht standardisierten Diäten variieren und so die Nahrungsaufnahme der Tiere beeinflussen. Dies kann Auswirkungen auf die Vergleichbarkeit haben (Hairiri und Thibault 2010). Des Weiteren wurden die Tiere während des Versuches in unterschiedlichen Gruppengrößen gehalten, teils mussten im Verlauf Umsetzungen auf Grund sozialer Unverträglichkeit erfolgen. Dies bedingt ein interindividuell unterschiedliches Bewegungsverhalten und dadurch unter Umständen eine andere Gewichtsentwicklung. 


\subsection{Einfluss einer reduzierten BRAP-Expression auf die korpuskulären Blutbestandteile}

Im Rahmen der Hämatopoese ist der MAPK-Erk-Signalweg an der Proliferation und Differenzierung aller Zellreihen beteiligt (Chung und Kondo 2011). Darüber hinaus ist die Modulation des MAPK-Erk-Signalweges von Bedeutung für den Erhalt des Stammzellpools im Knochenmark (Oostendorp et al. 2008). Nach Verabreichung einer Hochfettdiät werden in der Literatur Veränderungen des Blutbilds im Sinne einer niedriggradigen Inflammation beschrieben. Dazu zählen unter anderem ein Anstieg der Leukozyten, insbesondere der neutrophilen Granulozyten, und des C-reaktiven Proteins (CRP) sowie die Entwicklung einer Anämie (Cortez et al. 2013; Do Carmo et al. 2013). In den hier durchgeführten Analysen zeigten sich unter Hochfettdiät ebenfalls deutliche Veränderungen. Bei weitgehend gleichbleibenden Leukozytenzahlen war der Anteil der neutrophilen Granulozyten unter Hochfettdiät gegenüber der Kontrolldiät signifikant erhöht. In der IMP-KO-Gruppe war dies nicht festzustellen. Hsu et al konnten nachweisen, dass die Aktivierung des MAPK-Erk-Signalwegs zu einer Verschiebung der Zelldifferenzierung im Knochenmark hin zur myeloiden Zellreihe führt (Hsu et al. 2007). Es wäre also möglich, dass es unter diesen Umständen zu keiner weiteren Steigerung der Granulopoese durch die Hochfettdiät kommt. Der Einfluss des MAPK-Erk-Signalweges auf die Erythropoese wird kontrovers diskutiert (Guihard et al. 2010). In der vorliegenden Arbeit findet sich ebenfalls kein Anhalt für eine Veränderung des roten Blutbildes in der IMP-KO-Gruppe gegenüber der Kontrollgruppe. Es fällt aber auf, dass es in beiden Gruppen unter Hochfettdiät zu einer signifikanten Erniedrigung der Erythrozytenzahl kommt. Ein ähnlicher, jedoch nicht signifikanter Trend lässt sich bei der HämoglobinKonzentration sowie dem Hämatokrit erkennen. Unter Hochfettdiät wurde in anderen Arbeiten das Auftreten einer inflammatorischen Anämie (sog. anemia of chronic disease) beschrieben (Yanoff et al. 2007). Dies wird durch erhöhte Hepcidin-Konzentrationen, einem Akute-Phase-Protein, erklärt (Chung J et al. 2011). Eine Eisenmangelanämie lässt sich hingegen bei unveränderten Erythrozyten-Indices ausschließen.

Die Auswirkungen von Adipositas und Hochfettdiät auf die Lymphozytenzahl und -funktion sind in der Literatur bislang nicht eindeutig beschrieben. Es gibt jedoch Hinweise darauf, dass unter Hochfettdiät die Lymphopoese - und hier vor allem die Entwicklung der B-Zellreihe - gestört ist (Adler et al. 2014). Dies wäre eine mögliche Erklärung für den Rückgang der Lymphozyten, relativ zur Leukozytenzahl als auch absolut in der Kontrollgruppe unter Hochfettdiät.

Einen weiteren signifikanten Befund stellt der Anteil der basophilen Granulozyten dar, welcher unter Hochfettdiät in der IMP-KO-Gruppe gegenüber der Kontrolldiät erhöht war. Über die Funktion des MAPK-Erk-Signalwegs in Basophilen ist nur wenig bekannt. Gibbs et al. fanden eine Erk1/2-abhängige Modulation der Leukotrien-Synthese, die aber gegenüber dem p38-Signalweg nur eine untergeordnete Rolle spielt (Gibbs et al. 2005). 
Nebenbefundlich zeigten sich unter Hochfettdiät noch ein jeweils nicht-signifikanter Trend $(p=0,521)$ zu einem geringeren Monozyten-Anteil sowie ein höherer Anteil von Eosinophilen in der IMP-KO-Gruppe gegenüber der Kontrollgruppe. Dies ist insofern bemerkenswert, als dass mit zunehmender atherosklerotischer Belastung und insbesondere nach kardiovaskulären Ereignissen eine Zunahme an zirkulierende Monozyten beobachtet wurde (Dutta et al. 2012). Eine mögliche Erklärung hierfür stellen die Ergebnisse von Asada et al. dar, die auf Zellkulturebene eine signifikant erhöhte Apoptoserate in mit BRAP-siRNA-transfizierten Monozyten fanden (Asada et al. 2004). Der höhere Anteil an Eosinophilen in der IMP-KO-Gruppe deckt sich mit den Befunden von HernandezHernandez et al., die eine negative Regulation des Transkriptionsfaktors GATA-1 durch den MAPK-Erk-Signalweg beschreiben (Hernandez-Hernandez et al. 2006). GATA-1 bewirkt während der Hämatopoese dosisabhängig unter anderem eine Differenzierung hin zu Eosinophilen Granulozyten (Kulessa et al. 1995).

\subsection{Einfluss der BRAP-Expression auf die atherosklerotische Belastung}

Atherosklerose ist eine systemische, inflammatorische Erkrankung, die sich in den mittleren und großen arteriellen Gefäßen manifestiert (Ross 1999). Die MAPK-Signalwege spielen eine zentrale Rolle in der Modulation der Plaquebildung (Muslin 2008). Von Matheny et al. wurde erstmals postuliert, dass BRAP eine regulierende Wirkung im MAPKErk-Signalweg ausübt, indem es durch Interaktion mit KSR die Bildung des Raf-MEKErk-Komplexes hemmt (Matheny et al. 2004). Genomweite Assoziationsstudien in asiatischen Populationen weckten dann den Verdacht, dass eine erhöhte Expression von BRAP mit einem erhöhten Risiko für das Auftreten der koronaren Herzkrankheit und von Myokardinfarkten einhergeht (Ozaki et al. 2009; Hinohara et al. 2009). Als zugrundeliegender Pathomechanismus wurde zum einen eine Steigerung der NFxBExpression und zum anderen eine Beeinflussung im Sinne einer vermehrten Translokation von NFxB in den Zellkern diskutiert (Ozaki et al. 2009; Liao et al. 2011; Takashima et al. 2013). NFxB ist ein Transkriptionsfaktor mit wesentlicher Bedeutung für diverse immunologische Prozesse, wie beispielsweise Inflammation und Aktivierung von Zellen der angeborenen sowie der erworbenen Immunabwehr (Sun und Ley 2008). NFxB wird überwiegend mit proinflammatorischen und proatherogenen Mechanismen in Verbindung gebracht, die Evidenz deutet aber ebenso auf eine relevante Beteiligung an der Entzündungsresolution hin, die zeitlich und örtlich getrennt sein kann (De Winther et al. 2005).

In der hier vorgelegten Arbeit wurde daher untersucht, ob sich eine verringerte BRAPExpression auf die atherosklerotische Belastung im Allgemeinen bzw. die zelluläre Zusammensetzung der Läsionen sowie die Stabilität der Läsionen im Speziellen auswirkt. Hierfür wurde zunächst die Ausdehnung der atherosklerotischen Läsionen nach 24 
Wochen Hochfettdiät im Bereich der Aortenwurzel erfasst und im Verhältnis zum Gefäßinnendurchmesser angegeben. Hier zeigte sich jedoch kein statistisch signifikanter Unterschied in Bezug auf die Reduktion des durchflossenen Gefäßlumens. Eine weitere Analyse im Bereich der A. brachiocephalica ergab ebenfalls keinen Hinweis auf Unterschiede hinsichtlich der Plaquegröße in der IMP-KO-Gruppe. In weiteren planimetrischen Untersuchungen fand sich darüber hinaus kein Hinweis auf kompensatorische Veränderungen der Gefäßwand, also ein sog. outward arterial remodelling. Ein solches Phänomen kann bei atherosklerotischen Veränderungen auftreten und den Schweregrad der Belastung verschleiern (Ward et al. 2000). Entsprechende Veränderungen gehören daneben zu den Kriterien einer instabilen Plaque (Bond und Jackson 2011).

Die im Rahmen dieser Arbeit erhobenen Befunde widersprechen den bisher publizierten Studien im Menschen, die eine Assoziation von erhöhter BRAP-Expression mit vermehrter Atherosklerose nahelegen (Ozaki et al. 2009; Hinohara et al. 2009). Auch wenn der Verdacht auf einen Zusammenhang plausibel dargelegt wurde, konnte keine der publizierten Studien einen klaren Beweis dafür erbringen, dass eine erhöhte BRAPTranskription direkt ursächlich für ein erhöhtes Risiko bzw. eine schwereren Verlauf einer eingetretenen Atherosklerose ist. Es ist angesichts der hier dargelegten Ergebnisse nicht auszuschließen, dass eine bislang unbekannte, konfundierende Variable existiert, die beide Phänomene verursacht. Umgekehrt ist die hier vorgelegte Arbeit die erste, die den Effekt einer reduzierten BRAP-Expression in vivo untersucht. Eine denkbare Erklärung ist, dass anders als eine Überexpression - ein heterozygoter BRAP-Knockout in vivo ausreichend kompensiert werden kann und eine stärkere Reduktion der BRAP-Expression notwendig wäre, um den vermuteten Effekt zu erzielen. So war in den Versuchen von Ozaki et al. auf Zellkulturebene eine nahezu vollständige Suppression der BRAP-Expression notwendig, um die NFxB-Aktivität annähernd zu halbieren (Ozaki et al. 2009). Dieser These steht allerdings entgegen, dass BRAP zumindest in der Embryogenese unverzichtbar ist und ein kompletter BRAP-Knockout in vivo letal ist (Grebe und Seidler 2016).

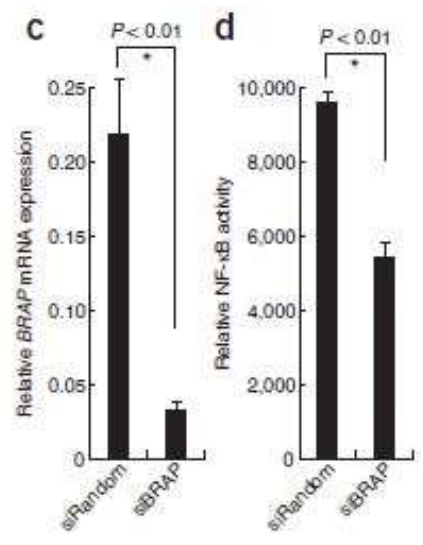

Abbildung 39: Expression von BRAP mRNA (c) bzw. NFxB-Aktivität (d) in HCAEC-Kulturen nach Behandlung mit unspezifischer (siRandom) oder BRAP-spezifischer siRNA (siBRAP). Aus Ozaki et al. 2009. Der Abdruck erfolgte mit freundlicher Genehmigung der Nature Publishing Group. 
In diesem Sinne ist es möglich, dass der von Takashima et al. beschriebene Effekt einer Modulation der NFxB-Kerntranslokation durch Bindung von BRAP an $\mathrm{I} x \mathrm{~B} \alpha$ zwar den physiologischen Gegebenheiten - beispielsweise beim Vorliegen des passenden SNPs entspricht, aber kein notwendiges Kriterium für diesen Vorgang darstellt und somit die Reduktion der BRAP-Expression ohne klinischen Effekt bleibt (Takashima et al. 2013). Es wurde bereits spekuliert, dass BRAP lediglich ein Mitglied einer größeren Familie von zytoplasmatischen Retentionsproteinen darstellt und daher möglicherweise auf Grund einer redundanten Auslegung dieses regulatorischen Systems kompensiert werden kann (Asada et al. 2004). Umgekehrt ist es nicht auszuschließen, dass die gefundenen Unterschiede tatsächlich auch biologisch bedeutsam sind, aber auf Grund einer zu niedrigen Anzahl an Versuchstieren nicht das vordefinierte statistische Signifikanzniveau erreichen konnten. Darüber hinaus sind die Effekte der Interaktion von BRAP und NFxB sowie die Beteiligung weiterer Interaktionspartner noch nicht ausreichend geklärt. So fanden Takashima et al., dass eine Überexpression von BRAP in mit TNF- $\alpha$ behandelten HeLaZellen zu einer abgeschwächten Translokation von NFxB in den Nukleus führt (Takashima et al. 2013). Andere Studien hingegen ergaben jedoch, dass eine reduzierte Präsenz von BRAP zu einer abgeschwächten Translokation führt (Ozaki et al. 2009; Liao et al. 2011). Takashima et al. führten als mögliche Erklärung an, dass das Ergebnis der Interaktion mit BRAP vom genauen Zeitpunkt während der NFxB-Aktivierung abhängen könnte (Takashima et al. 2013).

Weiterhin ist es denkbar, dass ein Überangebot an Lipiden den Effekt einer reduzierten BRAP-Expression überlagert hat. So führen sowohl Adipositas an sich als auch eine ERK1/2-Aktivierung zu einer reduzierten Expression des ATP-binding cassette transporter A1 (ABCA1) (Marrades et al. 2010; Wang et al. 2014). Der ABCA1 ist ein erster Linie ein Cholesterol-Transporter, der den Transport von überschüssigem Cholesterin und Phospholipiden aus der Zelle bewirkt sowie am Aufbau von HDL-Partikeln beteiligt ist (Yamauchi et al. 2004). Eine Hochfettdiät könnte so einen möglichen schwach ausgeprägten Effekt verschleiern oder - im Gegenteil - verstärken.

Weiterhin ist es denkbar, dass der Zeitpunkt der Tötung für die Analyse in Bezug auf die Plaqueausdehnung bzw. Lumenstenose entscheidend ist. In einer Langzeitstudie fanden sich aber in Präparaten $\operatorname{der} A$. brachiocephalica nach fünf bis 59 Wochen Hochfettdiät im Vergleich über die Zeit keine relevanten Unterschiede. Bei Analyse nach dem Kriterium einer akuten Plaqueruptur zeigten sich jedoch größere Plaques in der Gruppe mit einer akuten Ruptur. Dies wurde mit einer Neigung zu einem häufigerem Auftreten von Rupturen in dieser Gruppe erklärt (Williams et al. 2002). In dieser Arbeit fanden sich sowohl akute als auch abgelaufene verheilte Rupturen gleichermaßen in der IMP-KO wie auch in der Kontroll-Gruppe. Weitere Kriterien für instabile Plaques waren in keiner der beiden Gruppen erfüllt, so dass ein Einfluss von BRAP auf die Stabilität der atherosklerotischen Plaques fraglich erscheint. Jedoch ist es auch hier möglich, dass bei 
einer größeren Anzahl von untersuchten Tieren oder einem früheren bzw. späteren Untersuchungszeitpunkt ein statistisch signifikanter Effekt nachweisbar wäre.

Auch wenn die Dauer der Hochfettdiät für die Ausprägung relevanter Plaques von untergeordneter Bedeutung sein mag, so ist es denkbar, dass der Einfluss einer veränderten BRAP-Expression lediglich in einer frühen Phase der Plaqueentwicklung von Bedeutung ist. Es konnte in dieser Arbeit gezeigt werden, dass es in der IMP-KO-Gruppe zu einer Zunahme der abdominalen Fettdepots kommt - und in der Tendenz auch zu einem höheren Körpergewicht. Dies weist auf eine Veränderung des Lipidmetabolismus durch den heterozygoten Knockout hin. Die Initiation einer atherosklerotischen Läsion wiederum ist geprägt von der Ablagerung und Oxidierung von Lipoproteinen, die in der Folge von Makrophagen aufgenommen und metabolisiert werden. Dies führt zur Entstehung von sog. Schaumzellen, die in ausreichender Anzahl als fatty streaks (siehe auch Kapitel 1.1.2) sichtbar werden. Daher wäre es möglich, dass BRAP nur in der Frühphase zu einem messbaren Effekt führt. Es ist allerdings unklar, welchen Effekt der Erk1/2-Signalweg auf die Schaumzellentwicklung hat (Muslin 2008). Eine Exposition von Makrophagen mit oxLDL rief eine Aktivierung der JNK-, p38- und Erk1/2-Signalkaskaden hervor. Eine ErkAktivierung war dabei zuerst nachweisbar und trat nach ca. zwei Minuten auf, aber nur die pharmakologische in vitro Inhibition der JNK- und p38-Signalwege führte jeweils zu einer reduzierten Schaumzellbildung (Rahaman et al. 2006; Zhao et al. 2002).

Neben der Plaquegröße bzw. der durch die Plaques verursachten Lumenstenose ist die zelluläre Zusammensetzung dieser Plaques von Interesse. Auch bei gleicher Größenausdehnung können Veränderungen in der zellulären Zusammensetzung oder in der Funktionsfähigkeit der beteiligten zellulären Akteure über die Stabilität einer Läsion entscheiden (Libby 2002). Zur Klärung der Frage, ob eine reduzierte BRAP-Expression hierzu beiträgt, wurde im Rahmen dieser Arbeit das Vorkommen von Makrophagen, TLymphozyten und glatten Muskelzellen in den Plaques der Aortenwurzel und $\operatorname{der} A$. brachiocephalica mittels immunhistochemischer Färbungen untersucht. Weiterhin wurden in den Plaques der Aortenwurzel die Proliferationsrate und in den Plaques $\operatorname{der} A$. brachiocephalica der Kollagengehalt analysiert. Hierbei traten keine signifikanten Unterschiede zwischen der IMP-KO-Gruppe und der Kontroll-Gruppe auf. Jedoch sind (immun-)histochemische Färbungen in ihrer Aussagekraft begrenzt, denn sie lassen meist keine Aussage über die Funktionsfähigkeit der untersuchten Zellen zu. So ist es also nicht ausgeschlossen, dass die angefärbten zellulären Bestandteile in der IMP-KO-Gruppe Funktionsdefizite aufwiesen, die ein höheres Risiko für atherosklerotische Belastungen verursachen. Weiterhin ist es auch hier möglich, dass diskrete Unterschiede zwischen den Gruppen bestehen, die durch eine relativ geringe Anzahl von Proben nicht das geforderte statistische Signifikanzniveau erreichen oder auf Grund von Messungenauigkeiten gar nicht erfasst wurden. 
Grundsätzlich ist bei Studien zur Atherosklerose im Mausmodell zu bedenken, dass fundamentale Unterschiede zum menschlichen Organismus existieren. Mäuse sind ohne weitere genetische Eingriffe weitgehend resistent gegenüber ausgeprägten atherosklerotischen Veränderungen und können nur mit quasi-toxischen Hochfettdiäten zur Entwicklung von Läsionen im Anfangsstadium gebracht werden. Seit der Einführung des ApoE-Knockout-Mausmodells ist es immerhin möglich, die „spontane“ Plaqueentwicklung (und teilweise auch die Plaqueruptur als klinisch relevante Komplikation) zu beobachten und mit den Befunden im Menschen vergleichen (Bond und Jackson 2011). Insgesamt gibt es in der Ausprägung der für diese Arbeit untersuchten Plaques keinen Unterschied $\mathrm{zu}$ in anderen Studien veröffentlichten Ergebnissen. Eine mögliche Fehlerquelle ist aber, wie bereits in Kapitel 4.2 angesprochen, der Cholesteringehalt der Hochfettdiät. Hier ist es nicht ausgeschlossen, dass eine erhöhte Cholesterinkonzentration analog zur sog. westlichen Diät zu Unterschieden in der Plaqueausdehnung oder -stabilität geführt hätte. $\mathrm{Zu}$ beachten ist dabei, dass das Vorkommen der angeführten SNPs lediglich in asiatischen Populationen nachgewiesen wurde, nicht jedoch in Stichproben aus anderen Populationen mit europäischen oder nigerianischen Wurzeln (Ozaki et al. 2009). Gründe für diesen Sachverhalt finden sich in der Literatur nicht. Denkbar wäre, dass der SNP Evolutionsvorteile bietet, die nur in asiatischen Populationen zum Tragen kommen - beispielsweise in Zusammenhang mit Ernährungsgewohnheiten oder dem vorherrschenden genetischen Hintergrund.

\subsection{Zusammenfassung und Perspektiven}

In der hier vorgelegten Arbeit wurde die Hypothese zu Grunde gelegt, dass das Maß der BRAP-Expression einen Einfluss auf den Schweregrad der koronaren Herzkrankheit hat. Es wurden daher die Auswirkungen eines heterozygoten Knockouts im $\mathrm{ApoE}^{-/}$Mausmodell mit besonderem Fokus auf die atherosklerotische Belastung untersucht.

Zusammenfassend lässt sich feststellen, dass eine reduzierte BRAP-Expression durch den heterozygoten BRAP-Knockout im hier untersuchten Mausmodell keine geringere Atherosklerose im Vergleich zur Kontroll-Gruppe zur Folge hat. Sowohl der Grad der Lumenstenose als auch andere, mit einem höheren Schweregrad der Atherosklerose einhergehende Parameter, waren zwischen der IMP-KO-Gruppe und der Kontrollgruppe weitgehend gleich. Auch die Stabilität der Plaques zeigte keinen Unterschied. Jedoch führt eine geringere BRAP-Expression zu größeren abdominalen Fettdepots und in der Folge zu einem höheren Quotienten aus abdominalen Fett und Körpergewicht. Dies deutet auf eine Rolle von Brap im Lipidmetabolismus hin und könnte so auch einen diskreten Einfluss auf das kardiovaskuläre Risiko erklären. Es sind jedoch weitere Untersuchungen notwendig, um die Rolle von Brap in diesem Zusammenhang näher zu bestimmen. Dazu gehört notwendigerweise eine konsequente Untersuchung des metabolischen Phänotyps des IMP${ }^{/+} / \mathrm{ApoE}^{-/-}$-Mausmodells. Weiterhin sollten in vitro Funktionsanalysen von $\mathrm{IMP}^{-/+} / \mathrm{ApoE}^{-/-}$ 
Adipozyten und Makrophagen erfolgen, um die Grundlage für mögliche Querverbindungen zur Entwicklung von atherosklerotischen Plaques darstellen zu können. Besondere Aufmerksamkeit verdient die Antwort von $\mathrm{IMP}^{-/+} / \mathrm{ApoE}^{-/-}$-Makrophagen auf die Präsenz von ox-LDL. Wie von Muslin zusammenfassend dargestellt, wird der Erk1/2Signalweg noch vor den MAPK-Signalwegen (JNK, p38) bei Kontakt von Makrophagen zu ox-LDL aktiviert - jedoch ist seine Rolle in diesem Zusammenhang noch unklar und bedarf weiterer Untersuchungen (Muslin 2008). Diese Versuche könnten dazu beitragen, diesen Zusammenhang näher zu beleuchten, um auf diesem Wege einen möglichen Einfluss von BRAP auf die atherosklerotische Belastung weiter präzisieren zu können. 


\section{$5 \quad$ Literaturverzeichnis}

Adler BJ, Green DE, Pagnotti GM, Chan ME, Rubin CT (2014): High fat diet rapidly suppresses B lymphopoiesis by disrupting the supportive capacity of the bone marrow niche. PLoS ONE $\underline{9}$, e90639

Allahverdian S, Pannu PS, Francis GA (2012): Contribution of monocyte-derived macrophages and smooth muscle cells to arterial foam cell formation. Cardiovasc Res $\underline{95}$, 165-172

Asada M, Ohmi K, Delia D, Enosawa S, Suzuki S, Yuo A, Suzuki H, Mizutani S (2004): Brap2 functions as a cytoplasmic retention protein for $\mathrm{p} 21$ during monocyte differentiation. Mol Cell Biol 24, 8236-8243

Avery CL, He Q, North KE, Ambite JL, Boerwinkle E, Fornage M, Hindorff LA, Kooperberg C, Meigs JB, Pankow JS et al. (2011): A phenomics-based strategy identifies loci on APOC1, BRAP, and PLCG1 associated with metabolic syndrome phenotype domains. PLoS Genet I, e1002322

Baldwin AS (2001): Series Introduction: The transcription factor NF- $x$ B and human disease. J Clin Invest 107, 3-6

Ball RY, Stowers EC, Burton JH, Cary NR, Skepper JN, Mitchinson MJ (1995): Evidence that the death of macrophage foam cells contributes to the lipid core of atheroma. Atherosclerosis $\underline{114}, 45-54$

Bond AR, Jackson CL (2011): The fat-fed apolipoprotein E knockout mouse brachiocephalic artery in the study of atherosclerotic plaque rupture. J Biomed Biotechnol 2011, 379069

Bost F, Aouadi M, Caron L, Even P, Belmonte N, Prot M, Dani C, Hofman P, Pages G, Pouyssegur J et al. (2005): The Extracellular Signal-Regulated Kinase Isoform ERK1 Is Specifically Required for In Vitro and In Vivo Adipogenesis. Diabetes 노, 402-411

Buettner R, Schölmerich J, Bollheimer LC (2007): High-fat diets: modeling the metabolic disorders of human obesity in rodents. Obesity (Silver Spring) 15, 798-808

Caro CG, Fitz-Gerald JM, Schroter RC (1971): Atheroma and Arterial Wall Shear Observation, Correlation and Proposal of a Shear Dependent Mass Transfer Mechanism for Atherogenesis. Proc R Soc Lond B Biol Sci 177, 109-133

Chizhikov VV, Millen KJ (2005): Roof plate-dependent patterning of the vertebrate dorsal central nervous system. Dev Biol 277, 287-295 
Cholesterol Treatment Trialists' (2010): Efficacy and safety of more intensive lowering of LDL cholesterol: a meta-analysis of data from 170000 participants in 26 randomised trials. Lancet $\underline{376}, 1670-1681$

Chung E, Kondo M (2011): Role of Ras/Raf/MEK/ERK signaling in physiological hematopoiesis and leukemia development. Immunol Res $\underline{49}$, 248-268

Chung J, Kim MS, Han SN (2011): Diet-induced obesity leads to decreased hepatic iron storage in mice. Nutr Res $\underline{31}, 915-921$

Cortez M, Carmo LS, Rogero MM, Borelli P, Fock RA (2013): A high-fat diet increases IL$1, \mathrm{IL}-6$, and $\mathrm{TNF}-\alpha$ production by increasing $\mathrm{NF}-x \mathrm{~B}$ and attenuating PPAR- $\gamma$ expression in bone marrow mesenchymal stem cells. Inflammation $\underline{36}$, 379-386

Crevel RW, Friend JV, Goodwin BF, Parish WE (1992): High-fat diets and the immune response of C57Bl mice. Br J Nutr $\underline{67}, 17-26$

Criqui MH, Langer RD, Fronek A, Feigelson HS, Klauber MR, McCann TJ, Browner D (1992): Mortality over a Period of 10 Years in Patients with Peripheral Arterial Disease. N Engl J Med 326, 381-386

Czyzyk J, Chen H-C, Bottomly K, Flavell RA (2008): p21 Ras/impedes mitogenic signal propagation regulates cytokine production and migration in CD4 T cells. J Biol Chem $\underline{283}$, 23004-23015

Daly ME (2010): Determinants of platelet count in humans. Haematologica $\underline{96}, 10-13$

Davies RG, Wagstaff KM, McLaughlin EA, Loveland KL, Jans DA (2013): The BRCA1binding protein BRAP2 can act as a cytoplasmic retention factor for nuclear and nuclear envelope-localizing testicular proteins. Biochim Biophys Acta $\underline{1833}$, 3436-3444

Dellas C, Schremmer C, Hasenfuss G, Konstantinides SV, Schäfer K (2007): Lack of urokinase plasminogen activator promotes progression and instability of atherosclerotic lesions in apolipoprotein E-knockout mice. Thromb Haemost 모, 220-227

De Winther MPJ, Kanters E, Kraal G, Hofker MH (2005): Nuclear factor kappaB signaling in atherogenesis. Arterioscler Thromb Vasc Biol 25, 904-914

Dhillon AS, Hagan S, Rath O, Kolch W (2007): MAP kinase signalling pathways in cancer. Oncogene 26, 3279-3290

Do Carmo LS, Rogero MM, Paredes-Gamero EJ, Nogueira-Pedro A, Xavier JG, Cortez M, Borges MC, Fujii TM, Borelli P, Fock RA (2013): A high-fat diet increases interleukin-3 and granulocyte colony-stimulating factor production by bone marrow cells and triggers bone marrow hyperplasia and neutrophilia in Wistar rats. Exp Biol Med (Maywood) 238, 375-384 
Dreux AC, Lamb DJ, Modjtahedi H, Ferns GAA (2006): The epidermal growth factor receptors and their family of ligands: their putative role in atherogenesis. Atherosclerosis $\underline{186}, 38-53$

Dutta P, Courties G, Wei Y, Leuschner F, Gorbatov R, Robbins CS, Iwamoto Y, Thompson B, Carlson AL, Heidt T et al. (2012): Myocardial infarction accelerates atherosclerosis. Nature $\underline{487}, 325-329$

Falk E, Nakano M, Bentzon JF, Finn AV, Virmani R (2013): Update on acute coronary syndromes: the pathologists' view. Eur. Heart J $\underline{34}, 719-728$

Fulcher AJ, Roth DM, Fatima S, Alvisi G, Jans DA (2010): The BRCA-1 binding protein BRAP2 is a novel, negative regulator of nuclear import of viral proteins, dependent on phosphorylation flanking the nuclear localization signal. FASEB J 24, 1454-1466

Gehart H, Kumpf S, Ittner A, Ricci R (2010): MAPK signalling in cellular metabolism: stress or wellness? EMBO Rep 11, 834-840

Getz GS, Reardon CA (2006): Diet and murine atherosclerosis. Arterioscler Thromb Vasc Biol 26, 242-249

Ghosh S, Karin M (2002): Missing pieces in the NF-kappaB puzzle. Cell 109, 81-96

Gibbs BF, Wolff HH, Zillikens D, Grabbe J (2005): Differential role for mitogen-activated protein kinases in IgE-dependent signaling in human peripheral blood basophils: in contrast to p38 MAPK, c-Jun N-terminal kinase is poorly expressed and does not appear to control mediator release. Int Arch Allergy Immunol 136, 329-339

Glass CK, Witztum JL (2001): Atherosclerosis. the road ahead. Cell 104 (4), 503-516

Gordon T, Castelli WP, Hjortland MC, Kannel WB, Dawber TR (1977): High density lipoprotein as a protective factor against coronary heart disease. The Framingham Study. Am J Med 62, 707-714

Grebe C, Seidler T (2016): Schriftliche Mitteilung vom 14.10.2016 über die Auswirkungen eines brap-Knockouts in der Embryogenese, Göttingen

Guyton JR, Klemp KF (1993): Transitional features in human atherosclerosis. Intimal thickening, cholesterol clefts, and cell loss in human aortic fatty streaks. Am J Pathol $\underline{143}$ (5), 1444-1457

Guihard S, Clay D, Cocault L, Saulnier N, Opolon P, Souyri M, Pagès G, Pouysségur J, Porteu F, Gaudry M (2010): The MAPK ERK1 is a negative regulator of the adult steadystate splenic erythropoiesis. Blood $\underline{115}, 3686-3694$

Hansson GK (2005): Inflammation, atherosclerosis, and coronary artery disease. N Engl J Med $\underline{352}$ (16), 1685-1695

Hansson GK, Hermansson A (2011): The immune system in atherosclerosis. Nat Immunol 12, 204-212 
Hariri N, Thibault L (2010): High-fat diet-induced obesity in animal models. Nutr Res Rev $\underline{23}, 270-299$

Hayes SD, Liu H, MacDonald E, Sanderson CM, Coulson JM, Clague MJ, Urbé S (2012): Direct and indirect control of mitogen-activated protein kinase pathway-associated components, BRAP/IMP E3 ubiquitin ligase and CRAF/RAF1 kinase, by the deubiquitylating enzyme USP15. J Biol Chem 287, 43007-43018

Hazen SL, Heinecke JW (1997): 3-Chlorotyrosine, a specific marker of myeloperoxidasecatalyzed oxidation, is markedly elevated in low density lipoprotein isolated from human atherosclerotic intima. J Clin Invest $\underline{99}$, 2075-2081

Hedin U, Bottger BA, Luthman J, Johansson S, Thyberg J (1989): A substrate of the cellattachment sequence of fibronectin (Arg-Gly-Asp-Ser) is sufficient to promote transition of arterial smooth muscle cells from a contractile to a synthetic phenotype. Dev Biol $\underline{133}$, 489-501

Hernandez-Hernandez A, Ray P, Litos G, Ciro M, Ottolenghi S, Beug H, Boyes J (2006): Acetylation and MAPK phosphorylation cooperate to regulate the degradation of active GATA-1. EMBO J 25, 3264-3274

Hinohara K, Ohtani H, Nakajima T, Sasaoka T, Sawabe M, Lee B, Ban J, Park J, Izumi T, Kimura A (2009): Validation of eight genetic risk factors in East Asian populations replicated the association of BRAP with coronary artery disease. J Hum Genet $\underline{54}$, 642-646

Holdt LM, Teupser D (2013): From genotype to phenotype in human atherosclerosis-recent findings. Curr Opin Lipidol 24, 410-418

Hsu C, Kikuchi K, Kondo M (2007): Activation of mitogen-activated protein kinase kinase (MEK)/extracellular signal regulated kinase (ERK) signaling pathway is involved in myeloid lineage commitment. Blood 110, 1420-1428

Hsu P, Lin T, Su H, Juo SH, Lai W, Sheu S (2011): Synergistic effect between BRAP polymorphism and diabetes on the extent of coronary atherosclerosis in the Chinese population. Cardiology $\underline{120}, 3-8$

Hu E, Kim JB, Sarraf P, Spiegelman BM (1996): Inhibition of adipogenesis through MAP kinase-mediated phosphorylation of PPARgamma. Science 274, 2100-2103

Imaizumi T, Ando M, Nakatochi M, Yasuda Y, Honda H, Kuwatsuka Y, Kato S, Kondo T, Iwata M, Nakashima T et al. (2016): Effect of dietary energy and polymorphisms in BRAP and GHRL on obesity and metabolic traits. Obes Res Clin Pract 12 (1S1), 39-48

Inoue T, Plieth D, Venkov CD, Xu C, Neilson EG (2005): Antibodies against macrophages that overlap in specificity with fibroblasts. Kidney Int $\underline{67}, 2488-2493$

Ishibashi S, Herz J, Maeda N, Goldstein JL, Brown MS (1994): The two-receptor model of lipoprotein clearance: tests of the hypothesis in "knockout" mice lacking the low density 
lipoprotein receptor, apolipoprotein E, or both proteins. Proc Natl Acad Sci U S A 21, $4431-4435$

Jiao P, Feng B, Li Y, He Q, Xu H (2013): Hepatic ERK activity plays a role in energy metabolism. Mol Cell Endocrinol 375, 157-166

Jonasson L, Holm J, Skalli O, Bondjers G, Hansson GK (1986): Regional accumulations of $\mathrm{T}$ cells, macrophages, and smooth muscle cells in the human atherosclerotic plaque. Arteriosclerosis $\underline{6}, 131-138$

Jongstra-Bilen J, Haidari M, Zhu S-N, Chen M, Guha D, Cybulsky MI (2006): Low-grade chronic inflammation in regions of the normal mouse arterial intima predisposed to atherosclerosis. J Exp Med 203, 2073-2083

Klingenberg R, Gerdes N, Badeau RM, Gisterå A, Strodthoff D, Ketelhuth DFJ, Lundberg AM, Rudling M, Nilsson SK, Olivecrona G et al. (2013): Depletion of FOXP3+ regulatory T cells promotes hypercholesterolemia and atherosclerosis. J Clin Invest $\underline{123}, 1323-1334$

Kolch W (2005): Coordinating ERK/MAPK signalling through scaffolds and inhibitors. Nat Rev Mol Cell Biol $\underline{6}$, 827-837

Koon JC, Kubiseski TJ (2010): Developmental arrest of Caenorhabditis elegans BRAP-2 mutant exposed to oxidative stress is dependent on BRC-1. J Biol Chem $\underline{285}, 13437-13443$

Kulessa H, Frampton J, Graf T (1995): GATA-1 reprograms avian myelomonocytic cell lines into eosinophils, thromboblasts, and erythroblasts. Genes Dev 모 1250-1262

Lanctot AA, Peng C, Pawlisz AS, Joksimovic M, Feng Y (2013): Spatially dependent dynamic MAPK modulation by the Nde1-Lis1-Brap complex patterns mammalian CNS. Dev Cell 25, 241-255

Leeuwenburgh C, Hardy MM, Hazen SL, Wagner P, Oh-ishi S, Steinbrecher UP, Heinecke JW (1997): Reactive Nitrogen Intermediates Promote Low Density Lipoprotein Oxidation in Human Atherosclerotic Intima. J Biol Chem 272, 1433-1436

Li S, Ku CY, Farmer AA, Cong YS, Chen CF, Lee WH (1998): Identification of a novel cytoplasmic protein that specifically binds to nuclear localization signal motifs. J Biol Chem $\underline{273}, 6183-6189$

Liao Y, Wang Y, Guo Y, Ozaki K, Tanaka T, Lin H, Chang M, Chen K, Yu M, Sheu S et al. (2011): BRAP Activates Inflammatory Cascades and Increases the Risk for Carotid Atherosclerosis. Mol Med 17, 1065-1074

Liao Y, Lin H, Guo Y, Chen C, Huang Z, Juo SH, Lin R (2013): Lack of association between a functional variant of the BRCA-1 related associated protein (BRAP) gene and ischemic stroke. BMC Med Genet $\underline{14}, 17$

Libby P (2000): Changing concepts of atherogenesis J Intern Med 247 (3), S. 349-358. 
Lichtman AH, Clinton SK, Iiyama K, Connelly PW, Libby P, Cybulsky MI (1999): Hyperlipidemia and Atherosclerotic Lesion Development in LDL Receptor Deficient Mice Fed Defined Semipurified Diets With and Without Cholate. Arterioscler Thromb Vasc Biol 19, 1938-1944

Linton MF, Fazio S (2001): Class A scavenger receptors, macrophages, and atherosclerosis. Curr Opin Lipidol 12, 489-495

Liu JM, Davidson JM (1988): The elastogenic effect of recombinant transforming growth factor-beta on porcine aortic smooth muscle cells. Biochem Biophys Res Commun 154, 895-901

Llodrá J, Angeli V, Liu J, Trogan E, Fisher EA, Randolph GJ (2004): Emigration of monocyte-derived cells from atherosclerotic lesions characterizes regressive, but not progressive, plaques. Proc Natl Acad Sci U S A $\underline{101}, 11779-11784$

Lloyd-Jones D, Adams RJ, Brown TM, Carnethon M, Dai S, Simone G de, Ferguson TB, Ford E, Furie K, Gillespie C et al. (2010): Executive Summary: Heart Disease and Stroke Statistics--2010 Update: A Report From the American Heart Association. Circulation 121, 948-954

Lusis AJ (2000): Atherosclerosis. Nature 407, 233-241

Mach F, Schönbeck U, Sukhova GK, Bourcier T, Bonnefoy JY, Pober JS, Libby P (1997a): Functional CD40 ligand is expressed on human vascular endothelial cells, smooth muscle cells, and macrophages: implications for CD40-CD40 ligand signaling in atherosclerosis. Proc Natl Acad Sci U S A 94, 1931-1936

Mach F, Schönbeck U, Bonnefoy JY, Pober JS, Libby P (1997b): Activation of monocyte/macrophage functions related to acute atheroma complication by ligation of CD40: induction of collagenase, stromelysin, and tissue factor. Circulation $\underline{96}$, 396-399

Mach F, Schönbeck U, Sukhova GK, Atkinson E, Libby P (1998): Reduction of atherosclerosis in mice by inhibition of CD40 signalling. Nature $\underline{394}, 200-203$

Marrades MP, González-Muniesa P, Martínez JA, Moreno-Aliaga MJ (2010): A Dysregulation in CES1, APOE and Other Lipid Metabolism-Related Genes Is Associated to Cardiovascular Risk Factors Linked to Obesity. Obes Facts $\underline{3}$, 312-318

Martinet W, Knaapen MWM, Meyer GRY de, Herman AG, Kockx MM (2002): Elevated Levels of Oxidative DNA Damage and DNA Repair Enzymes in Human Atherosclerotic Plaques. Circulation 106, 927-932

Masuzaki H, Paterson J, Shinyama H, Morton NM, Mullins JJ, Seckl JR, Flier JS (2001): A transgenic model of visceral obesity and the metabolic syndrome. Science $\underline{294}, 2166-2170$ 
Matheny SA, Chen C, Kortum RL, Razidlo GL, Lewis RE, White MA (2004): Ras regulates assembly of mitogenic signalling complexes through the effector protein IMP. Nature $\underline{427}$, $256-260$

McLaren JE, Michael DR, Ashlin TG, Ramji DP (2011): Cytokines, macrophage lipid metabolism and foam cells: implications for cardiovascular disease therapy. Prog Lipid Res 50, 331-347

McMurray, H. F.; Parthasarathy, S.; Steinberg, D. (1993): Oxidatively modified low density lipoprotein is a chemoattractant for human T lymphocytes. J Clin Invest 92 (2), 1004-1008

Mietus-Snyder M, Friera A, Glass CK, Pitas RE (1997): Regulation of Scavenger Receptor Expression in Smooth Muscle Cells by Protein Kinase C: A Role for Oxidative Stress. Arterioscler Thromb Vasc Biol 17, 969-978

Mitra S, Goyal T, Mehta JL (2011): Oxidized LDL, LOX-1 and Atherosclerosis. Cardiovasc Drugs Ther $\underline{25}, 419-429$

Moore KJ, Tabas I (2011): Macrophages in the pathogenesis of atherosclerosis. Cell $\underline{145}$, $341-355$

Morrison DK (2001): KSR: a MAPK scaffold of the Ras pathway? J Cell Sci 114, 1609_ 1612

Munroe ME, Bishop GA (2007): A costimulatory function for T cell CD40. J Immunol $\underline{178}, 671-682$

Muslin AJ (2008): MAPK signalling in cardiovascular health and disease: molecular mechanisms and therapeutic targets. Clin Sci 115, 203-218

Nakashima Y, Plump AS, Raines EW, Breslow JL, Ross R (1994): ApoE-deficient mice develop lesions of all phases of atherosclerosis throughout the arterial tree. Arterioscler Thromb $\underline{14}$, 133-140

Nakashima Y, Chen Y, Kinukawa N, Sueishi K (2002): Distributions of diffuse intimal thickening in human arteries: preferential expression in atherosclerosis-prone arteries from an early age. Virchows Arch 441, 279-288

Nakashima Y, Wight TN, Sueishi K (2008): Early atherosclerosis in humans: Role of diffuse intimal thickening and extracellular matrix proteoglycans. Cardiovasc Res $\underline{79}, 14-23$

Napoli C, D'Armiento FP, Mancini FP, Postiglione A, Witztum JL, Palumbo G, Palinski W (1997): Fatty streak formation occurs in human fetal aortas and is greatly enhanced by maternal hypercholesterolemia. Intimal accumulation of low density lipoprotein and its oxidation precede monocyte recruitment into early atherosclerotic lesions. J Clin Invest $\underline{100}, 2680-2690$ 
Newby AC, Zaltsman AB (1999): Fibrous cap formation or destruction--the critical importance of vascular smooth muscle cell proliferation, migration and matrix formation. Cardiovasc Res $\underline{41}, 345-360$

Nguyen A, Burack WR, Stock JL, Kortum R, Chaika OV, Afkarian M, Muller WJ, Murphy KM, Morrison DK, Lewis RE et al. (2002): Kinase suppressor of Ras (KSR) is a scaffold which facilitates mitogen-activated protein kinase activation in vivo. Mol Cell Biol 22 , 3035-3045

Oostendorp RAJ, Gilfillan S, Parmar A, Schiemann M, Marz S, Niemeyer M, Schill S, Hammerschmid E, Jacobs VR, Peschel C et al. (2008): Oncostatin M-mediated regulation of KIT-ligand-induced extracellular signal-regulated kinase signaling maintains hematopoietic repopulating activity of Lin-CD34+CD133+ cord blood cells. Stem Cells 26, 2164-2172

Ory S, Morrison DK (2004): Signal transduction: implications for Ras-dependent ERK signaling. Curr Biol 14, R277-8

Ozaki K, Sato H, Inoue K, Tsunoda T, Sakata Y, Mizuno H, Lin T, Miyamoto Y, Aoki A, Onouchi Y et al. (2009): SNPs in BRAP associated with risk of myocardial infarction in Asian populations. Nat Genet $\underline{41}$, 329-333

Paigen B, Morrow A, Brandon C, Mitchell D, Holmes P (1985): Variation in susceptibility to atherosclerosis among inbred strains of mice. Atherosclerosis $\underline{57}, 65-73$

Petro AE, Cotter J, Cooper DA, Peters JC, Surwit SJ, Surwit RS (2004): Fat, carbohydrate, and calories in the development of diabetes and obesity in the C57BL/6J mouse. Metab Clin Exp 푸, $454-457$

Piedrahita JA, Zhang SH, Hagaman JR, Oliver PM, Maeda N (1992): Generation of mice carrying a mutant apolipoprotein $\mathrm{E}$ gene inactivated by gene targeting in embryonic stem cells. Proc Natl Acad Sci U S A $\underline{89}$, 4471-4475

Plump AS, Smith JD, Hayek T, Aalto-Setälä K, Walsh A, Verstuyft JG, Rubin EM, Breslow JL (1992): Severe hypercholesterolemia and atherosclerosis in apolipoprotein E-deficient mice created by homologous recombination in ES cells. Cell $\underline{71}$, 343-353

Pritchard CA, Samuels ML, Bosch E, McMahon M (1995): Conditionally oncogenic forms of the A-Raf and B-Raf protein kinases display different biological and biochemical properties in NIH 3T3 cells. Mol Cell Biol 15, 6430-6442

Prusty D (2002): Activation of MEK/ERK Signaling Promotes Adipogenesis by Enhancing Peroxisome Proliferator-activated Receptor gamma (PPARgamma) and C/EBPalpha Gene Expression during the Differentiation of 3T3-L1 Preadipocytes. J Biol Chem 277, 46226-46232 
Quinn MT, Parthasarathy S, Fong LG, Steinberg D (1987): Oxidatively modified low density lipoproteins: a potential role in recruitment and retention of monocyte/macrophages during atherogenesis. Proc Natl Acad Sci U S A $\underline{84}$, 2995-2998

Rahaman SO, Lennon DJ, Febbraio M, Podrez EA, Hazen SL, Silverstein RL (2006): A CD36-dependent signaling cascade is necessary for macrophage foam cell formation. Cell Metab $\underline{4}, 211-221$

Rassow J: Biochemie, 2. Auflage; Thieme, Stuttgart 2008

Reardon CA, Blachowicz L, White T, Cabana V, Wang Y, Lukens J, Bluestone J, Getz GS (2001): Effect of immune deficiency on lipoproteins and atherosclerosis in male apolipoprotein E-deficient mice. Arterioscler Thromb Vasc Biol 21, 1011-1016

Research Diets. D12451: Rodent Diet with $45 \mathrm{kcal} \%$ fat https://researchdiets.com/formulas/d12451 (Stand 22.06.2018)

Robinson MJ, Cobb MH (1997): Mitogen-activated protein kinase pathways. Curr Opin Cell Biol $\underline{9}, 180-186$

Ross R (1999): Atherosclerosis--an inflammatory disease. N Engl J Med 눙, 115-126

Sale EM, Atkinson PG, Sale GJ (1995): Requirement of MAP kinase for differentiation of fibroblasts to adipocytes, for insulin activation of p90 S6 kinase and for insulin or serum stimulation of DNA synthesis. EMBO J 14, 674-684

Schaar JA, Muller JE, Falk E, Virmani R, Fuster V, Serruys PW, Colombo A, Stefanadis C, Ward Casscells S, Moreno PR et al. (2004): Terminology for high-risk and vulnerable coronary artery plaques. Report of a meeting on the vulnerable plaque, June 17 and 18, 2003, Santorini, Greece. Eur Heart J 25, 1077-1082

Schneider H, Downey J, Smith A, Zinselmeyer BH, Rush C, Brewer JM, Wei B, Hogg N, Garside P, Rudd CE (2006): Reversal of the TCR stop signal by CTLA-4. Science $\underline{313}$, 1972-1975

Schönbeck U, Libby P (2001): CD40 signaling and plaque instability. Circ Res $\underline{89}, 1092$ 1103

Schrijvers DM (2005): Phagocytosis of Apoptotic Cells by Macrophages Is Impaired in Atherosclerosis. Arterioscler Thromb Vasc Biol 25, 1256-1261

Smith JD, Trogan E, Ginsberg M, Grigaux C, Tian J, Miyata M (1995): Decreased atherosclerosis in mice deficient in both macrophage colony-stimulating factor (op) and apolipoprotein E. Proc Natl Acad Sci U S A $\underline{92}$, 8264-8268

Spencer E, Jiang J, Chen ZJ (1999): Signal-induced ubiquitination of IkappaBalpha by the F-box protein Slimb/beta-TrCP. Genes Dev 13, 284-294

Stary HC, Blankenhorn DH, Chandler AB, Glagov S, Insull W, Richardson M, Rosenfeld ME, Schaffer SA, Schwartz CJ, Wagner WD (1992): A definition of the intima of human 
arteries and of its atherosclerosis- prone regions. A report from the Committee on Vascular Lesions of the Council on Arteriosclerosis, American Heart Association. Circulation $\underline{85}$, 391-405

Stary HC, Chandler AB, Glagov S, Guyton JR, Insull W, Rosenfeld ME, Schaffer SA, Schwartz CJ, Wagner WD, Wissler RW (1994): A definition of initial, fatty streak, and intermediate lesions of atherosclerosis. A report from the Committee on Vascular Lesions of the Council on Arteriosclerosis, American Heart Association. Circulation 무, 2462-2478

Stiko-Rahm A, Hultgårdh-Nilsson A, Regnström J, Hamsten A, Nilsson J (1992): Native and oxidized LDL enhances production of PDGF AA and the surface expression of PDGF receptors in cultured human smooth muscle cells. Arterioscler Thromb 12, 10991109

Stocker R, Keaney JF Jr (2004): Role of Oxidative Modifications in Atherosclerosis. Physiological Reviews 노, 1381-1478

Subramanian S, Han CY, Chiba T, McMillen TS, Wang SA, Haw A, Kirk EA, O'Brien KD, Chait A (2008): Dietary cholesterol worsens adipose tissue macrophage accumulation and atherosclerosis in obese LDL receptor-deficient mice. Arterioscler Thromb Vasc Biol 28, 685-691

Sun S, Ley SC (2008): New insights into NF- $x$ B regulation and function. Trends Immunol $\underline{29}, 469-478$

Surwit RS, Feinglos MN, Rodin J, Sutherland A, Petro AE, Opara EC, Kuhn CM, RebufféScrive M (1995): Differential effects of fat and sucrose on the development of obesity and diabetes in C57BL/6J and A/J mice. Metab Clin Exp 44, 645-651

Tabas I (2010): Macrophage death and defective inflammation resolution in atherosclerosis. Nat Rev Immunol $\underline{10}, 117$

Takashima O, Tsuruta F, Kigoshi Y, Nakamura S, Kim J, Katoh MC, Fukuda T, Irie K, Chiba T, Srinivasula SM (2013): Brap2 Regulates Temporal Control of NF- $x$ B Localization Mediated by Inflammatory Response. PLoS ONE $\underline{8}$, e58911

Tall AR, Yvan-Charvet L (2015): Cholesterol, inflammation and innate immunity. Nat Rev Immunol 15, 104-116

Teupser D, Persky AD, Breslow JL (2003): Induction of atherosclerosis by low-fat, semisynthetic diets in LDL receptor-deficient $\mathrm{C} 57 \mathrm{BL} / 6 \mathrm{~J}$ and $\mathrm{FVB} / \mathrm{NJ}$ mice: comparison of lesions of the aortic root, brachiocephalic artery, and whole aorta (en face measurement). Arterioscler Thromb Vasc Biol 23, 1907-1913

Therrien M, Michaud NR, Rubin GM, Morrison DK (1996): KSR modulates signal propagation within the MAPK cascade. Genes Dev $\underline{10}$, 2684-2695 
Tontonoz P, Nagy L, Alvarez JG, Thomazy VA, Evans RM (1998): PPARgamma promotes monocyte/macrophage differentiation and uptake of oxidized LDL. Cell $\underline{93}$, $241-252$

Tsai P, Lin T, Hsu P, Wang Y, Liao Y, Juo SH (2011): Polymorphism of 270 A G in BRAP is Associated with Lower Ankle-Brachial Index in a Taiwanese Population. J Atheroscler Thromb 18, 413-420

Tsai P, Liao Y, Lin T, Hsi E, Yang Y, Juo SH (2012): Additive effect of ANRIL and BRAP polymorphisms on ankle-brachial index in a Taiwanese population. Circ J $\underline{76}$, 446-452

Van Craeyveld E, Gordts SC, Singh N, Jacobs F, Geest B de (2012): A critical reassessment of murine and rabbit models of atherosclerosis: Focus on lesion progression and remodelling. Acta Cardiol 67, 11-21

VanderLaan PA, Reardon CA, Thisted RA, Getz GS (2009): VLDL best predicts aortic root atherosclerosis in LDL receptor deficient mice. J Lipid Res $\underline{50}$, 376-385

Varnava AM, Mills PG, Davies MJ (2002): Relationship between coronary artery remodeling and plaque vulnerability. Circulation 105, 939-943

Vergnes L, Phan J, Strauss M, Tafuri S, Reue K (2003): Cholesterol and cholate components of an atherogenic diet induce distinct stages of hepatic inflammatory gene expression. J Biol Chem $\underline{278}$, 42774-42784

Wang Y, Wu J, Tang Y, Zhang M, Li Y, Chen K, Zeng M, Yao F, Xie W, Zheng X et al. (2014): Urotensin II increases foam cell formation by repressing ABCA1 expression through the ERK/NF- $x$ B pathway in THP-1 macrophages. Biochem Biophys Res Commun $\underline{452}$, 998-1003

Ward MR, Pasterkamp G, Yeung AC, Borst C (2000): Arterial remodeling. Mechanisms and clinical implications. Circulation 102, 1186-1191

Weber C, Zernecke A, Libby P (2008): The multifaceted contributions of leukocyte subsets to atherosclerosis: Lessons from mouse models. Nat Rev Immunol $\underline{8}, 802-815$

WHO: The top 10 causes of death. Fact Sheet N³10.: Updated July 2013; http://www.who.int/mediacentre/factsheets/fs310/en/index.html (Stand 02.01.2014)

Williams H, Johnson JL, Carson KG, Jackson CL (2002): Characteristics of Intact and Ruptured Atherosclerotic Plaques in Brachiocephalic Arteries of Apolipoprotein E Knockout Mice. Arterioscler Thromb Vasc Biol 22, 788-792

Wolf D, Stachon P, Bode C, Zirlik A (2014): Inflammatory mechanisms in atherosclerosis. Hamostaseologie 34, 63-71

Wu L, Xi B, Hou D, Zhao X, Liu J, Cheng H, Shen Y, Wang X, Mi J (2013): The single nucleotide polymorphisms in BRAP decrease the risk of metabolic syndrome in a Chinese young adult population. Diab Vasc Dis Res $\underline{10}$, 202-207 
Yamauchi Y, Chang CCY, Hayashi M, Abe-Dohmae S, Reid PC, Chang T, Yokoyama S (2004): Intracellular cholesterol mobilization involved in the ABCA1/apolipoproteinmediated assembly of high density lipoprotein in fibroblasts. J Lipid Res $\underline{45}$, 1943-1951

Yanoff LB, Menzie CM, Denkinger B, Sebring NG, McHugh T, Remaley AT, Yanovski JA (2007): Inflammation and iron deficiency in the hypoferremia of obesity. Int J Obes (Lond) $\underline{31}, 1412-1419$

Zarins CK, Giddens DP, Bharadvaj BK, Sottiurai VS, Mabon RF, Glagov S (1983): Carotid bifurcation atherosclerosis. Quantitative correlation of plaque localization with flow velocity profiles and wall shear stress. Circ Res $\underline{53}$, 502-514

Zha Y, Marks R, Ho AW, Peterson AC, Janardhan S, Brown I, Praveen K, Stang S, Stone JC, Gajewski TF (2006): T cell anergy is reversed by active Ras and is regulated by diacylglycerol kinase- $\alpha$. Nat Immunol 7, 1166-1173

Zhang F, Liu C, Xu Y, Qi G, Yuan G, Cheng Z, Wang J, Wang G, Wang Z, Zhu W et al. (2014): A Two-Stage Association Study Suggests BRAP as a Susceptibility Gene for Schizophrenia. PLoS One $\underline{9}$, e86037

Zhang SH, Reddick RL, Burkey B, Maeda N (1994): Diet-induced atherosclerosis in mice heterozygous and homozygous for apolipoprotein E gene disruption. J Clin Invest $\underline{94}, 937-$ 945

Zhao M, Liu Y, Wang X, New L, Han J, Brunk UT (2002): Activation of the p38 MAP kinase pathway is required for foam cell formation from macrophages exposed to oxidized LDL. Apmis 110, 458-468 


\section{Danksagung}

Bei der Erarbeitung der vorliegenden Dissertation habe ich vielfältige Unterstützung erfahren. Besonderen Dank schulde ich Herrn Prof. Dr. med. Gerd Hasenfuß als Leiter der Klinik für Kardiologie und Pneumologie, an der ich nicht nur einen Teil meiner fachlichen Grundausbildung erwarb, sondern auch an das wissenschaftliche Arbeiten herangeführt wurde.

Einen wesentlichen Anteil am Zustandekommen dieser Arbeit haben darüber hinaus Dr. med. Tim Seidler und Dr. rer. nat. Cornelia Volland. Ihnen verdanke ich die Idee zu dieser Arbeit, und ihre stete Bereitschaft, mir mit Rat und Tat zur Seite zu stehen, hat mir in den einzelnen Phasen ihrer Durchführung sehr geholfen. Dr. med. Katrin Schäfer gebührt ein herzlicher Dank für ihre wertvolle Hilfe bei methodischen und inhaltlichen Fragestellungen im Bereich Atherosklerose im ApoE-Knockout-Modell.

Herzlich zu danken habe ich aber auch für die vielen und oft unterschätzten Hilfen im Laboralltag, die mir Jessica Spitalieri, Gudrun Müller und Karina Zimmermann zuteilwerden ließen.

Für die freundschaftliche Zusammenarbeit und die gegenseitige Motivation bedanke ich mich herzlich bei meinen Mit-Doktoranden Mareike Schubert, Sebastian Bremer, Markus Bernhard und Sebastian Herzberg. 